UNIVERSIDADE DE SÃO PAULO

FACULDADE DE MEDICINA DE RIBEIRÃO PRETO

Programa de Pós-Graduação em Ciências da Saúde

Aplicadas ao Aparelho Locomotor

LEONARDO RIGOBELLO BATTAGLION

Estabilização e fixação de fraturas distais do rádio.

Uso do método dos elementos finitos

Ribeirão Preto - SP 



\title{
Estabilização e fixação de fraturas distais do rádio. Uso do método dos elementos finitos
}

\author{
Dissertação apresentada à Faculdade de Medicina de \\ Ribeirão Preto da Universidade de São Paulo para a \\ obtenção do título de Mestre no Programa de Pós- \\ Graduação em Ciências da Saúde Aplicadas ao \\ Aparelho Locomotor.
}

Orientador: Prof. Dr. Antonio Carlos Shimano

\section{Versão Corrigida}

"Versão corrigida. A versão original encontra-se disponível tanto na Biblioteca da Unidade que aloja o Programa, quanto na Biblioteca Digital de Teses e Dissertações da USP (BDTD)" 
Elaborada pela Biblioteca Central do Campus USP - Ribeirão Preto

Battaglion, Leonardo Rigobello

Estabilização e fixação de fraturas distais do rádio. Uso do método dos elementos finitos. Ribeirão Preto, 2019.

139p. : il.; $30 \mathrm{~cm}$

Dissertação apresentada à Faculdade de Medicina de Ribeirão Preto da Universidade de São Paulo para a obtenção do título de Mestre no Programa de Pós-Graduação em Ciências da Saúde Aplicadas ao Aparelho Locomotor.

Orientador: Prof. Dr. Antonio Carlos Shimano

1. Método dos elementos finitos. 2. Fraturas do rádio distal. 3. Placa volar com gancho. 4. Fixação da faceta do semilunar. 5. Ensaio de cisalhamento. 
FOLHA DE APROVAÇÃO

\section{LEONARDO RIGOBELLO BATTAGLION}

\section{Estabilização e fixação de fraturas distais do rádio. Uso do método dos elementos finitos}

Dissertação apresentada à Faculdade de Medicina de Ribeirão Preto da Universidade de São Paulo para a obtenção do título de Mestre no Programa de PósGraduação em Ciências da Saúde Aplicadas ao Aparelho Locomotor.

Aprovado em:

BANCA EXAMINADORA

Prof.(a).Dr.(a).:

Instituição

Julgamento:

Assinatura:

Prof.(a).Dr.(a).:

Instituição

Julgamento:

Assinatura:

Prof.(a).Dr.(a).:

Instituição

Julgamento:

Assinatura:

Prof.(a).Dr.(a):

Instituição

Julgamento:

Assinatura: 



\section{Dedicatória}


Dedico este trabalho primeiramente a Deus e todos os Santos por ser essencial em minha vida.

Aos meus familiares, minha mãe Dulcinéia Rigobello, meu tio José Luis Rigobello, minha tia Vera Lucia Rigobello, meu cachorro Junior Rigobello; in memorian meu avô José Rigobello, minha avó Altina Montagnini Rigobello, minha tia Marina Rigobello e meu cachorro Bola Rigobello. 


\section{AgradecimentosEspeciais}


Ao meu orientador Prof. Dr. Antonio Carlos Shimano, pelo exemplo de seriedade, profissionalismo, dedicação, por toda confiança, incentivo, sábios ensinamentos e amizade. 

Agradecimentos 

Agradeço a todas as pessoas que, de modo direto ou indireto, participaram na realização deste trabalho.

Ao Prof. Dr. José Batista Volpon.

A minha Coorientadora Engenheira Dra Ana Paula Macedo sábios ensinamentos e amizade.

Ao Amigo Henrique de Barros Pinto Netto pela colaboração, amizade e incentivo.

Ao Antonio Tufi Neder Filho pela amizade.

A CAPES pelo incentivo financeiro.

Aos amigos de Pós-Graduação Jéssica, Marcela, Bruna, Carla, Ana Clara, Rita, Anderson, Romero, Iara, Patricia, Suelen, Aline.

Aos funcionários do Laboratório de Bioengenharia da Faculdade de Medicina de Ribeirão Preto, Maria Teresinha de Moraes, Rita Cossalter, Francisco Mazzocato (Chico) e Ariane Zamarioli por toda amizade e agradável convívio.

Ao Departamento de Biomecânica, Medicina e Reabilitação do Aparelho Locomotor da Faculdade de Medicina de Ribeirão Preto.

À Faculdade de Medicina de Ribeirão Preto. 



\section{RESUMO}

Battaglion, LR. Estabilização e fixação de fraturas distais do rádio. Uso do método dos elementos finitos. Ribeirão Preto, 2019. 139p. Dissertação de mestrado. Faculdade de Medicina de Ribeirão Preto, Universidade de São Paulo.

A placa juntamente com os parafusos como elementos de fixação e redução do rádio distal já é de grande uso, porém a presença de um fragmento irregular de tamanho especifico faz com que sua fixação e redução sejam comprometidas por placa volar convencional. A fixação do fragmento da faceta do semilunar volar é difícil devido à forma do osso. O Método dos Elementos Finitos é um método numérico muito eficaz, utilizado para solucionar problemas complexos, este tipo de análise admite a representação precisa da geometria complexa e inclusão das diferentes propriedades dos materiais, permitindo a aplicação de carregamentos em pontos específicos da estrutura. $\mathrm{O}$ objetivo deste trabalho foi analisar as tensões e deformações geradas nos modelos com sistema de fixação do fragmento específico do canto volar ulnar do rádio, com placa volar modificada com gancho, com diferentes comprimentos e angulações, utilizando o Método dos Elementos Finitos para simulação do ensaio de cisalhamento. Para validação dos modelos virtuais foram utilizados os resultados dos ensaios de cisalhamento realizados com três modelos (Modelo 1 físico M1F), (Modelo 2 físico M2F) e (Modelo 3 físico M3F), simulando a fratura de cisalhamento palmar da extremidade distal do rádio humano com a variação de angulação da placa volar modificada com gancho (PVGM). Foram propostos e confeccionados seis modelos digitais através do programa Rhinoceros 6 para a realização das simulações: Modelo 1 (M1D): PVMG com gancho de $3 \mathrm{~mm}$ e ângulo de $90^{\circ}$ em relação à placa fixada por três parafusos, um no fragmento e dois no osso; Modelo 2 (M2D): PVMG com gancho de $3 \mathrm{~mm}$ e ângulo de $120^{\circ}$ em relação à placa fixada por três parafusos, um no fragmento e dois no osso; Modelo 3 (M3D): PVMG com gancho de $3 \mathrm{~mm}$ e ângulo $60^{\circ}$ em relação à placa fixada por três parafusos, um no fragmento e dois no osso; Modelo 4 (M4D): PVMG com gancho de $6 \mathrm{~mm}$ e ângulo de $90^{\circ}$ em relação à placa fixada por três parafusos, um no fragmento e dois no osso; Modelo 5 (M5D): PVMG com gancho de $6 \mathrm{~mm} 120^{\circ}$ em relação à placa fixada por três parafusos, um no fragmento e dois no osso; Modelo 6 (M6D): PVMG com gancho de $6 \mathrm{~mm}$ e ângulo de 
$60^{\circ} \mathrm{em}$ relação à placa fixada por três parafusos, um no fragmento e dois no osso. Estes modelos tridimensionais foram exportados para o programa Simlab ${ }^{\mathrm{TM}}$, onde foram realizadas as simulações. A validação foi obtida pela comparação da rigidez relativa obtida no ensaio mecânico e o resultado pelo Método dos Elementos Finitos que foram 18,99\% para M1D e M1F; 19,66\% para M2D e M2F; 14,98\% para M3D e M3F. Podemos observar que, com as aplicações de cargas, o modelo M4D foi o melhor dentre todos, o M2D foi o que apresentou maiores deslocamentos. Observamos em todos os modelos que o ponto de maior Tensão Equivalente de Von Mises foi na região onde não há parafuso, gerando assim estresse e possível falha do material. Os ganchos de angulação de $90^{\circ}$ devido à estabilidade do ângulo e ao comprimento de $6 \mathrm{~mm}$ garantiram maior estabilidade, menor tensão e menores deslocamentos do sistema.

Palavras-chave: Método dos elementos finitos, fraturas do rádio distal, Placa volar modificada com gancho, fixação e redução da faceta do semilunar, Ensaio de cisalhamento. 
Abstract 


\begin{abstract}
Battaglion, LR. Stabilization and fixation of distal radius fractures. Use of the Finite Element Method . Ribeirão Preto, 2019. 139p. Master Dissertation. Faculdade de Medicina de Ribeirão Preto, Universidade de São Paulo.
\end{abstract}

The plate along with the screws and mounting components and reduction of the distal radius is already in great use, but the presence of an irregular fragment of specific size makes its fixation and reduction to be compromised by conventional volar plate. The fixation of the fragment of the semilunar volar facet is difficult due to the shape of the bone. The Finite Element Method is a very efficient numerical method used to solve complex problems, this type of analysis admits the accurate representation of the complex geometry and inclusion of the different properties of materials, allowing the application of loads at specific points of the structure. The objective of this work was to analyze the tensions and deformations generated in models with specific fragment fixation of the ulnar volar corner of radius, with volar plate modified with hook, with different lengths and angles, using the Finite Element Method for simulation of shear test. For the validation of the virtual models were used the results of shear tests conducted with three models (Physical Model $1 \mathrm{M} 1 \mathrm{~F}$ ), (Physical Model $2 \mathrm{M} 2 \mathrm{~F}$ ) and (Physical Model $3 \mathrm{M} 3 \mathrm{~F}$ ), simulating the palmar shear fracture of the distal end of the human radius with the variation of angulation of the volar plate modified with hook (PVGM). They were proposed and made six digital models using Rhinoceros 6 program for the implementation of simulations: Model 1 (M1D): PVMG with hook of $3 \mathrm{~mm}$ and angle of $90^{\circ}$ in relation to the plate attached by three screws, one on the fragment and two on the bone; Model 2 (M2D): PVMG with hook of 3mm and angle of $120^{\circ}$ in relation to the plate attached by three screws, one on the fragment and two on the bone; Model 3 (M3D): PVMG with hook of $3 \mathrm{~mm}$ and angle of $60^{\circ}$ in relation to the plate attached by three screws, one on the fragment and two on the bone: Model 4 (M4D): PVMG with hook of $6 \mathrm{~mm}$ and angle of $90^{\circ}$ in relation to the plate attached by three screws, one on the fragment and two on the bone; Model 5 (M5D): PVMG with hook of $6 \mathrm{~mm}$ and angle of $120^{\circ}$ in relation to the plate attached by three screws, one on the fragment and two on the bone; Model 6 (M6D): PVMG with hook of $6 \mathrm{~mm}$ and angle of $60^{\circ}$ In relation to the plate attached by three screws, one on the fragment and two $o n$ the bone. These three-dimensional models were exported to the Simlab ${ }^{\mathrm{TM}}$ program, where carried out the simulations. The validation was obtained by comparing the relative stiffness obtained in the mechanical tests and the results by the Finite Element Method which were $18.99 \%$ for M1D and M1F; $19.66 \%$ for M2D and M2F; $14.98 \%$ for M3D and M3F.We can observe that with the load applications the M4D model was the best among all, the M2D showed the largest displacements. We observed in all models that the point of highest Tension Equivalent of Von Mises was in the region where there is no screw, thus generating stress and possible failure of the material. The hooks of angulation of $90^{\circ}$ due to the stability of the angle and length of $6 \mathrm{~mm}$ ensured greater stability, lower tension and lower system displacements

Keywords: Finite Element Method, Distal Radius Fractures, Volar Plate modified with hook, Fixation and reduction of the lunate facet, Shear test. 



\section{LISTA DE FIGURAS}

Figura 1. (A) A visão sagital do rádio distal mostra a projeção volar para cima. (B) visão ilustra a configuração triangular da faceta semilunar e a projeção anterior. (C) visão axial da superfície articular do rádio distal mostra as facetas do escafóide e semilunar. 42

Figura 2. Classificação $A O$ para fraturas da extremidade distal do rádio. Fonte Manual 23 A1 Fratura da ulna; A2 Fratura simples do rádio; A3 Fratura cominutiva do rádio; B1 Traço sagital; B2 Fragmento dorsal; B3 Fragmento volar C1 Articular e metafisária simples; C2 metafisária multifragmentada; C3 Articular Multifragmentada a ( ) demonstra o local do

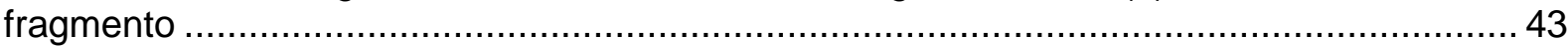

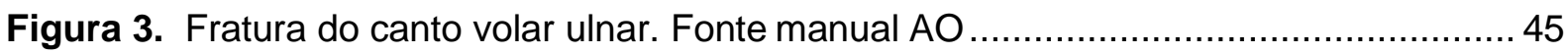

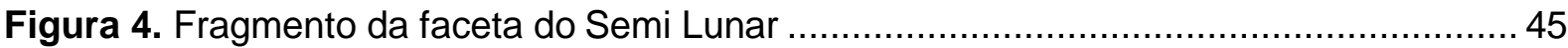

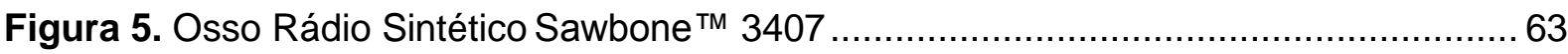

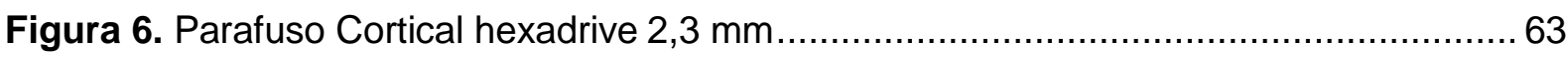

Figura 7. Vista de frente da Placa volar modificada com gancho de $2 \mathrm{~mm}$ espessura e

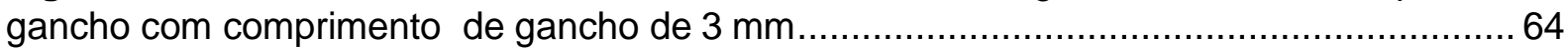

Figura 8. Vista em perfil da Placa volar modificada com gancho ....................................... 64

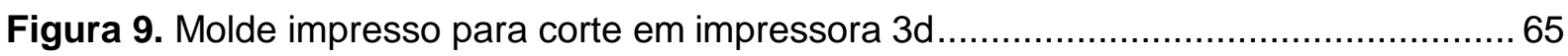

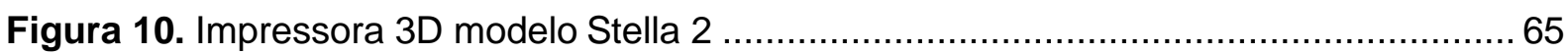

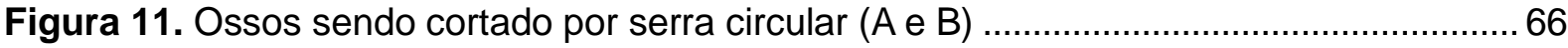

Figura 12. Conjuntos montados Ossos Placas com suas respectivas angulações e

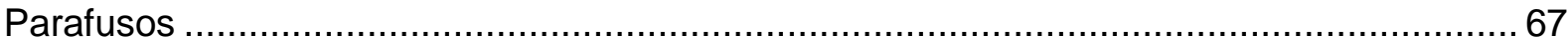

Figura 13. Resina acrílica auto polimerizante da marca AutoCril $(A)$, e peróxido de

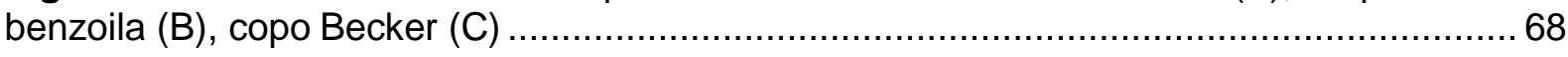

Figura 15(A) Molde usado para inclusão dos ossos (B) osso incluído na resina .................. 68

Figura 14. (A) Molde usado para inclusão dos ossos (B) osso incluído na resina ................ 68

Figura 16. Modelos montados e incluídos na resina .................................................. 69

Figura 17. Acessórios do ensaio mecânico (A) célula de carga (B) anteparo para conectar

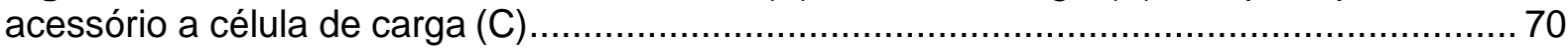

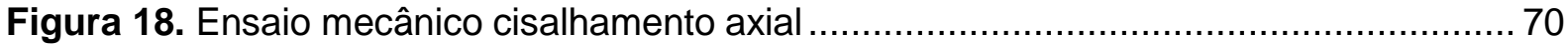

Figura 19. Imagem do rádio convertido do protocolo de comunicação que incorpora imagens DICOM para. STL com Software InVesalius ${ }^{\mathrm{TM}}$ Sólido 3D) ......................................... 72

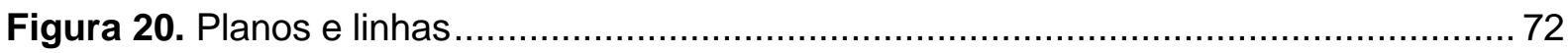


Figura 21. Medição com paquímetro de placa volar com gancho e parafuso cortical..... 73

Figura 22. $C A D$ feito de cada parte individualmente, osso sem fragmento $(A)$, osso com fragmento $(B)$, placa $(C)$, placa com parafusos $(D)$ e conjunto todomontado $(E)$ 74

Figura 23. Medidas do fragmento e as PVMG com gancho de diferentes angulações e comprimento.... 75

Figura 24 contatos e malha tetraédrica A e B 76

Figura 25. Condições de Contorno Vista frontal (A) (região de aplicação de cargas), Dorsal (B) (região de aplicação de cargas) e Inferior $(C)$ indicados pela seta (região de restrição de movimentos, fixação). 78

Figura 26. Força $(\mathrm{N}) \times$ Deslocamento $(\mathrm{mm})$ para o ensaio Mecânico (MUE) e pelo Método dos Elementos Finitos (MEF) para o grupo M1D

Figura 27. Força $(\mathrm{N}) \times$ Deslocamento $(\mathrm{mm})$ para o ensaio Mecânico (MUE) e pelo Método dos Elementos Finitos (MEF) para o grupo M2D.

Figura 28. Força $(\mathrm{N}) \times$ Deslocamento $(\mathrm{mm})$ para o ensaio Mecânico (MUE) e pelo Método dos Elementos Finitos (MEF) para o grupo M3D

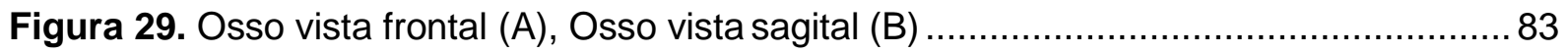

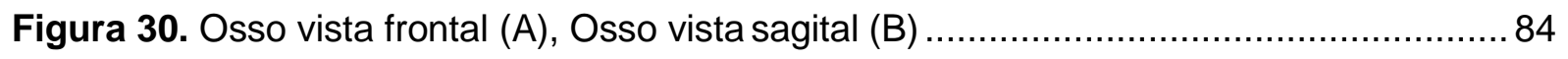

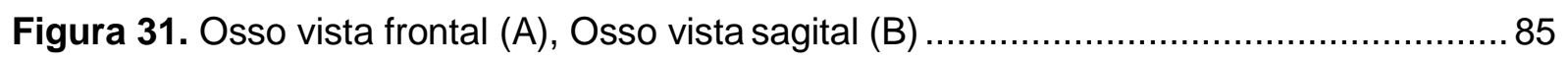

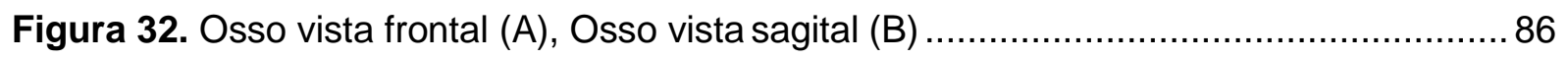

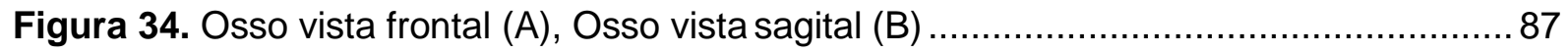

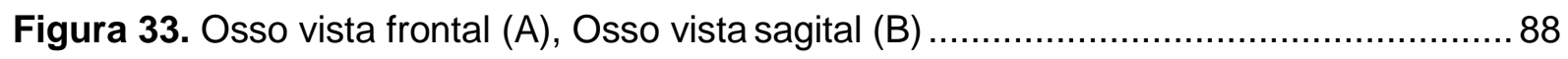

Figura 35. Gráfico força x Deslocamento pelo Método dos Elementos Finitos..................... 89

Figura 36. Comparações da Tensão Máxima PPrincipal vista dorsal: demonstrando pelas

$(\uparrow)$ região do segundo parafuso, seta verde $(\uparrow)$ região do terceiro parafuso.90

Figura 37. Comparações da Tensão Máxima Principal vista dorsal: demonstrando pelas setas os pontos de tensão seta vermelha) na região do primeiro parafuso, seta preta $(\uparrow)$ (4) região onde a tensão esta espalhada na região dorsal do osso, seta verde ) região $\uparrow$ do 92

Figura 38. Comparações da Tensão Máxima Principal vista longitudinal: demonstrando pelas setas os pontos de tensão seta vermelha ) na região do segundo parafuso, seta preta ( $\uparrow$ ) região do primeiro parafuso, seta verde ( ) região do terceiro parafuso, seta 4 azul( 4 ) seta laranja ) região frontal 
Figura 39. Comparações da Tensão Máxima Principal vista frontal osso sem o fragmento: demonstrando pelas setas os pontos de tensão seta vermelha ) na região de contato $\uparrow$ osso e fragmento (inferior), seta preta ) região do primeiro parafuso, seta verde ( 4 ) região de contato osso e fragmento (inferior)......

Figura 40. Comparações da Tensão Máxima Principal vista axial corte no local do fragmento em que o gancho entra: demonstrando pelas setas os pontos de tensão seta laranja) na região ao redor do fragmento, seta preta ( ) região ao redor do primeiro parafuso e locais de contato osso placa.

Figura 41. Comparações da Tensão Mínima Principal vista frontal osso sem o fragmento: demonstrando pelas setas as regiões de tensão seta vermelha ( ) na região de ancoragem da placa e primeiro parafuso seta preta ) região ao redor do gancho (inferior $\uparrow$ ao gancho), seta ) região de ancoragem da placa, seta ) região espalhada $\uparrow$ Tao redor dos segundos e terceiros parafusos, seta verde ) região de ancoragem da 4 região do terceiro parafuso da placa 100

Figura 42 Comparações da Tensão Mínima Principal vista dorsal: demonstrando pelas setas os pontos de tensão seta vermelha ( ) na região dorsal ao redor do segundo e terceiro 4 parafuso, seta verde ( ) região espalhada na lateral dorsal do osso 4

Figura 43. Comparações da Tensão Máxima Principal vista sagital: demonstrando pelas setas os pontos de tensão seta laranja ( $\uparrow$ ) região frontal (fragmento), seta preta ) região $\uparrow$ do primeiro parafuso, seta vermelha ( 4 ) região frontal, seta verde ( ) região do ter, seta 4 azul ) região dorsal, seța laranja ( ) região frontal 104 4

Figura 44. Comparações da Tensão Máxima Principal vista frontal do fragmento: demonstrando pelas setas os pontos de tensão, seta verde ) região ao redor do primeiro parafuso, seta azul ) região espalhada de contato fragmento osso..... 106

Figura 45. Comparações da Tensão Mínima Principal vista axial corte no local do fragmento em que o gancho entra: demonstrando pelas setas os pontos de tensão seta verde ( ) na 4 região ao redor do fragmento, seta azul ) região ao redor do primeiro parafuso e locais 4

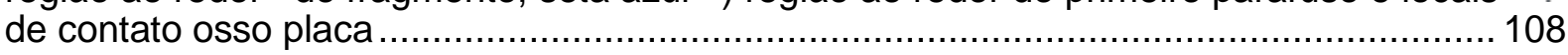

Figura 46. Comparações da Tensão Mínima Principal vista axial corte no local do fragmento em que o gancho entra: demonstrando pelas setas os pontos de tensão seta laranja ) região $\uparrow$ da curvatura do gancho, seta vermelha ) região do primeiro parafuso, seta preta 
)região do segundo parafuso, seta azul ) região onde não tem parafuso (terceiro orifício da placa), seta verde ) região do terceiro parafuso

4

Figura 47. Comparações da Tensão Mínima Principal vista axial corte no local do fragmento em que o gancho entra: demonstrando pelas setas os pontos de tensão seta laranja ( ) região 4

da curvatura do gancho, seta vermelha $\Delta$ ) região do primeiro parafuso, seta preta ( ) $\uparrow$ região do segundo parafuso, seta azul ( ) região onde não tem parafuso (terceiro orifício da

placa), seta verde ) região do terceiro parafuso

Figura 48. Comparações da Tensão Equivalente de Von Mises: demonstrando pelas setas os pontos de tensão seta laranja ( ) região de passos de rosca primeiro parafuso, seta vermelha ( ) região da haste e cabeça primeiro parafuso, seta preta ( )região dos $\uparrow \uparrow$ passos de passos rosca segundo parafuso,seta azul ) região haste e cabeça terceiro parafuso ) região dos passos de rosca terceiro parafuso 4

Figura 49. Comparações da Tensão Equivalente de Von Mises: demonstrando pelas setas os pontos de tensão, seta vermelha ( ) região dde contato parafuso placa, seta preta ( $\uparrow \uparrow$ ) região da cabeça dos parafuso 116

Figura 50. Comparações das angulações através de radiografias do rádio antes e depois do Ensaio Mecânico de Compressão Axial: A,C e E antes do Ensaio Mecânico; B, D e f depois do Ensaio Mecânico. 


\section{Lista de Tabelas}

Tabela 1. Dimensões dos parafusos e placas

Tabela 2. Grupos para ensaio mecânico.

Tabela 3. Modelos Digitais

Tabela 4. Propriedades do Modelo Número de Elementos e Nós de cada 76

Tabela 5. Deslocamentos Dos Ensaios Mecânicos e do Método dos Elementos Finitos 81

Tabela 6. Rigidez Relativa do conjunto 


\section{Lista de quadros}

Quadro 1 - Propriedades dos materiais.

Quadro 2. Deslocamentos dos modelos pelo Método Dos Elementos Finitos

Quadro 3. Comparação das angulações antes e depois 


\section{LISTA DE ABREVIATURAS E SIGLAS}

\begin{tabular}{|c|c|}
\hline Min & minuto \\
\hline $\mathrm{cm}$ & centímetro \\
\hline $\mathrm{mm}$ & milímetro \\
\hline $\mathrm{AO}$ & Arbeitsgemeinschaft für Osteosynthese \\
\hline MEF & Método dos Elementos Finitos \\
\hline HCRP & Hospital das Clínicas de Ribeirão Preto \\
\hline FMRP & Faculdade de Medicina de Ribeirão Preto, \\
\hline USP & Universidade de São Paulo \\
\hline TM & Trade mark \\
\hline $\mathrm{kPa}$ & kilo Pascal \\
\hline $\mathrm{mPa}$ & giga Pascal \\
\hline $3 D$ & tridimensional \\
\hline ( & marca registrada \\
\hline STL & Standard Triangle Language \\
\hline PLA & Poliácido Láctico \\
\hline M1F & grupo um físico \\
\hline $\mathrm{M} 2 \mathrm{~F}$ & grupo dois físico \\
\hline M3F & grupo três físico \\
\hline
\end{tabular}


grupo seis físico

M1D

Modelo um Digital

M2D

Modelo dois Digital

M3D

Modelo tres Digital

M4D

Modelo quatro Digital

M5D

Modelo cinco Digital

M6D

Modelo seis Digital

$\mathrm{GHz}$

giga-hertz

RAM

Random Access Memory

DICOM

Digital Imaging and Communications in Medicine

CAD

computer-aided design

STEP

Standard for the Exchange of Product model data

$\mathrm{N}$

Newtons

MUE

máquina universal de ensaios

PVMG

placa volar modificada com gancho 


\section{LISTA DE SÍMBOLOS}

E

módulo da elasticidade

V

coeficiente de poisson

graus 
Sumário 



\section{SUMÁRIO}

1. INTRODUÇÃO

1.1 Classificação das fraturas do rádio distal segundo AO (Manual AOArbeitsgemeinschaft für Osteosynthese - AO) ............................................................. 43

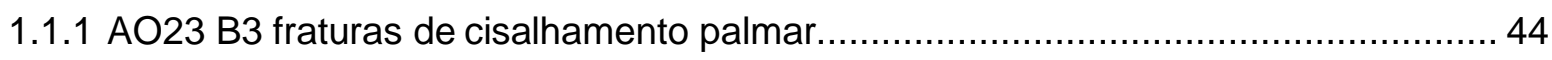

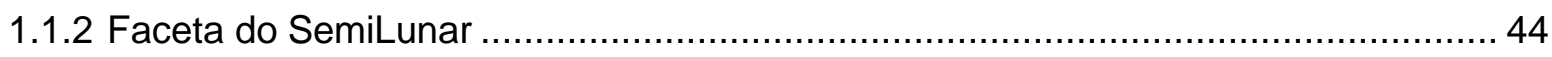

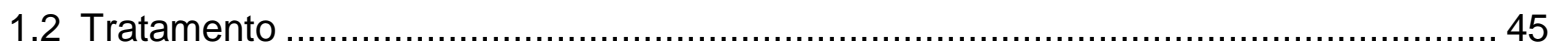

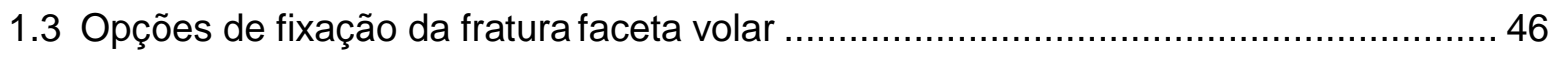

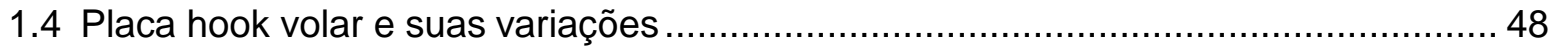

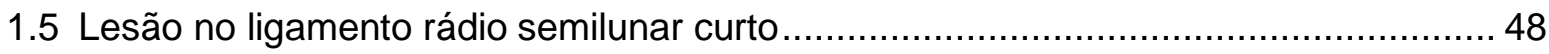

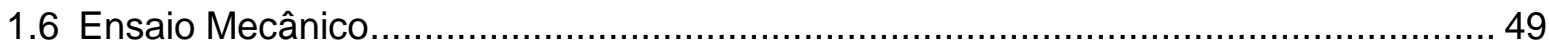

1.7 Método Dos Elementos Finitos (MEF) …………............................................... 49

1.7.1 Utilização do Método Dos Elementos Finitos na Ortopedia...................................... 50

1.8 Propriedades dos Materiais e Características do Modelo ……….............................50

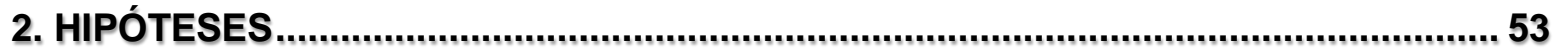

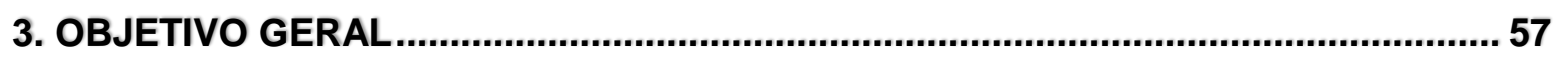

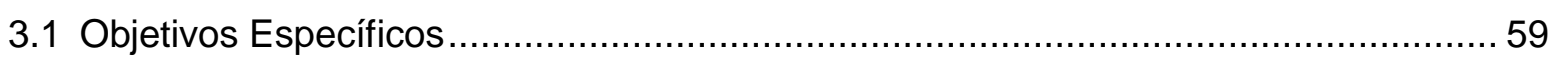

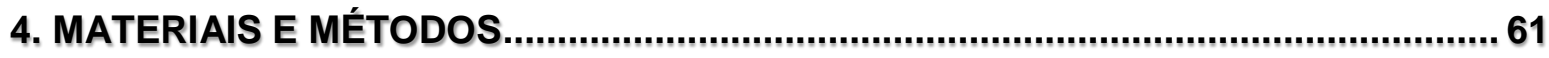

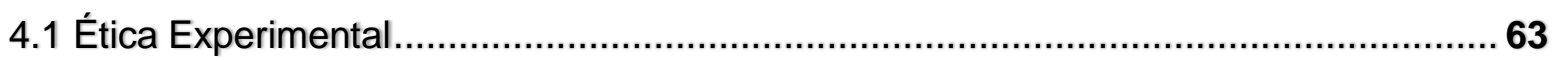

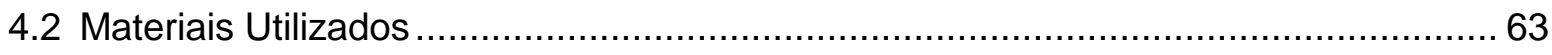

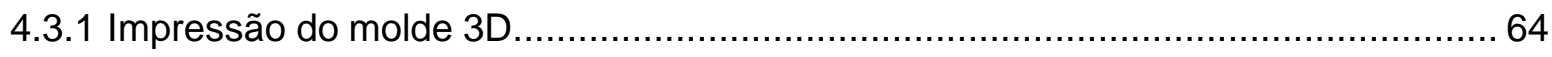

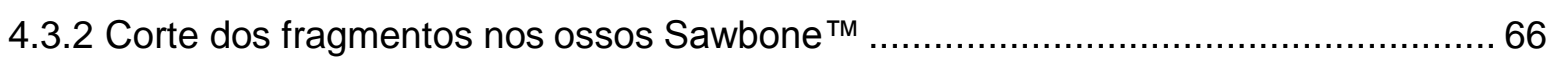

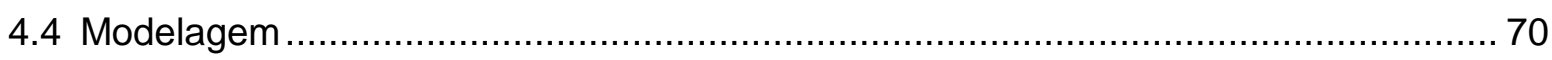

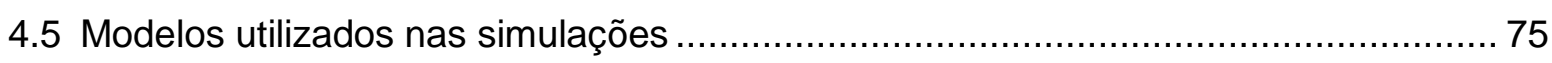

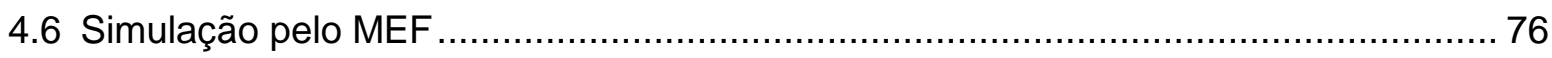

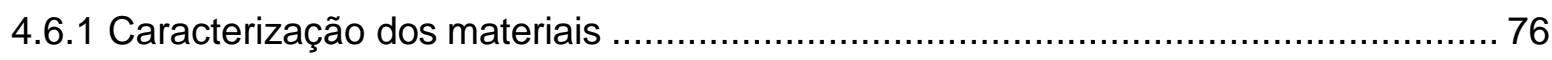

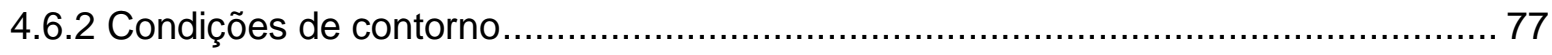

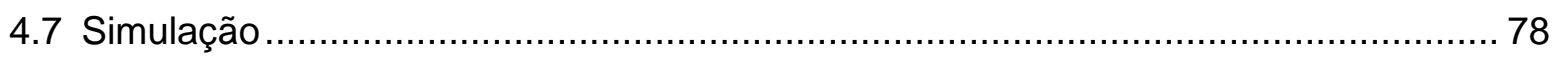

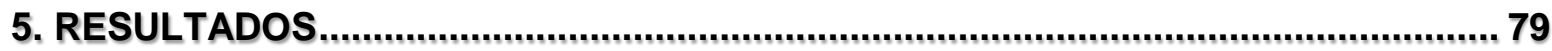

5.1 Comparação de Angulação .............................................................................117

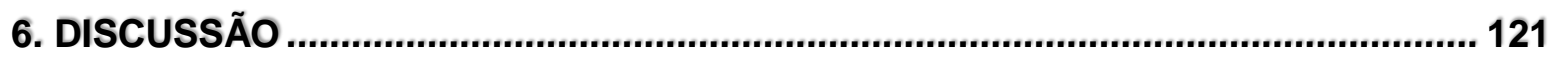




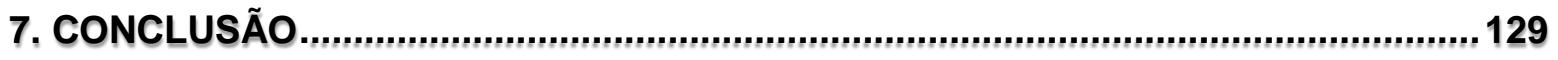

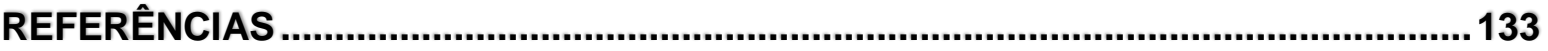




\section{Introdução}






\section{INTRODUÇÃO}

As fraturas decorrentes de traumas de baixa energia estão associadas aos pacientes idosos devido à osteoporose ou osteopenia, e os traumas de alta energia aos mais jovens devido a acidentes de trânsito e prática esportiva (ORBAY; FERNANDEZ, 2002).

Pela alta relevância com que aparecem nos centros médicos, as fraturas intra-articulares da extremidade distal do rádio são consideradas de elevada complexidade, em especial, aquelas com desvio, em razão do tamanho e redução

dos fragmentos e sua relação com o movimento das articulações rádio cárpica e rádio ulnar distal (MELONE, 1984), o que justifica e apoia, ainda mais, a sua análise.

As intervenções cirúrgicas continuam evoluindo com base nos resultados dos estudos clínicos mais atuais. Os avanços durante a última década aumentaram a variedade de opções de fixações disponíveis, porém a superioridade clínica de algumas modalidades de tratamento permanece sem consenso, pois há fatores, como o padrão de fratura, exigências funcionais, outras lesões concorrentes e integridade, dos tecidos moles vizinhos, que devem ser considerados (ALLURI; HILL; GHIASSI, 2016).

Com o desenvolvimento de materiais de fixação com ênfase nas placas bloqueadas e os sistemas de fixação dos fragmentos específicos, são de indicação do uso tratamento com redução aberta e fixação interna.

A fixação das fraturas da extremidade distal do rádio por placa volar bloqueada foi considerada durante os dez últimos anos o padrão ouro no tratamento destas fraturas, entretanto um fragmento específico com dimensões (altura em média de $7 \mathrm{~mm}$, com variação de $1 \mathrm{~mm}$ para mais ou para menos, largura de 17 $\mathrm{mm}$, com variação de $4 \mathrm{~mm}$, para mais ou para menos, e comprimento maior que 14 $\mathrm{mm}$ ) como mostra a figura 1 tem apresentado dificuldade de fixação e redução utilizando a fixação por placa volar bloqueada (OBATA et al., 2017). Em 2004, Harness et al. relataram que a fixação do fragmento da faceta do semilunar volar com uma placa de fixação volar é difícil devido à forma do osso, que é plana no corte sagital pois a placa inclina-se para o lado ulnar no plano axial. Além disso, em 2014 Beck et al. relataram os fatores de risco para o deslocamento de um fragmento da faceta do semilunar baseado em vários parâmetros de radiografia. 
Figura 1. (A) A visão sagital do rádio distal mostra a projeção volar para cima. (B) visão ilustra a configuração triangular da faceta semilunar e a projeção anterior. (C) visão axial da superfície articular do rádio distal mostra as facetas do escafoide e semilunar.
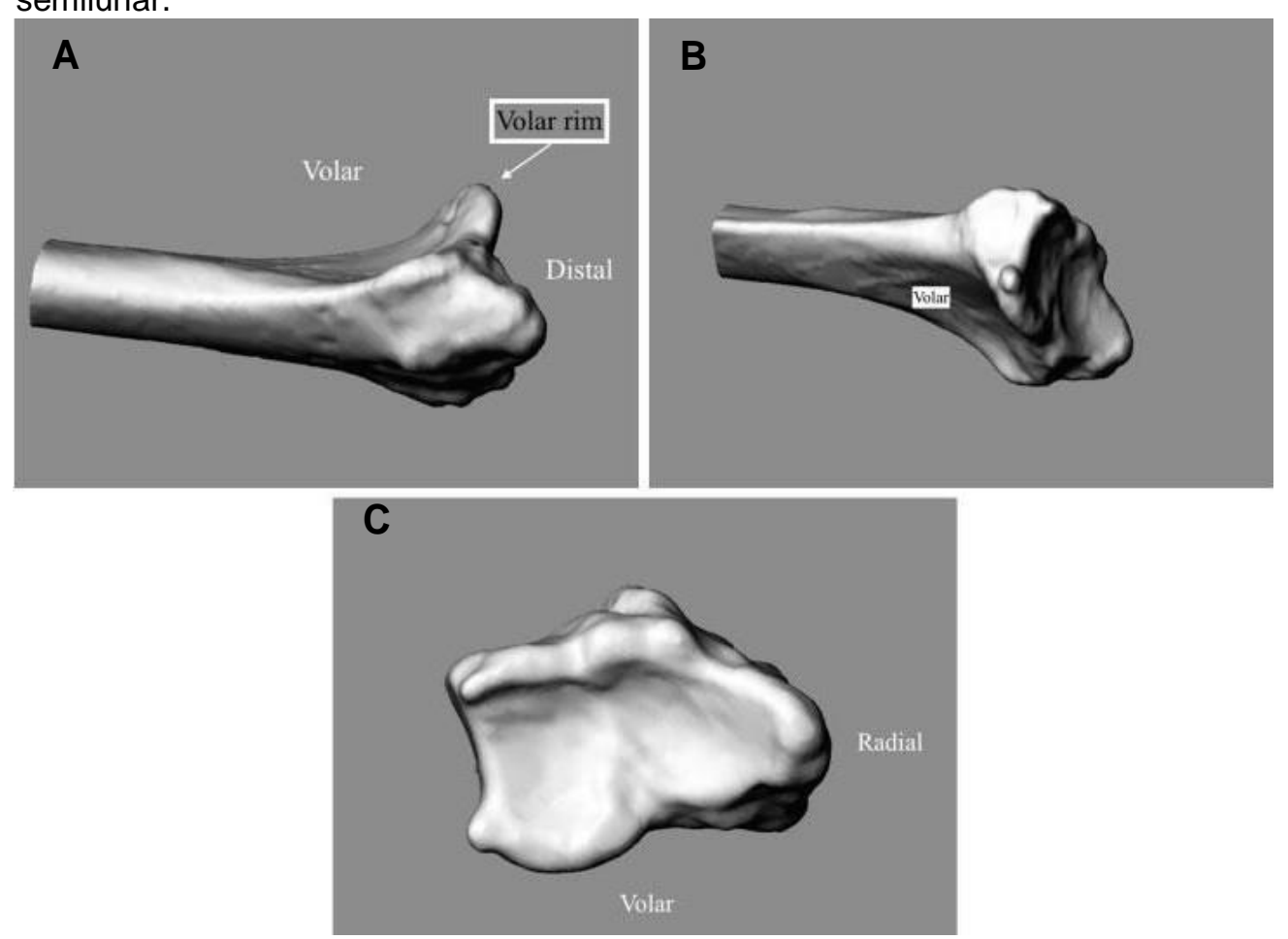

Embora o fragmento de fratura da faceta do semilunar possa ser um achado isolado, ele é frequentemente encontrado como parte de uma fratura intra-articular cominutiva do rádio distal. Se não for identificado e reconhecido no pré-operatório ou intraoperatório, a fixação com a placa volar bloqueada pode deixar de estabilizar e reduzir o fragmento, pois se apresenta mais distal do local a fixação pela placa volar e não permanece conectado a nenhum fragmento maior.

Vários autores sugerem diversas soluções para o tratamento, incluindo a técnica de fixação específica do fragmento (CHIN; JUPITER, 1999). No entanto, estas fraturas foram descritas de tamanha exigência de técnica por exigir uma curva de aprendizado maior para fixação adequada da fratura (CHIN; JUPITER, 1999). Necessitando, às vezes, de incisões com placas múltiplas e parafusos combinados para alcançar a estabilidade necessária dos fragmentos.

Antes do seu uso clínico, os implantes, parafusos e placas passam por uma diversidade de testes mecânicos e de biocompatibilidade com o objetivo de avaliar as tensões geradas pelos conjuntos de redução e fixação na redução e estabilização das fraturas testando a compatibilidade mecânica e avaliação biológica. (MACEDO et.; 2015). 
O método de avaliação que tem seu uso crescente é o método de elementos finitos (MEF). Este é um método matemático de análise de tensões que pode ser usado para a avaliação das tensões geradas pelas fixações nos ossos, assim como novas técnicas cirúrgicas, permitindo a diminuição do número de ensaios mecânicos e consequentemente a redução de gastos (BORIE, 2013).

Uma grande vantagem do uso do método é a possibilidade de alterações nas condições de simulação que em um ensaio mecânico seria possível, porém com maior gasto de tempo e dinheiro. Este método também possibilita a avaliação do implante em situações semelhantes às encontradas no uso da pratica clínica.

\subsection{Classificação das fraturas do rádio distal segundo AO (Manual AO- Arbeitsgemeinschaft für Osteosynthese - AO)}

Segundo classificação AO Arbeitsgemeinschaft für Osteosynthese (Manual $\mathrm{AO})$, as lesões do rádio distal dividem o envolvimento intra-articular em três grandes grupos que podem ser subdivididos em 27 padrões de fratura distintos. $O$ tipo $A$ descreve fraturas extra-articulares: A1 Fratura da ulna, rádio intacto; A2- Fratura simples do rádio (Colles quando o desvio é dorsal e Smith quando o desvio é volar); A3 Fratura Cominutiva do rádio. $\mathrm{O}$ tipo $\mathrm{B}$ se relaciona com acometimento parcial da superfície articular: B1 Traço sagital; B2 Fragmento dorsal (Barton); B3 Fragmento volar (Barton reverso). O tipo $\mathrm{C}$ corresponde a fraturas articulares completas: $\mathrm{C} 1$ Articular e metafisária simples; C2 metafisária multifragmentada; C3 Articular multifragmentada (Müller AO Classification of Fractures_Long Bones, 2007) (Figura 2). 
Figura 2. Classificação $A O$ para fraturas da extremidade distal do rádio. Fonte Manual $23 A 1$ Fratura da ulna; A2- Fratura simples do rádio; A3 Fratura Cominutiva do rádio; B1 Traço sagital; B2 Fragmento dorsal; B3 Fragmento volar C1 Articular e metafisária simples;

C2metafisária multifragmentada; C3 Articular Multifragmentada a () demonstra o local do fragmento.
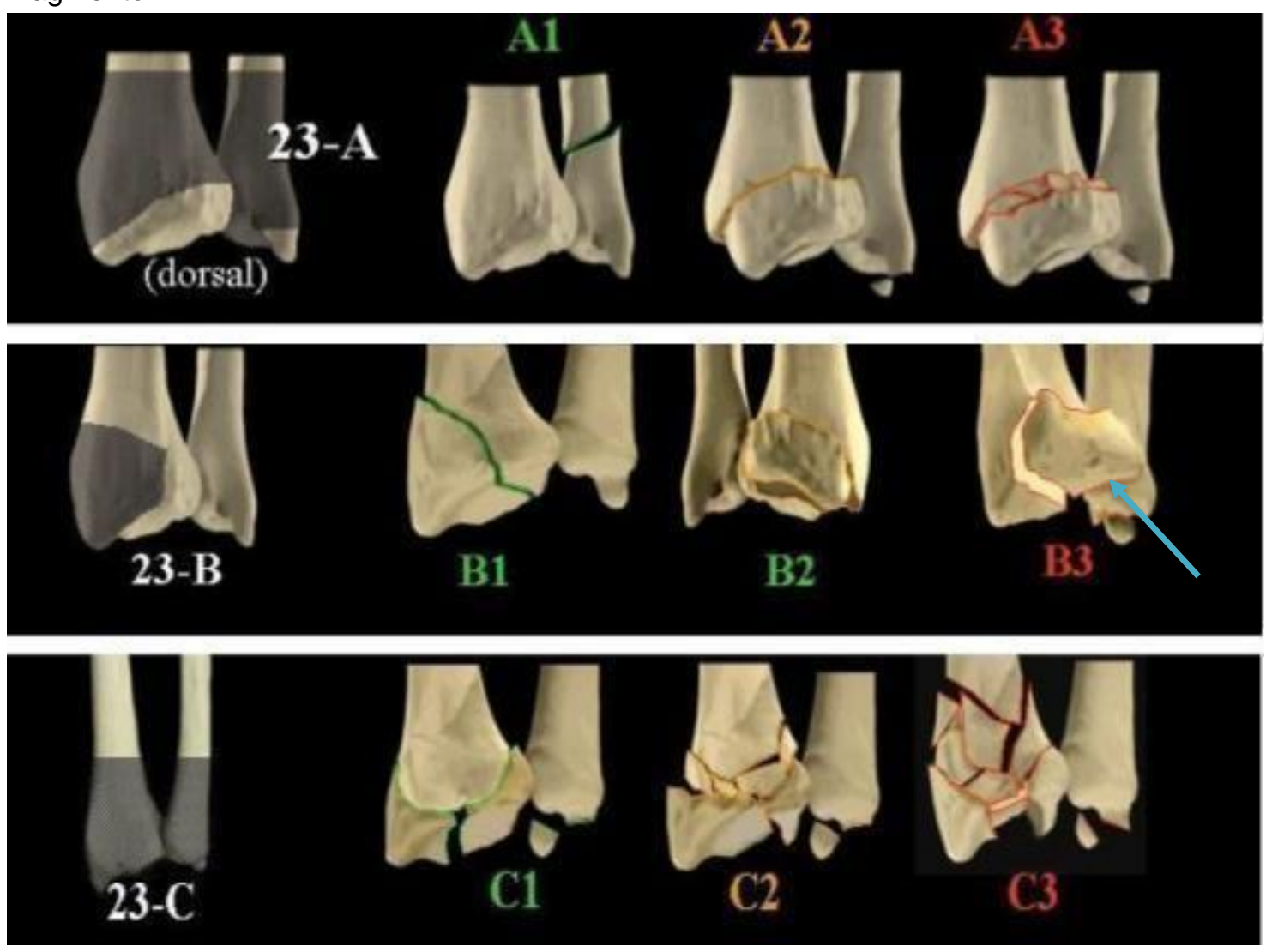

\subsubsection{A023 B3 Fraturas de cisalhamento palmar}

A impactação extensa da superfície articular pode estar presente, tanto no nível do fragmento de cisalhamento palmar como no remanescente articular dorsal. Tais lesões são instáveis com subluxação palmar do carpo. A fixação com placa de sustentação palmar está indicada para estabilizar a fratura (figura 2) (Manual AO).

\subsubsection{Faceta do Semilunar}

O fragmento da faceta do semilunar (figura 3) foi primeiro descrito por Harness et al. (2004). Esse estudo relatou dificuldade em redução e fixação do fragmento com placa volar devido à estrutura anatômica e biomecânica nesta região. Em 2014 Beck et al. relataram os fatores de risco para o deslocamento do fragmento da faceta do semilunar baseados em vários parâmetros de radiografia simples (BECK,2014). 
Figura 3. Fratura do canto volar ulnar.

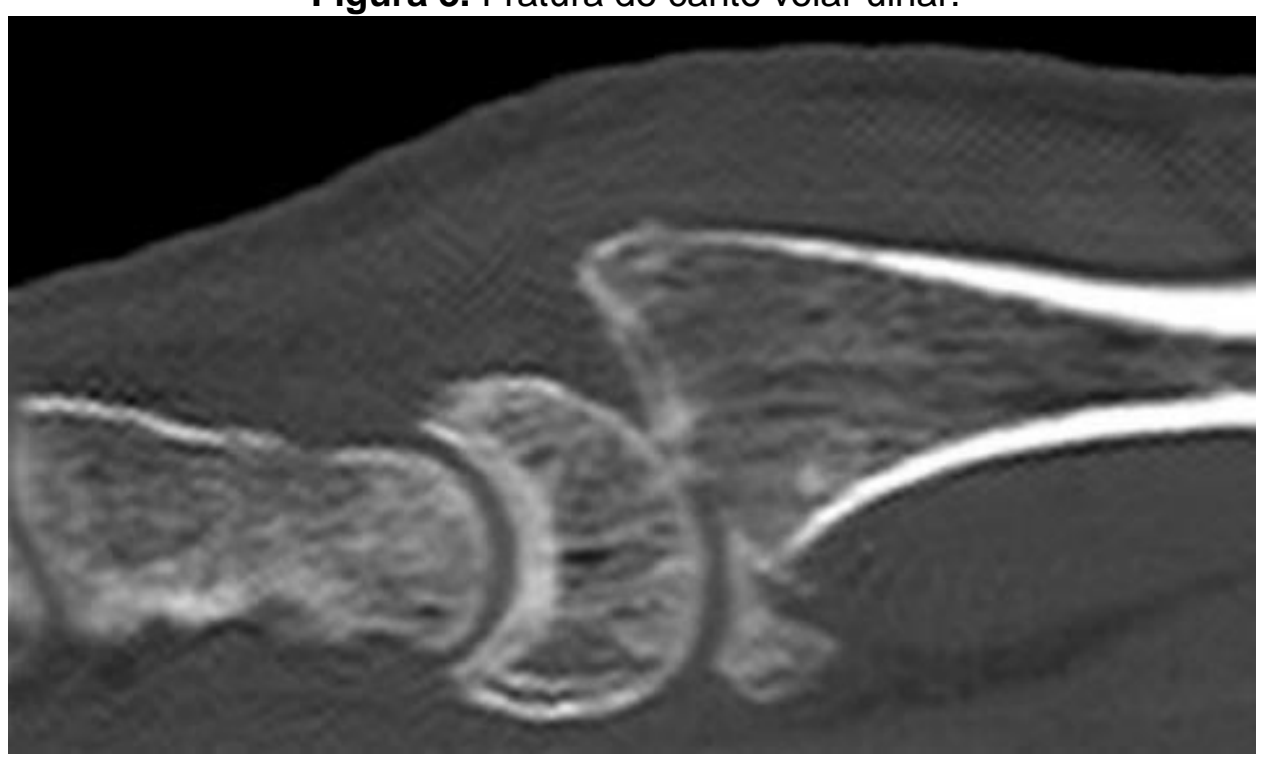

Fonte manual $\mathrm{AO}$

Há relatos inadequados de redução e fixação de fragmentos da faceta do semilunar (CHIN; JUPITER, 1999), sendo necessária nova intervenção cirúrgica devido à falta de clareza pré-operatória do fragmento. Sendo raros a escolha do tratamento adequado e posicionamento para redução da fratura, é difícil avaliar fatores de risco figura 4 (por exemplo, tamanho, forma e posição do fragmento) para o deslocamento do fragmento da faceta do semilunar e para determinar o apropriado tipo de fixação e redução (OBATA et al., 2017).

Figura 4. Fragmento da faceta do Semi Lunar
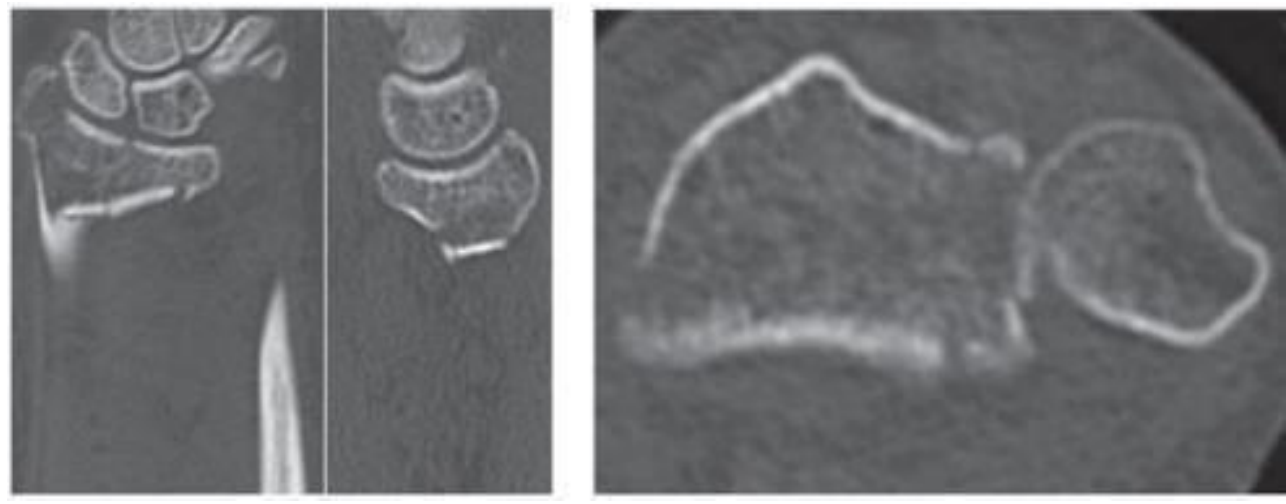

CHIN; JUPITER, 1999

\subsection{Tratamento}

Devido à alta incidência das fraturas distais do rádio e devido a sua complexa anatomia, a fixação e redução acontecem por um rigoroso diagnóstico de identificação dos fragmentos específicos. 
A redução anatômica significa a rigorosa reconstituição estrutural do rádio distal, ou seja, a recuperação da altura do rádio, da congruência articular e o restabelecimento dos parâmetros dos ângulos de inclinação radial e palmar (GRINDEL, 2007).

A fixação e redução com placa volar se tornou a técnica padrão ouro para o tratamento de vários tipos destas fraturas em razão da sua boa aceitação, bons resultados e poucas complicações clínicas (ORBAY, 2002; ORBAY, 2004; ROZENTAL; BLAZAR, 2006).

No entanto, a presença do fragmento de dimensões reduzidas revelou limitação importante na fixação das fraturas da extremidade distal do rádio por placas volares mostrando a instabilidade da faceta anterior do semilunar. A falta de estabilização e fixação deste fragmento acarreta a luxação rádio-cárpica e/ou luxação da rádio-ulnar distal, por estarem inseridos neste osso os ligamentos rádio semilunar curto e o ligamento volar rádio-ulnar distal, com isso gerando a necessidade de utilização de outro tipo de fixação.

Fraturas do rádio distal com acometimento do canto volar ulnar é onde se origina o ligamento rádio semilunar curto. São de difícil tratamento apesar das mudanças no projeto de placas volares com extensão para canto ulnar volar proporcionando apoio à faceta volar do semilunar, a fixação permanece um desafio em fragmentos menores que $14 \mathrm{~mm}$ em comprimento. Para capturar estes pequenos fragmentos marginais, a placa volar convencional deve ser alocada distalmente, o que pode resultar na irritação e / ou ruptura do tendão pela proximidade com a placa.

\subsection{Opções de fixação da fratura faceta volar}

Fraturas da extremidade distal do rádio distal com pequenos fragmentos marginais são instáveis e podem ser de difícil tratamento. $O$ fragmento da faceta volar do semilunar recebeu atenção na última década devido ao potencial de perda de fixação e subluxação do carpo (BECK, 2016).

A faceta ulnar volar pode fraturar isoladamente ou mais comumente está associado às fraturas causadas por força de cisalhamento, bem como fraturas cominutivas graves do rádio distal. A fixação estável da faceta ulnar volar é crítica porque a instabilidade resulta em subluxação ou luxação do carpo volar, com isso, a função acaba sendo prejudicada, o que acarreta dores traumáticas, 
apesar de os cirurgiões estarem cientes essa potencial armadilha, a perda de fixação contínua pode ocorrer (HARNESS et al., 2004).

Jupiter et al. em 1999 observaram que a grande maioria das fraturas decorridas por cisalhamento do rádio distal apresenta no mínimo dois fragmentos articulares, a faceta do escafoide e a do semilunar, porém o de maior dificuldade de fixação e estabilização é o canto volar ulnar. Beck et al. em 2014 descobriram que o tamanho do fragmento e a quantidade do deslocamento davam a garantia de que a placa volar não assegurava a estabilidade e fixação devida do fragmento, gerando opções de novas técnicas de redução e estabilização do canto volar ulnar.

O tratamento das fraturas por cisalhamento é um desafio, pois geralmente apresenta achados radiográficos sutis que podem ser omitidos na avaliação inicial (SYNEK, 2016). A fixação desse fragmento crítico pode ser desafiadora devido à anatomia do canto volar ulnar. A faceta ulnar volar serve como local da origem do ligamento rádio semilunar curto (HARNESS et al., 2004; ANDERMAHR, 2006). A faceta é mais proeminente volarmente do que o restante do rádio distal em cerca de $3 \mathrm{~mm}$. Devido a essa elevação volar, as placas de bloqueio do rádio distal volar padrão normalmente não se adaptam bem ao longo do canto volar ulnar (ANDERMAHR, 2006). Por esta razão, ocorre a perda de redução e subluxação volar do carpo que é singularmente preocupante em pacientes tratados com fixação de fraturas que envolvem a faceta semilunar.

Se não forem tratadas de maneira adequada as fraturas que lesionam a faceta ulnar volar do semilunar, ocorrerá a subluxação volar do carpo acarretando em dor, diminuição da função da amplitude de movimento do punho, artrose e diminuição de força. Perda de supinação do antebraço e extensão do punho são problemas precoces frequentes entre esses pacientes $(\mathrm{RUCH}, 2006)$. A perda de supinação não é bem tolerada e pode ter um impacto significativo na função.

Para a fixação específica do fragmento algumas técnicas foram caracterizadas com a inclusão de fixações por parafusos verticalmente ou horizontalmente, fios de Kirschner e o desenvolvimento de placas especificas com a presença de gancho (BECK, 2014). 


\subsection{Placa hook volar e suas variações}

Placas volares com gancho foram introduzidas para fixação do canto volar ulnar da faceta do semilunar, fragmento específico. Tem tamanho estreito característico com gancho de tamanho e ângulo variável permitindo a fixação de fraturas de borda volar muito distais em pacientes com osteoporose. (BECK, 2014).

No entanto, a presença do fragmento com tamanho variado possibilita opção pré-cirúrgica que, de acordo com a dimensão, a adequação necessária para a redução e fixação com a placa com angulação e tamanho do gancho variável de acordo com o pré-operatório feito para se destacar o tamanho do osso desprendido.

\subsection{Lesão no ligamento rádio semilunar curto}

$\mathrm{Na}$ instabilidade pós-traumática isolada das Lesões da Articulação Ulnar Radial Distal (DRUJ), o mais comum é um evento traumático envolvendo uma queda da mão estendida ou uma rotação forçada do pulso, que é seguida por um punho inchado e dor agravada pelo movimento do antebraço e punho.

A dor em repouso e o inchaço normalmente melhoram, entretanto a dor na utilização do punho continua e pode se associar com sintomas de instabilidade mecânica, incluindo fraqueza e estalo.

Reconstrução dos ligamentos rádio-ulnar oferece a melhor possibilidade de restaurar as restrições primárias do DRUJ normais. Embora os papéis precisos dos ligamentos radio-ulnar serem debatidos, os ligamentos volares e dorsais agem em conjunto com as bordas do entalhe sigmoide para estabilizar junta, e ambos são necessários para a estabilidade normal em qualquer direção (KIHARA, 1995). Picos de tensão ligamentar nos extremos de translação e rotação como a cabeça ulnar simultaneamente comprimem contra uma borda do entalhe gerando uma pressão contra a luxação. Apesar de um ligamento possivelmente fornecer a restrição dominante sob uma condição específica, o outro ligamento é uma contenção secundária, e ambos devem ser lesados para possibilitar uma luxação completa (MINO; PALMER; LEVINSOHN, 1983). Em pacientes com lesão bidirecional ou instabilidade unidirecional grave, ambos os ligamentos são lesados.

Portanto, reconstruir ambos os ligamentos seria fornecer 0 melhor restabelecimento da congruência normal da DRUJ. 


\subsection{Ensaio Mecânico}

A importância das propriedades mecânicas fez com que, em 1640, GALILEU GALILEI iniciasse os estudos das características mecânicas dos ossos longos em vários animais. A partir de então, vários autores, utilizando cada qual uma determinada técnica e objetivo, buscaram maiores informações e conhecimento do osso como material biológico (SHIMANO, 1994).

Uma vez que o esqueleto está funcionando como um sistema que suporta cargas, e é submetido a um conjunto de forças que ocasionam deformações (ALISTER; MOYLE, 1983), a Biomecânica apresenta-se como um valioso instrumento de medida no estudo e compreensão desses eventos e suas consequências, atuando, portanto, como um elo fundamental entre as ciências exatas e biológicas (PESSAN; VOLPON; SHIMANO, 1996).

Para determinar as propriedades mecânicas do osso, o ensaio mecânico é considerado como padrão ouro. Infelizmente, é um teste destrutivo e sua metodologia não é aplicável in vivo (VAN LENTHE; STAUBER; MÜLLER, 2006). Nos últimos anos, com o desenvolvimento de novas tecnologias que possibilitaram os desenhos mais complexos de ossos faz com que se empregue o Método dos Elementos Finitos para simular e verificar a distribuição de tensão e deformação a partir de uma solução de equações de equilíbrio juntamente com cargas aplicadas e limitações (DETOLLA, 2000), o método tem se mostrado importante na compreensão da biomecânica de ossos e implantes.

\subsection{Método Dos Elementos Finitos (MEF)}

O método foi elaborado preliminarmente de forma intuitiva, que preconizava a substituição do meio continuo em análise por um conjunto finito de partes menores (elementos) que é interligado entre si (nós). A formulação do elemento foi realizada através do princípio dos deslocamentos virtuais (SORIANO, 2003).

O MEF é um método numérico muito eficaz, utilizado para solucionar problemas complexos. Este tipo de análise permite a representação precisa da geometria complexa e inclusão das diferentes propriedades dos materiais, permitindo a aplicação de carregamentos em pontos específicos da estrutura. As tensões máximas, mínimas e as deformações podem ser obtidas (SORIANO, 2003).

A utilização do método pode ser para um estudo estático ou dinâmico. $O$ MEF é aplicado atualmente nos mais diversos campos da engenharia. $\mathrm{Na}$ área médica, 
mais especificamente dentro da ortopedia e biomecânica, a sua utilização nos centros mais avançados, mostrando que esta é uma ferramenta importante para o estudo, pesquisa e simulação de soluções de problemas mecânicos estruturais envolvendo implantes ortopédicos em geral (apud: MACEDO, 2009).

\subsubsection{Utilização Do Método Dos Elementos Finitos na Ortopedia}

O Método dos Elementos Finitos (MEF) foi iniciado na biomecânica com o objetivo de averiguar as tensões, relacionadas com a arquitetura dos ossos e o procedimento de remodelação dos mesmos (HUISKES; CHAO, 1983).

O método é desenvolvido em vários ramos da engenharia, na área médica com enfoque especialmente na Ortopedia e Biomecânica na simulação de próteses, órteses, placas e parafusos de fixação, mostra-se ser uma ferramenta poderosa na simulação das condições mecânicas em ossos.

Os métodos de ensaios utilizados para estudar o comportamento mecânico de ossos apresentam limitações devido a sua complexidade, estes procedimentos só eram aplicáveis a meios contínuos homogêneos e de geometria simples (SORIANO, 2003).

Em 1972 Brekelmans, Poort e Slooff utilizaram diversos métodos de ensaio para avaliar o comportamento de ossos para tentar ultrapassar algumas destas limitações, era frequente a substituição de derivadas exatas por derivadas aproximadas, calculadas com base em grelhas de pontos comparadas sendo que segundo os autores o MEF seria uma ferramenta versátil e dinâmica para o uso na ortopedia (apud: MACEDO, 2009).

Os modelos de elementos finitos específicos têm sido uma ferramenta eficaz tanto para a avaliação da tensão óssea como para a avaliação da resistência à fratura (EDWARDS; TROY, 2012).

\subsection{Propriedades dos Materiais e Características do Modelo}

No estudo pelo MEF os materiais utilizados podem ser divididos de acordo com suas características em dois tipos de grupos, os dúcteis e os não dúcteis, de acordo com a análise a ser estudada. Os materiais metálicos, como placas e parafusos pertencem aos grupos dos dúcteis, que tem a tensão medida pelo ensaio de tensão equivalente de von Mises. Essa tensão é de magnitude proporcional à energia de distorção, usada em ensaios de falha de materiais dúcteis, em que é 
prevista a falha, independe do estado de tensão/deformação, significando que as tensões de tração e de compressão são consideradas iguais e tratadas da mesma forma(DONATO; BIANCHI, 2011). A tensão equivalente de von Mises não é aplicada para análise de ossos, pois estes pertencem à segunda categoria (material frágil) e as tensões máxima e mínima principais são adequadas para o estudo (BORIE, 2013 apud DEJAK; MLOTOKOWSKI, 2008). Para as análises de ossos e cerâmica, que são materiais frágeis, as tensões máximas e mínimas principais são apropriadas para a avaliação (DEJAK; MLOTKOWSKI, 2008). A tensão equivalente de Von Mises não deve ser utilizada para ossos (PETRIE; WILLIAMS, 2005).

$\mathrm{Na}$ análise pelo MEF é feita a simulação de um grupo de forças diferentes que atuam de forma no sistema, sendo assim a força de tração composta por uma carga que propende a esticar ou estender o sólido (ANUSAVICE, 2005). Sendo que este tipo de força apresenta valores positivos no momento em que é avaliada a tensão máxima principal.

Para à análise da Mínima Principal tem-se a força de compressão composta por carga que propende a comprimir ou reduzir o sólido, sendo que este tipo de forças tem apresentado valores negativos (MATSUNAGA et al., 2008; ANUSAVICE, 2005).

Cada tipo de material apresenta características próprias e únicas de elasticidade na presença de uma força. O módulo de elasticidade, ou módulo de Young, indica a rigidez de um material e pode ser definido como uma constante de proporcionalidade de deformação de um material submetido a uma tensão específica, dentro de um regime elástico (DARVELL, 2012; ANUSAVICE, 2005). O coeficiente de Poisson é uma constante que se relaciona com o comportamento sob tração ou compressão de um material, onde o mesmo é submetido a um alongamento lateral em direção perpendicular ao eixo da carga, sempre que as deformações forem pequenas (KANBARA et al., 2012; DARVELL, 2012).

Com isso as propriedades elásticas dos materiais podem apresentar quatro tipos de comportamentos: Isotrópico, as propriedades dos materiais são iguais em todas as direções, precisando apenas de duas variáveis, módulo da elasticidade e coeficiente de Poisson (KORIOTH; VERSLUIS 1997; BORIE, 2013); Anisotrópico, o material apresenta variações de comportamento mecânicos nas diferentes direções (BORIE, 2013;); Ortotrópico, possui dois planos ortogonais de simetria, onde as propriedades dos materiais são independentes da direção com o plano. 
Transversalmente isotrópico, o material possui as mesmas propriedades em um plano e diferentes em direção normal deste plano (eixo Z) (KORIOTH, 1997). Sendo que o osso apresenta um comportamento anisotrópico e viscoelástico (TURNER et al., 1999; HUANG et al., 2008).

Os ossos corticais e trabeculares são frequentemente modelados com propriedades linearmente elásticas, homogêneos e isotrópicos (CATTANEO; DALSTRA; MELSEN, 2005). A maioria dos estudos exclui os detalhes da rede trabecular devido à inabilidade para obtê-los, considerando-os como homogêneo ( $\mathrm{CHU}$ et al., 2012). A vantagem de modelar detalhadamente a estrutura trabecular do osso é que em vez de assumir o volume continuo e homogêneo, podem ser consideradas as propriedades anisotrópicas, próprias e naturais da sua estrutura (LIMBERT et al., 2010). 
2. Hipóteses 



\section{HIPÓTESES}

- H0: O comprimento e angulação do gancho da placa volar modificada influencia o comportamento mecânico da fixação do fragmento reduzido ulnar.

- H1: O comprimento e a angulação do gancho da placa volar modificada não influencia o comportamento mecânico da fixação do fragmento reduzido ulnar. 

3. ObjetivoGeral 



\section{OBJETIVO GERAL}

Analisar as tensões e deformações geradas nos modelos com sistema de fixação do fragmento específico do canto volar ulnar do rádio, com placa volar modificada com gancho, com diferentes comprimentos e angulações, utilizando o Método dos Elementos Finitos, simulando o ensaio de cisalhamento.

\subsection{Objetivos Específicos}

- Realizar a modelagem da placa, parafusos e do rádio, utilizando imagens da tomografia computadorizada de modelos de ossos sintéticos.

- Realizar simulações através do Método dos Elementos Finitos dos modelos estudados

- Validar os modelos propostos no MEF comparando com os resultados dos deslocamentos obtidos no Ensaio Mecânico de cisalhamento em modelos reais utilizando as fixações com placas volares modificadas com gancho, de diferentes comprimentos e ângulos.

- Comparar as tensões máximas e mínimas geradas no osso pelos sistemas de fixação analisados.

- Comparar os deslocamentos gerados nos sistemas de fixação analisados. 



\section{MatériaiseMétodos}





\section{MATERIAIS E MÉTODOS}

\section{1 Ética Experimental}

Este projeto teve início após a obtenção de declaração de dispensa de comitê de ética em pesquisa da Comissão de Ética em Pesquisa HCRP (Anexo A)

\subsection{Materiais Utilizados}

Foram utilizados 3 modelos ósseos de rádio esquerdo, quarta geração modelo 3407 (Sawbones ${ }^{\mathrm{TM}}$; Pacific Laboratories Inc., Vashon, WA; model \# 3407) (figura 5), apropriados para ensaios biomecânicos. As especificações desses modelos estão na tabela1. O custo médio de cada rádio é de $U \$ 200,00$ (duzentos dólares) mais a taxa de importação em torno de $\mathbf{U} \$ 80,00$ (oitenta dólares).

Esses modelos têm como medidas: a) comprimento $25 \mathrm{~cm}$; b) largura da parte central da diáfise $16 \mathrm{~mm}$; c) largura na extremidade distal $35 \mathrm{~mm}$ : d) largura na extremidade proximal $27 \mathrm{~mm}$.

Foram utilizadas placas volares modificadas tipo gancho de $2 \mathrm{~mm}$ com variação de angulação de $60^{\circ}, 90^{\circ}$ e $120^{\circ}$ todas com ganchos de $3 \mathrm{~mm}$ de comprimento (figuras 7 e 8) utilizando parafusos corticais de $2,3 \mathrm{~mm}$ sendo cada conjunto composto de uma placa e 3 parafusos corticais (figura 6).

Figura 5. Osso Rádio Sintético Sawbone ${ }^{\mathrm{TM}} 3407$

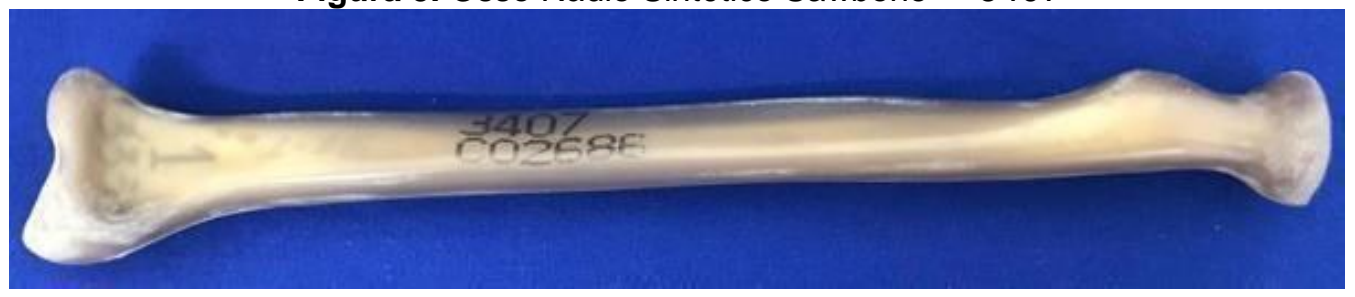

Figura 6. Parafuso Cortical hexadrive $2,3 \mathrm{~mm}$

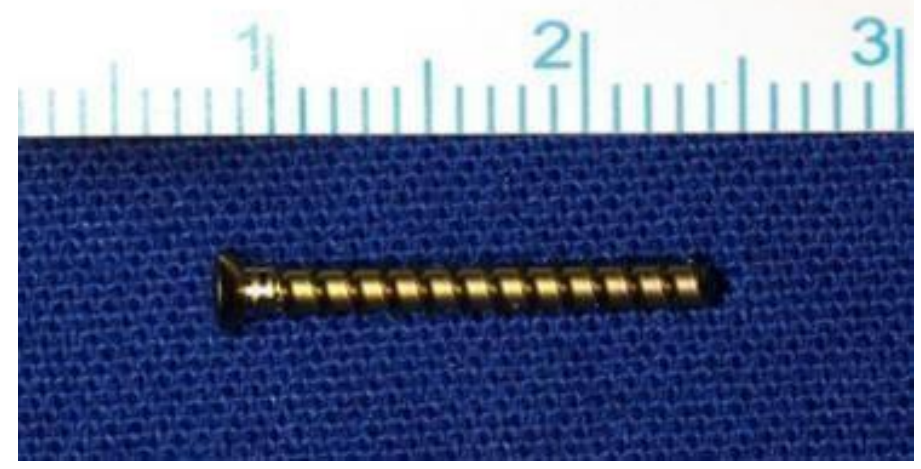


Figura 7. Vista de frente da Placa volar modificado com gancho de $2 \mathrm{~mm}$ espessura e gancho com comprimento de gancho de $3 \mathrm{~mm}$

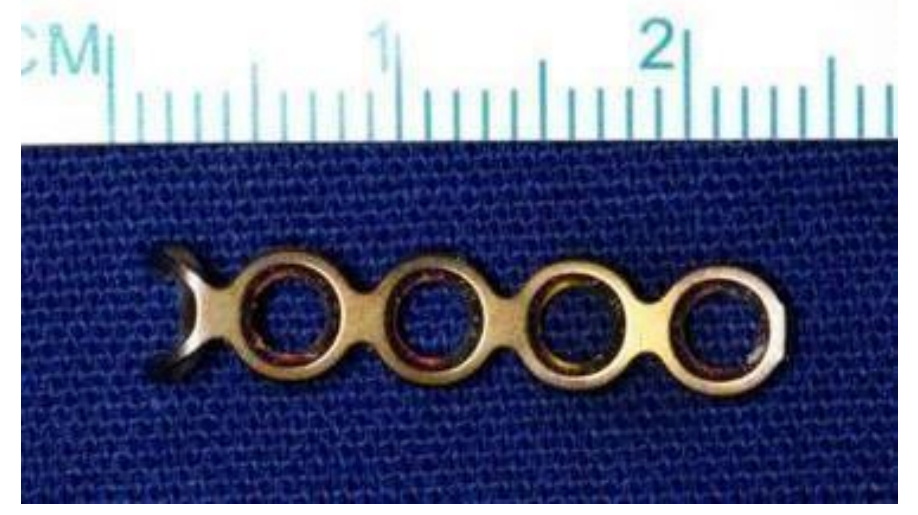

Figura 8. Vista em perfil da Placa volar modificada com gancho

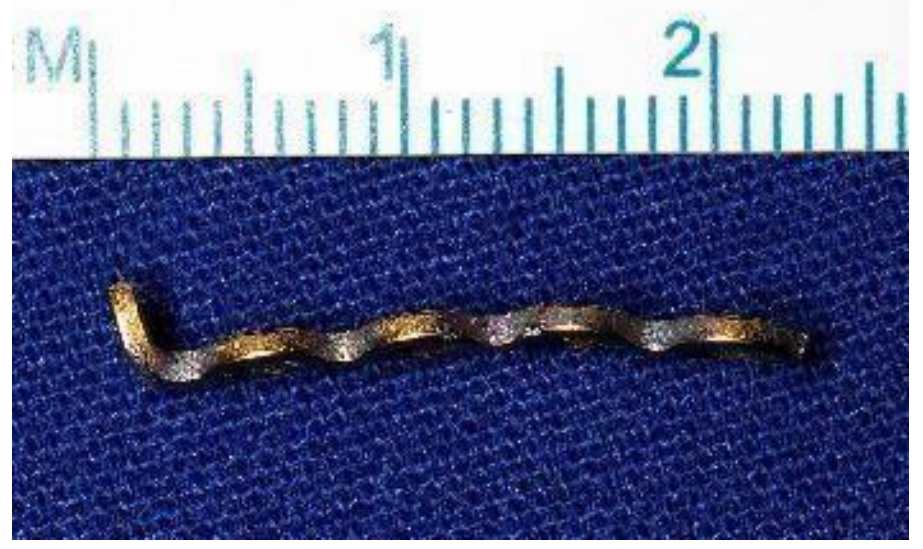

Tabela 1. Dimensões dos parafusos e placas

\begin{tabular}{ccccc}
\hline & $\begin{array}{c}\text { Comprimento } \\
(\mathbf{m m})\end{array}$ & $\begin{array}{c}\text { Diâmetro } \\
(\mathbf{m m})\end{array}$ & $\begin{array}{c}\text { Passo de } \\
\text { rosca }(\mathbf{m m})\end{array}$ & $\begin{array}{c}\text { Gancho } \\
(\mathbf{m m})\end{array}$ \\
\hline Parafusos & 18 & 2,3 & 2 & - \\
Placas & 25 & 2 & - & $3 \mathrm{~mm}$ \\
Ossos & 250 & 30 & - & - \\
\hline
\end{tabular}

\subsection{Preparação dos modelos}

\subsubsection{Impressão do molde 3D}

No laboratório de Bioengenharia da FMRP/USP foi impresso o molde em impressora 3D modelo (Stella $\AA^{8}$ ) (figura 10) para servir de gabarito de corte para os ossos sintéticos. Os cortes foram confeccionados através de um arquivo STL originário de tomografia computadorizada dos ossos sintéticos. Molde este que foi impresso com o devido fragmento separado de acordo com a (figura 9) molde com tamanho idêntico ao osso sintético a ser utilizado, este foi confeccionado em o filamento de Poliácido Láctico (PLA). O tempo 
gasto para imprimir o molde foi em torno de duas horas e dezesseis minutos para o osso e vinte e oito minutos para o fragmento. Os modelos impressos do rádio e do fragmento serviram como protótipo para os cortes a serem realizados nos ossos Sawbone ${ }^{\mathrm{TM}}$.

Figura 9. Molde impresso para corte em impressora 3D

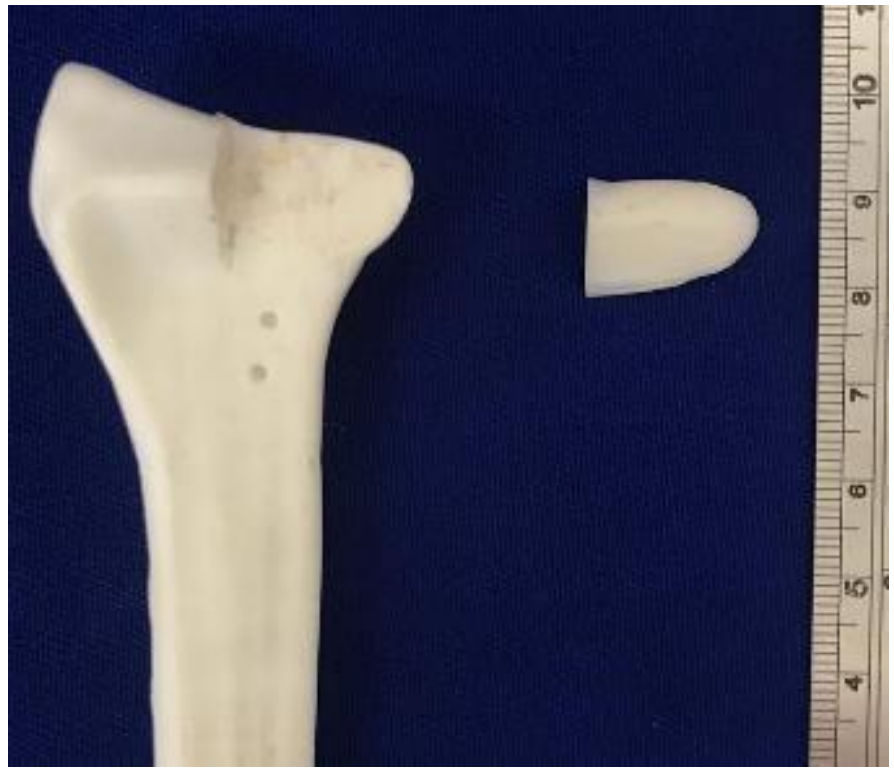

Figura 10. Impressora 3D modelo Stella 2

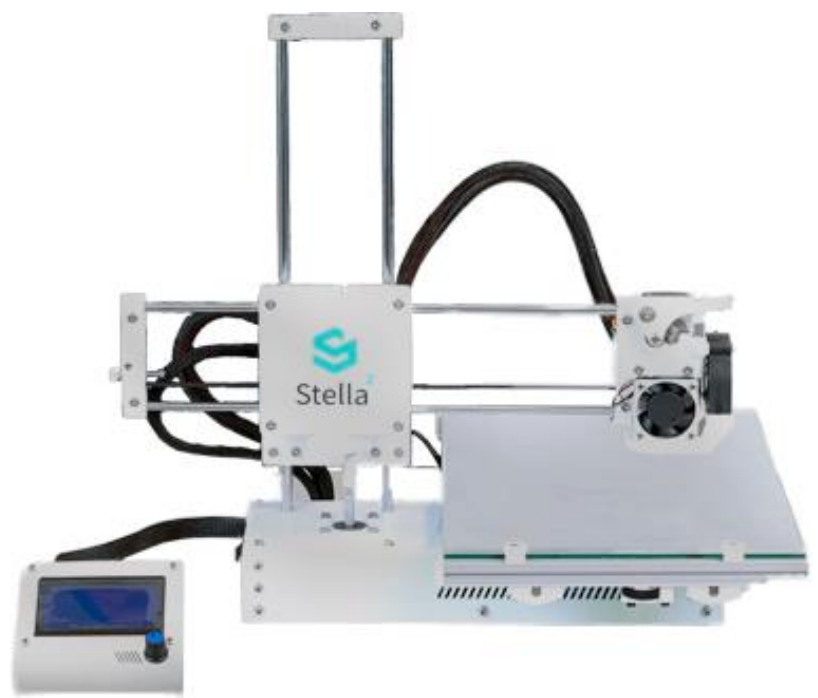




\subsubsection{Corte dos fragmentos nos ossos Sawbone ${ }^{\mathrm{TM}}$}

Os cortes dos fragmentos do canto volar ulnar dos três rádios da Sawbone ${ }^{\mathrm{TM}}$ foram realizados na oficina de Precisão da Prefeitura do Campus da USP de Ribeirão Preto. Cada rádio foi posicionado sobre um acessório da Serra Circular, que o fixou sobre um anteparo de madeira transfixado por duas hastes metálicas e apoiado em sua base para garantir a padronização. Com isso foi realizado o corte do fragmento do canto volar ulnar de cada um dos três rádios (Figura 1A e B)

Figura 11. ossos sendo cortados por serra circular (A e B)
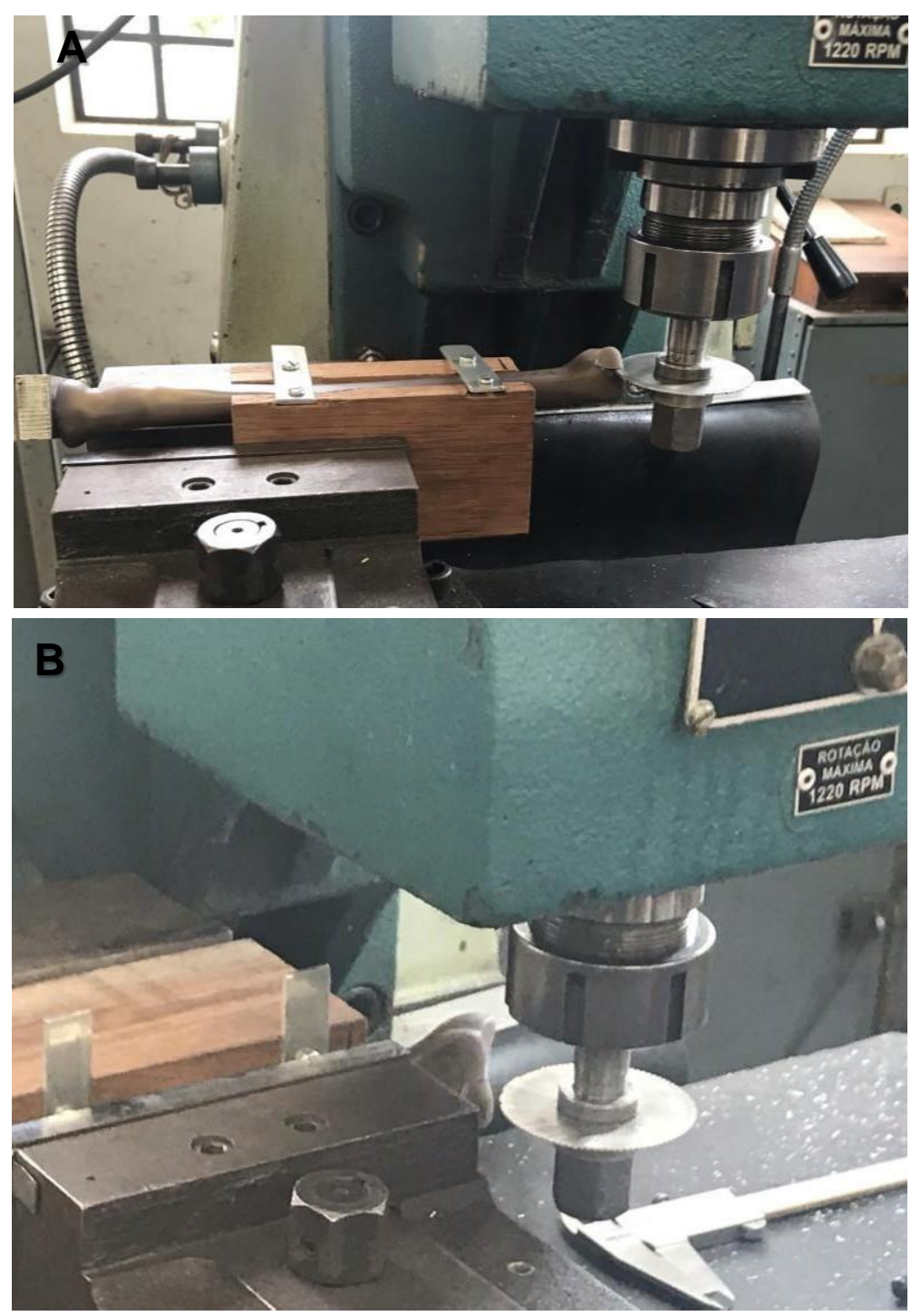

Posteriormente foi cortada a porção distal de cada rádio, utilizando uma serra manual. O comprimento total de cada osso foi padronizado em $132 \mathrm{~mm}$. Foram realizadas as montagens dos três modelos físicos, sendo a placa modificada tipo 
gancho com três variações de ângulo. Os ossos foram perfurados com uma broca de $2 \mathrm{~mm}$, usando a Drill Locking Peg como guia para fixação. A placa foi posicionada de forma que reduza e fixe o fragmento da faceta do semilunar.

Feitas as variações de angulações de placas e assim fixadas de acordo com os modelos propostos, cada montagem recebeu a placa e seus devidos parafusos conforme a (figura 12).

Figura 12. Conjuntos montados Ossos Placas com suas respectivas angulações e Parafusos

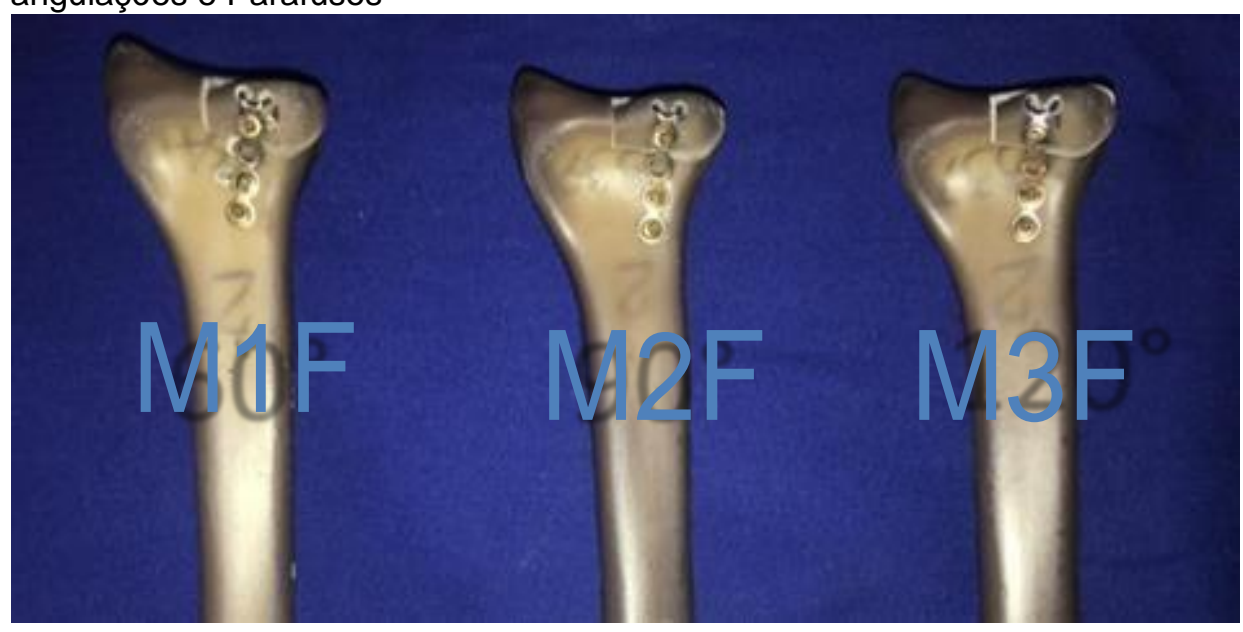

\section{Confecção das bases de apoio dos modelos}

As bases de apoio dos modelos foram confeccionadas com resina acrílica autopolimerizável (AutoCrilß) (figura 13). A resina foi preparada conforme recomendação do fabricante. As medidas médias das bases na forma de um cubo foram de $(50 \mathrm{~mm} \times 50 \mathrm{~mm} \times 45 \mathrm{~mm})$ comprimento, largura e altura, respectivamente, medidos em milímetros. Para isso, foi confeccionado um molde em teflon (Figura 14 e 15). 
Figura 13. resina acrílica auto polimerizante da marca AutoCril $\circledast(A)$, e peróxido de benzoila $(B)$, copo Becker (C)

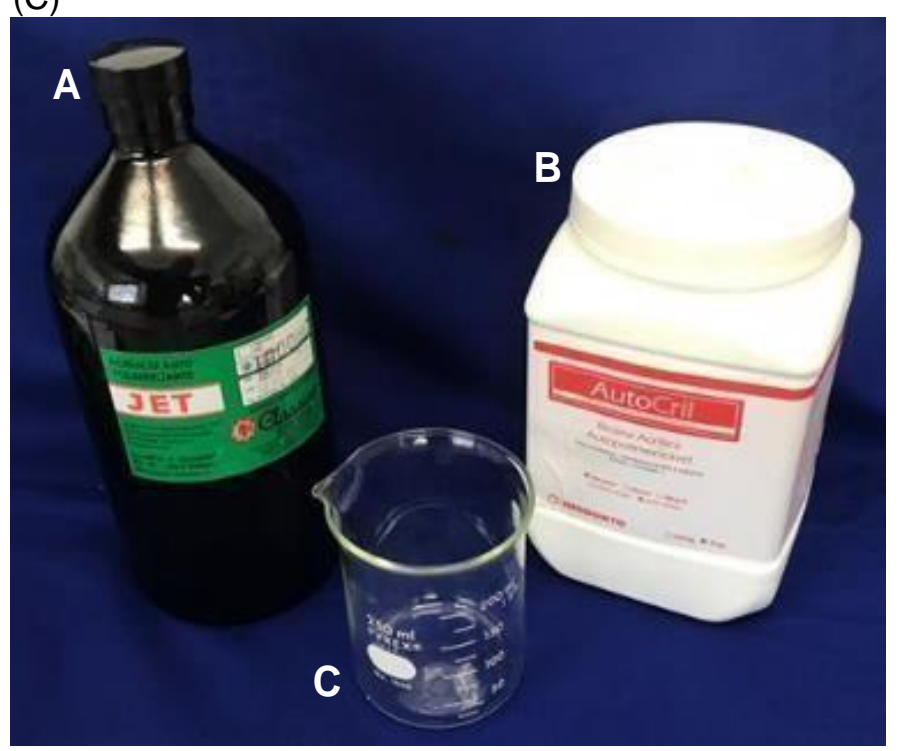

Figura 14. (A) Molde usado para inclusão dos ossos

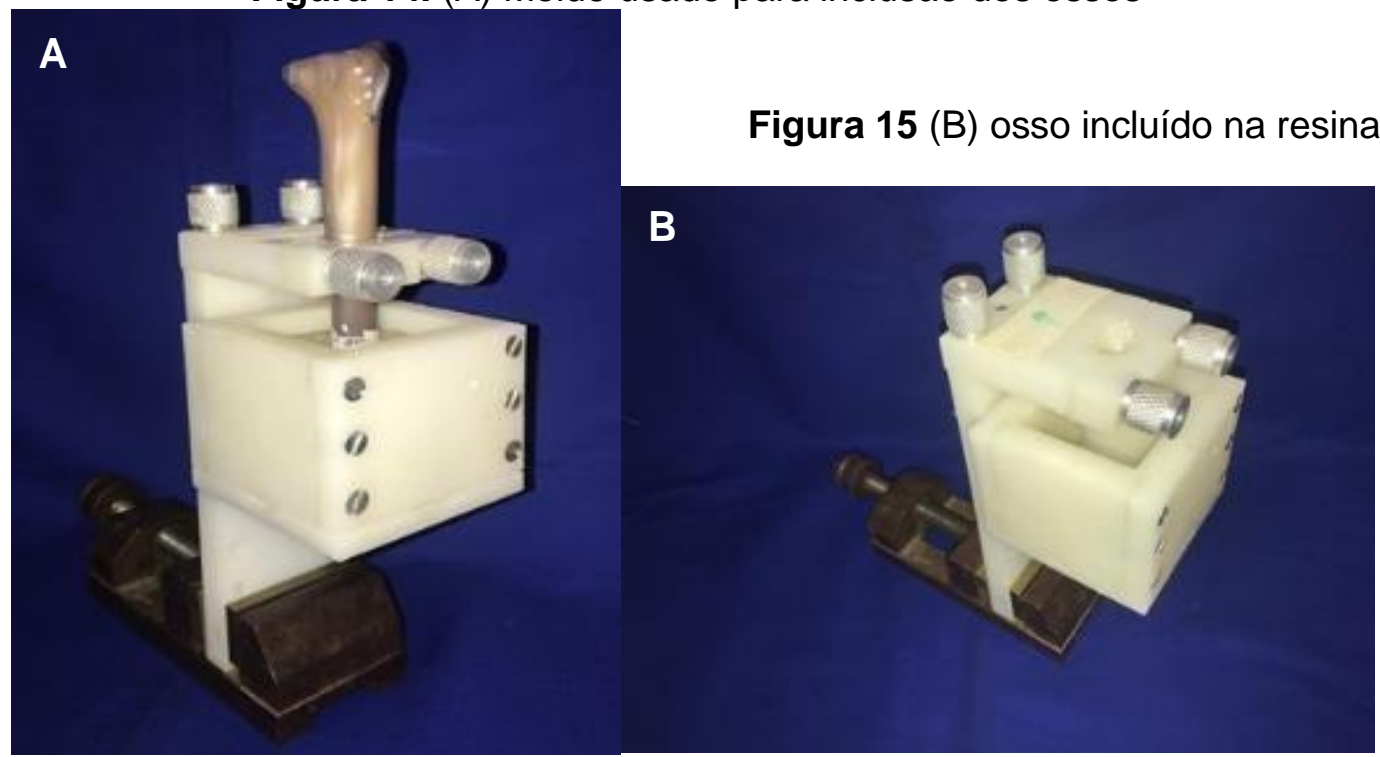

\section{Modelos montados para o Ensaio Mecânico.}

Os três modelos físicos propostos para realização dos ensaios mecânicos e cisalhamento foram: Modelo 1 (M1F): Placa volar modificada com gancho (PVMG) com gancho de $3 \mathrm{~mm}$ e ângulo de $90^{\circ}$ em relação à placa fixada por três parafusos, um no fragmento e dois no osso; Modelo 2 (M2F): PVMG com gancho de $3 \mathrm{~mm}$ e ângulo de $120^{\circ}$ em relação à placa fixada por três parafusos, um no fragmento e dois no osso; Modelo 3 (M3F): PVMG com gancho de $3 \mathrm{~mm}$ e ângulo de 
$60^{\circ}$ em relação à placa fixada por três parafusos, um no fragmento e dois no osso. Conforme a (figura 16) e (Tabela 2).

Tabela 2. grupos para ensaio mecânico.

\begin{tabular}{ccc}
\hline GRUPOS & GANCHO & ÄNGULO \\
\hline M1F & $3 \mathrm{~mm}$ & $90^{\circ}$ \\
M2F & $3 \mathrm{~mm}$ & $120^{\circ}$ \\
M3F & $\underline{3 \mathrm{~mm}}$ & $\underline{60^{\circ}}$ \\
\hline
\end{tabular}

Figura 16. Modelos montados e incluídos na resina

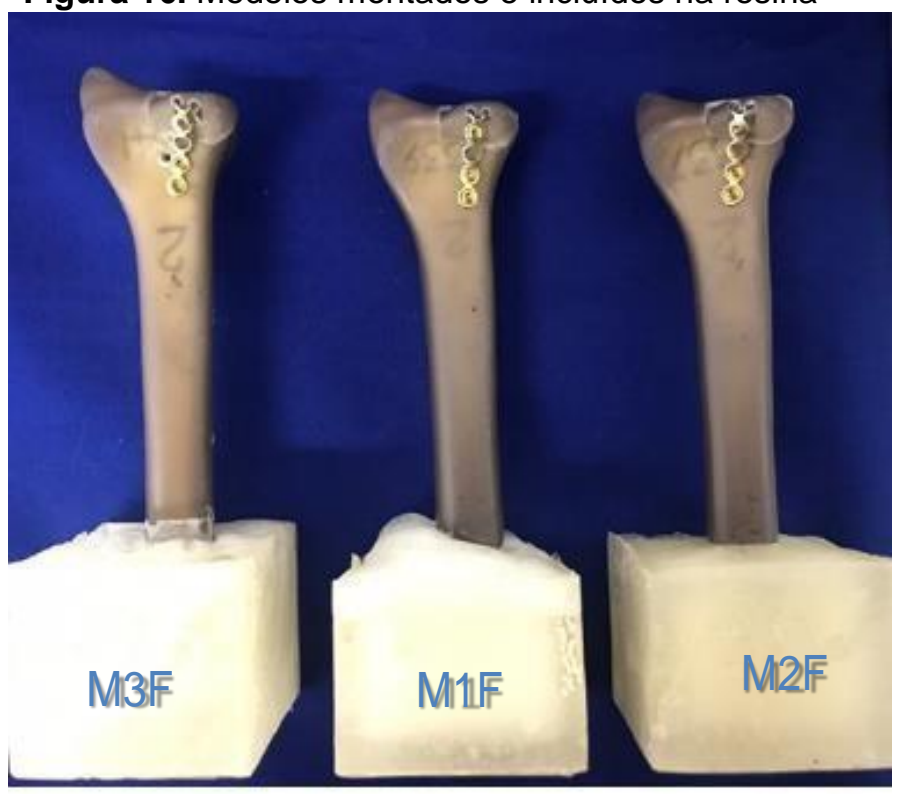

\section{Ensaio Mecânico Cisalhamento}

No laboratório de Bioengenharia da FMRP/USP foram realizados os Ensaios Mecânicos de Cisalhamento (figura 18) na máquina universal de ensaio EMIC® (modelo DL10000), a célula de carga utilizada foi de 100 kgf. A aplicação de carga foi realizada sobre o fragmento por meio de um acessório especialmente confeccionado (Figura 17). A velocidade de aplicação da carga foi de $5 \mathrm{~mm} / \mathrm{min}$. 
Figura 17. Acessórios do ensaio mecânico (A) célula de carga (B) anteparo para conectar acessório a célula de carga (C) acessório

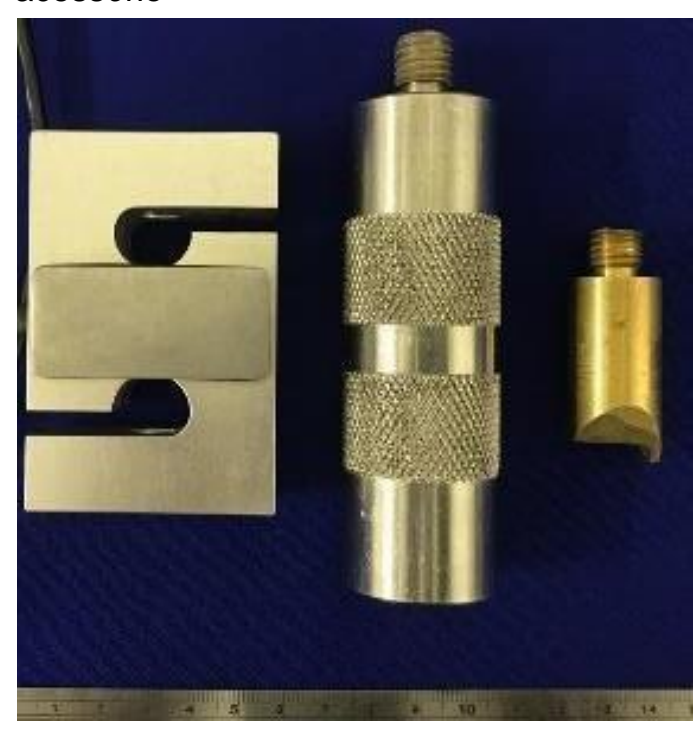

Figura 18. Ensaio mecânico cisalhamento axial

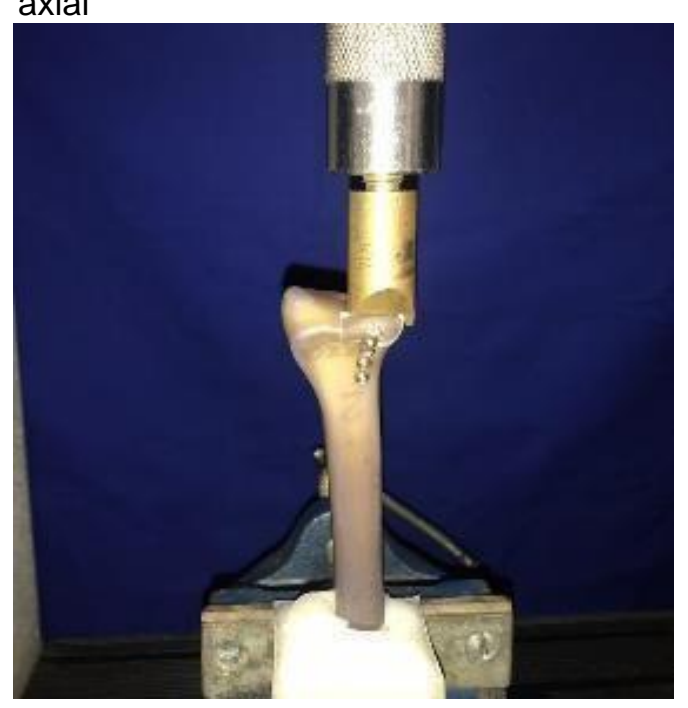

\subsection{Modelagem}

Foi utilizado um computador com processador Intel Xeon CPU E-3-1240 v3 3.40GHz, com memória RAM de 32 GB com sistema operacional de 64 bits Windows 7. Os modelos virtuais tridimensionais (3D) de cada sistema (placa, parafuso, osso) foram confeccionados no programa Rhinoceros ${ }^{\mathrm{TM}} 6$. A análise pelo Método dos Elementos Finitos foi realizada no programa SimLab ${ }^{\mathrm{TM}}$ utilizando o solver Optistruct. 
A simulação pelo Método dos Elementos Finitos necessita da confecção de modelos 3D. Para a confecção dos modelos foi utilizado o Programa Rhinoceros6 ${ }^{\mathrm{TM}}$, neste foram criados os modelos de cada parte do conjunto que foram simulados.

A partir dos modelos sintéticos foram obtidas as imagens tomográficas dos ossos, arquivo este no protocolo de comunicação que engloba arquivos tipo DICON (Digital Imaging and Communications in Medicine). O tomógrafo utilizado foi $\mathrm{O}$ Emotion (16 canais, Siemens $\left.{ }^{\mathrm{TM}}\right)$ com resolução de $(512 \times 512)$ e distância entre cortes de $1 \mathrm{~mm}$.

$\mathrm{O}$ arquivo (DICOM), foi importado para o programa InVesalius ${ }^{\mathrm{TM}}$ para a reconstrução tridimensional da estrutura anatômica. Baseado em um conjunto de imagens bidimensionais, obtidas através de equipamentos da tomografia computadorizada, o programa permite que sejam gerados modelos tridimensionais das regiões de interesse do sistema ali importado. Após reconstruir tridimensionalmente as imagens DICOM, o programa permite a geração de arquivos $3 \mathrm{D}$ no formato STereoLithography (STL), embora às vezes seja também referido como "Standard Triangle Language" (STL).

No programa InVesalius foram importadas todas as fatias para a obtenção do STL com as imagens que seriam usadas no processo de obtenção do sólido 3D, com isso temos a opção da geração multiplanar que nos mostra a visão de fatias sagitais, coronais, axiais e o volume. A partir do volume tem se a criação da superfície 3D onde se pode ter a opção de seleção das regiões de interesse por meio da opção de utilização de máscaras e ou filtros que fazem com que o arquivo seja ocultado ou retratado de acordo com o algoritmo em questão, gerando assim a superfície 3D. De acordo com a (figura 19) 
Figura 19. Imagem do rádio convertido do protocolo de comunicação que incorpora imagens DICOM para. STL com Software InVesalius ${ }^{\mathrm{TM}}$ Sólido 3D).

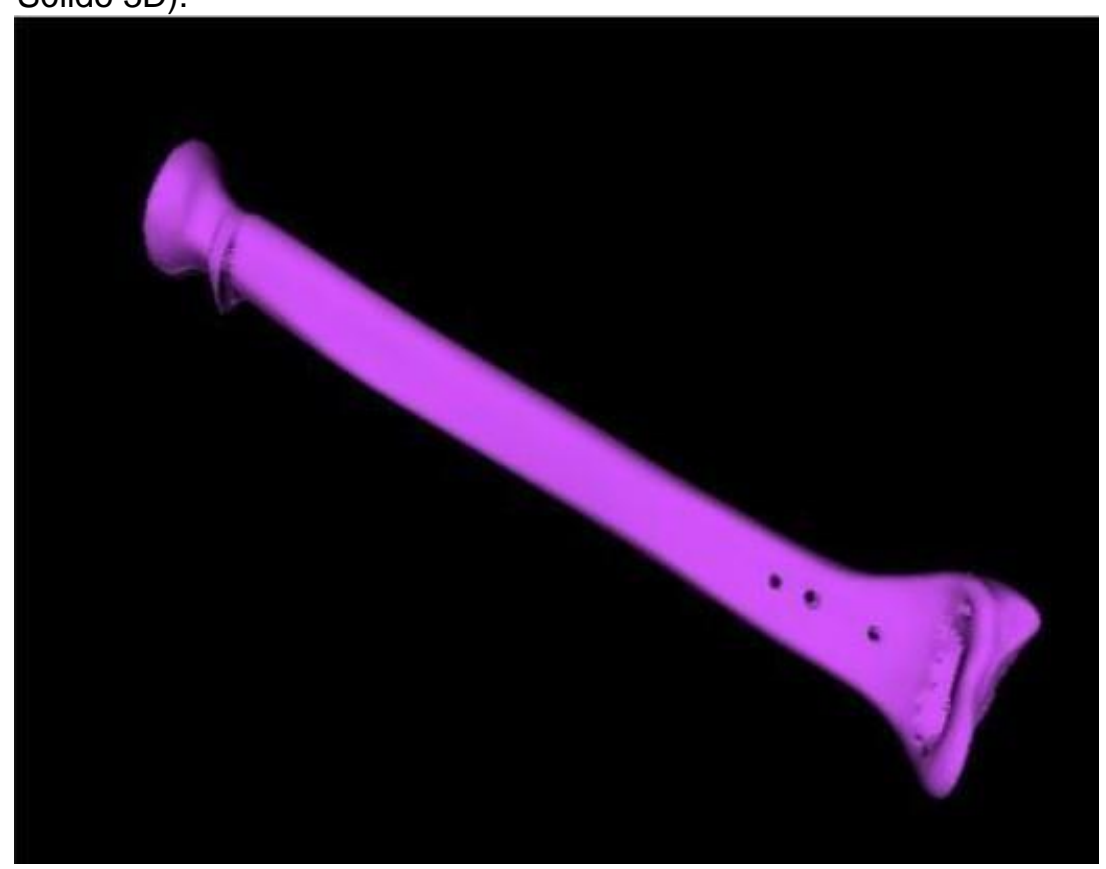

No Programa Rhinoceros $6^{\mathrm{TM}}$ foi feita a confecção do Biocad 3D, através da intersecção dos planos para se obter os contornos do sólido (osso) em questão como mostra a (figura $20 \mathrm{~A}$ ), traçadas todas as linhas das partes a serem desenvolvidas, estas foram cortadas e reconstruídas alterando os seus números de pontos, posteriormente foram cortadas e unidas para ter o início da fase de criação das superfícies feitas a partir de três ou quatro linhas (figura 20 B).

Figura 20. Planos e linhas

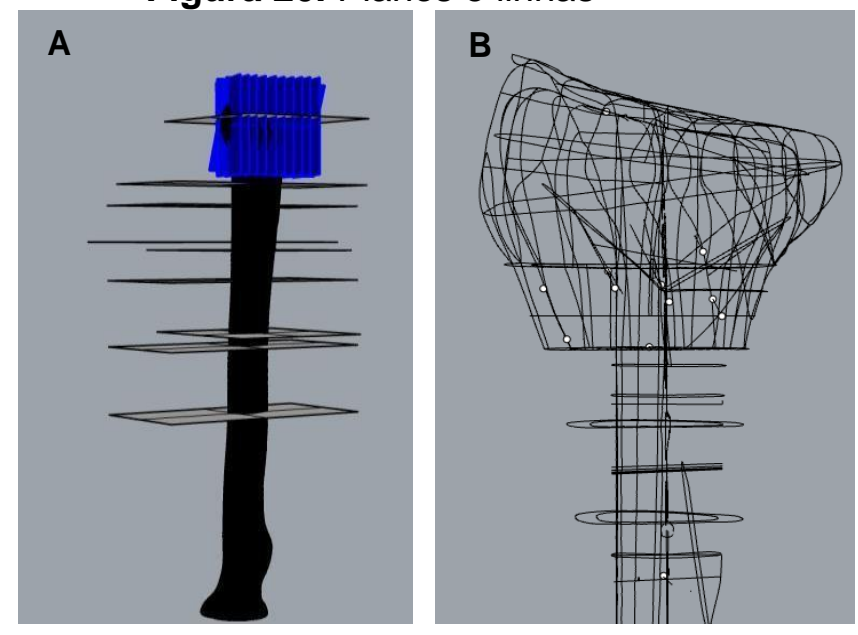

A modelagem de placa e parafusos foi feita através das medidas utilizando um paquímetro (marca Mitutoyo) e foram medidos o comprimento do parafuso, 
passo de rosca, diâmetro externo e interno (figura 21 (A). No programa Rhinoceros 6 foram confeccionados os objetos para as placas criou-se um sólido com as seguintes dimensões: $25 \mathrm{~mm}$ de comprimento por $5 \mathrm{~mm}$ de largura, $2 \mathrm{~mm}$ de espessura com 5 orifícios e seus respectivos ganchos de 3 e $6 \mathrm{~mm}$ (figura 21 (B)); no caso dos parafusos, os sólidos foram desenvolvidos seguindo pelo desenho do perfil da rosca e suas curvas sendo este sólido com as dimensões $18 \mathrm{~mm}$ de comprimento de 2,3 mm de diâmetro.

Figura 21. Medição com paquímetro de placa volar com gancho e parafuso cortical.

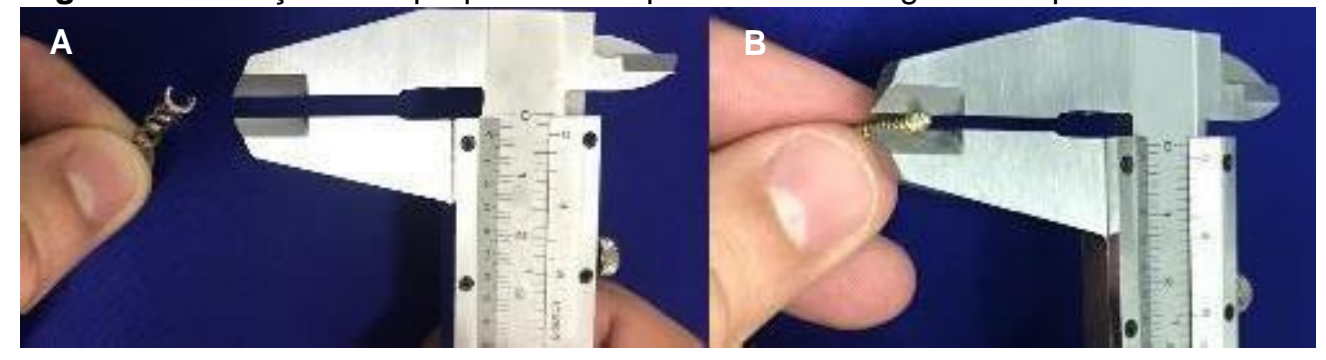

Finalizadas as modelagens do rádio, placas e parafusos estes foram exportados ao programa Rhinoceros ${ }^{\mathrm{TM}} 6$ para montagem dos modelos com 0 sistema de fixação com placa volar modificada com gancho de diferentes ângulos e comprimento. A sequência de montagem e preparação dos modelos foi: alinhamento do rádio, placa e parafusos, de acordo com o modelo proposto (figura 22); medição e corte do fragmento do canto volar ulnar (figura 23); e posicionamento geral de todo sistema para haver uma comunicação entre as diferentes partes do Biocad®.

Com isso, foram desenvolvidas as montagens de seis sólidos com suas variáveis. As figuras 22 e 23 apresentam a montagem do sistema em 3D. 
Figura 22. $C A D$ feito de cada parte individualmente, osso sem fragmento $(A)$, osso com fragmento $(B)$, placa $(C)$, placa com parafusos (D) e conjunto todo montado (E).
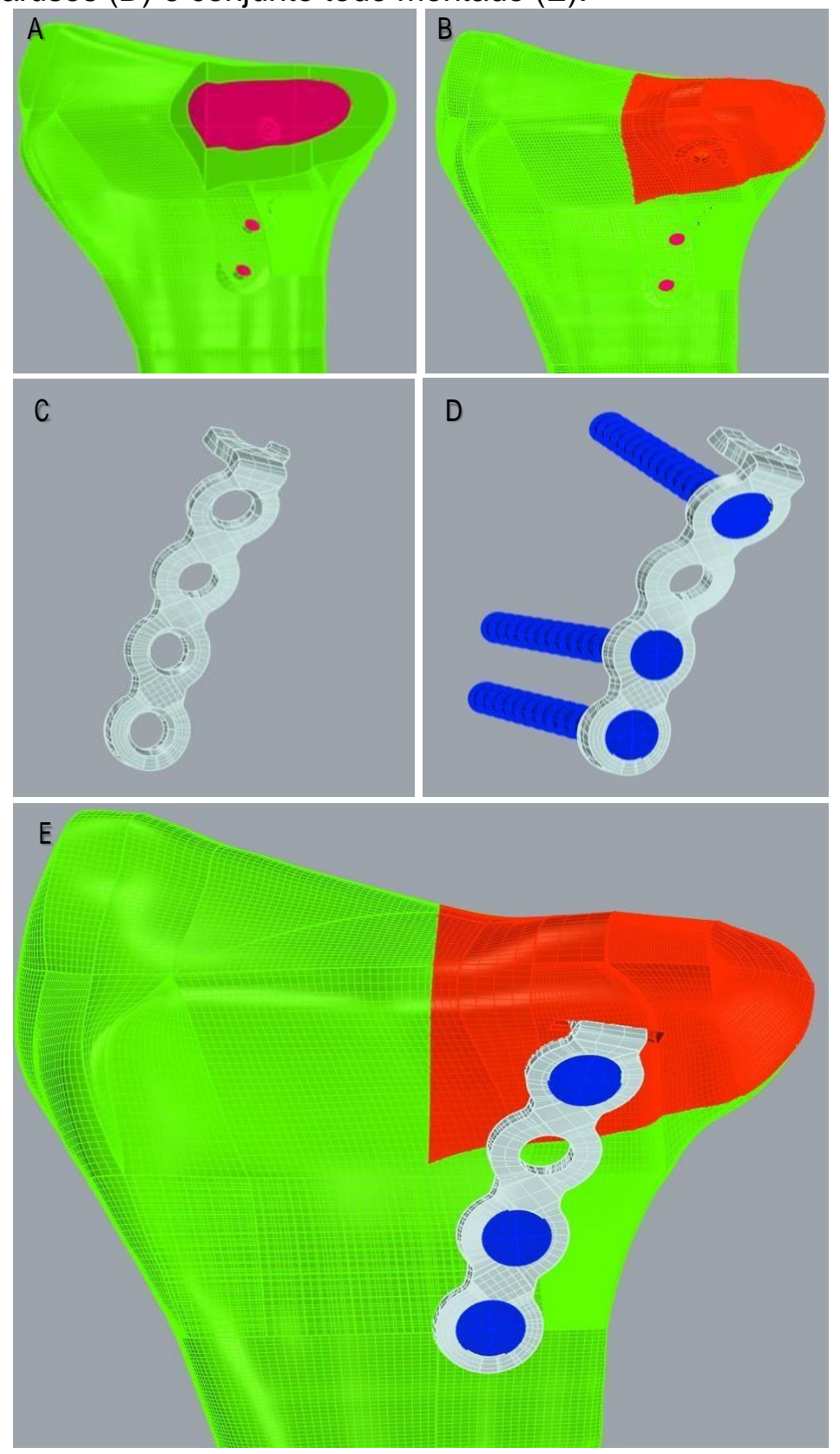

Sólidos desenvolvidos pelo programa de modelagem com suas respectivas variações de gancho. Após a modelagem em 3D do sistema foi gerado um arquivo STEP (Standard for the Exchange of Product model data) utilizando o programa Rhinoceros $6^{\mathrm{TM}}$. 
Figura 23. Medidas do fragmento e as PVMG com gancho de diferentes angulações e comprimento

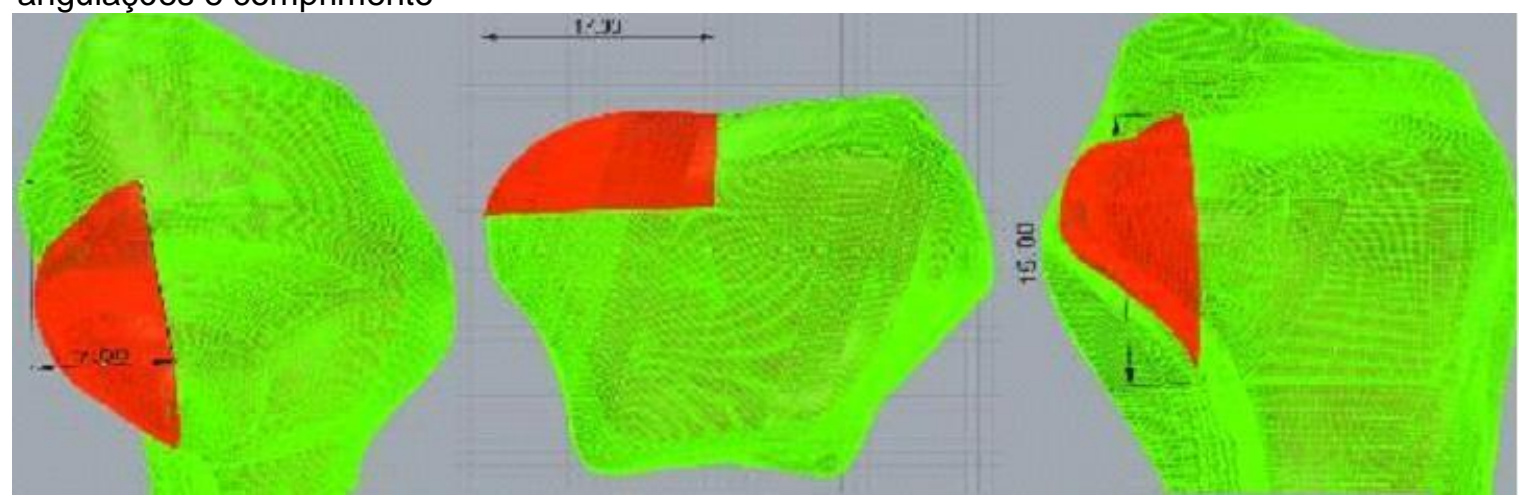

\subsection{Modelos utilizados nas simulações}

Os seis modelos digitais propostos para realização das simulações foram: Modelo 1 (M1D): PVMG com gancho de 3mm e ângulo de $90^{\circ}$ em relação à placa fixada por três parafusos, um no fragmento e dois no osso; Modelo 2 (M2D): PVMG com gancho de $3 \mathrm{~mm}$ e ângulo de $120^{\circ}$ em relação à placa fixada por três parafusos, um no fragmento e dois no osso; Modelo 3 (M3D): PVMG com gancho de $3 \mathrm{~mm}$ e ângulo $60^{\circ}$ em relação à placa fixada por três parafusos. um no fragmento e dois no osso: Modelo 4 (M4D): PVMG com gancho de $6 \mathrm{~mm}$ e ângulo de $90^{\circ}$ em relação à placa fixada por três parafusos, um no fragmento e dois no osso; Modelo 5 (M5D): PVMG com gancho de $6 \mathrm{~mm} 120^{\circ}$ em relação à placa fixada por três parafusos, um no fragmento e dois no osso; Modelo 6 (M6D): PVMG com gancho de $6 \mathrm{~mm}$ e ângulo $60^{\circ} \mathrm{em}$ relação à placa fixada por três parafusos, um no fragmento e dois no osso. Representados na tabela 3. As validações dos modelos digitais foram realizadas utilizando os resultados dos ensaios mecânicos dos modelos físicos (M1F, M2F e M3F) foram propostas as modificações de acordo com o modelo figura 24.

Figura 24. Medidas do fragmento e as PVMG com gancho de diferentes angulações e comprimento

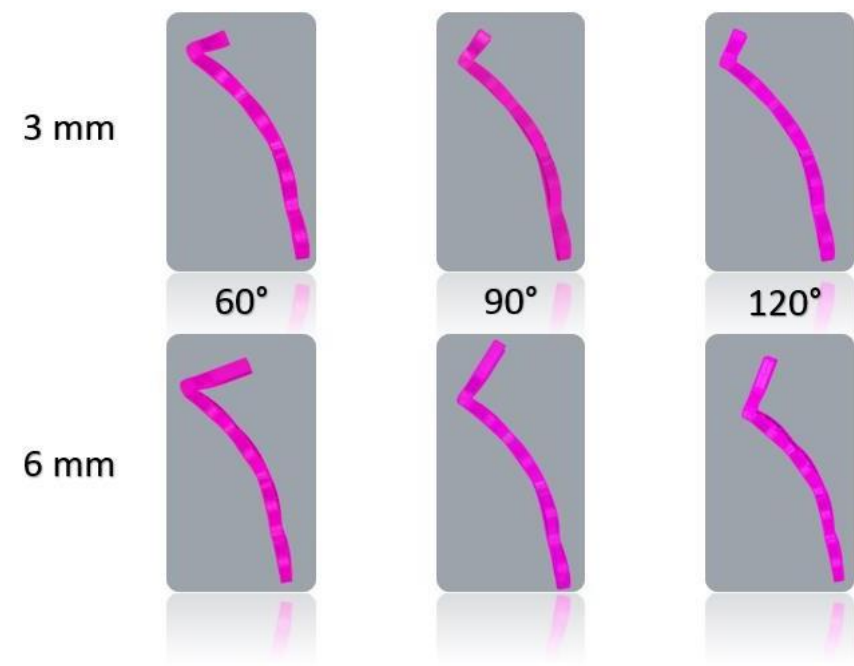


Tabela 3. Modelos Digitais

\begin{tabular}{ccc}
\hline Grupos & Gancho $(\mathbf{m m})$ & Ängulo $\left(^{\circ}\right)$ \\
\hline M1D & 3 & $90^{\circ}$ \\
\hline M2D & 3 & $120^{\circ}$ \\
\hline M3D & 3 & $60^{\circ}$ \\
\hline M4D & 6 & $90^{\circ}$ \\
\hline M5D & 6 & $120^{\circ}$ \\
\hline M6D & 6 & $60^{\circ}$
\end{tabular}

\subsection{Simulação pelo MEF}

Para as simulações utilizando o MEF os arquivos STEP foram importados ao programa Simlab ${ }^{\mathrm{TM}}$, com identificação de cada parte dos modelos digitais. Posteriormente ao controle de malhas de cada parte (figura $25(\mathrm{~A})$ ), deve-se tomar 0 cuidado para manter sempre o tamanho do elemento, para não haver problemas de contatos entre as diferentes partes figura (figura 24 (B)) (rádio, fragmento, placa e parafusos) nas simulações. O elemento adotado para formação das malhas foi a tetraédrico. A quantidade de nós também foi definida de acordo com a (tabela 4).

Tabela 4 - Propriedades do Modelo Número de Elementos e Nós de cada modelo

\begin{tabular}{ccccccc}
\hline & \multicolumn{3}{c}{ Nós } & \multicolumn{3}{c}{ Elementos } \\
\hline Grupos & Internos & superfície & total & Bar 3 & Tri6 & Tet 10 \\
\hline M1D & 381519 & 274168 & 655687 & 22809 & 137092 & 385707 \\
\hline M2D & 382845 & 275108 & 657953 & 22841 & 137562 & 386978 \\
\hline M3D & 380821 & 271384 & 652205 & 22693 & 135700 & 384139 \\
\hline M4D & 385084 & 276474 & 661558 & 23030 & 138246 & 389242 \\
\hline M5D & 385747 & 276350 & 662097 & 23068 & 138184 & 389640 \\
\hline M6D & 386855 & 276184 & 663039 & 22953 & 138102 & 390418 \\
\hline
\end{tabular}

Figura 25. contatos e malha tetraédrica $A$ e $B$

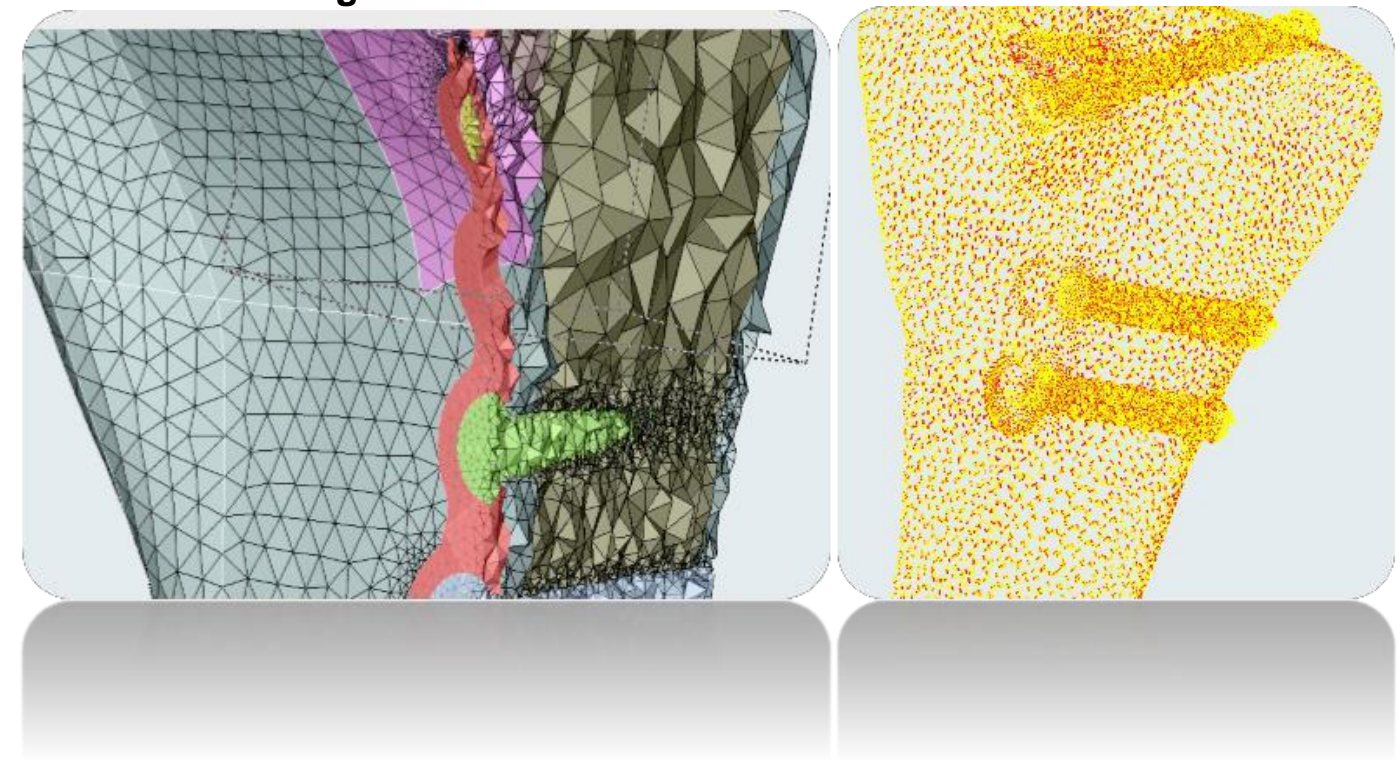

\subsubsection{Caracterização dos materiais}


Para realização das simulações foi necessário conhecer e definir as propriedades dos materiais de cada uma das partes dos modelos digitais, sendo eles: osso cortical, osso trabecular e liga de titânio. As propriedades dos materiais, utilizados para as simulações são: Módulo de Elasticidade e Coeficiente de Poisson (Quadro 1).

Quadro 1 - Propriedades dos materiais.

\begin{tabular}{|c|c|c|}
\hline Material & Módulo de elasticidade e (MPa) & Coeficiente de Poisson (v) \\
\hline Osso Cortical & 13700 & 0,30 \\
\hline Osso Trabecular & 1370 & 0,30 \\
\hline Liga de Titânio & 114000 & 0,33 \\
\hline
\end{tabular}

Com a malha volumétrica de cada parte do modelo e com as propriedades foram atribuídas as seguintes características: identificação, entidade do sólido, comportamento isotrópico, tipo do material e o número da propriedade.

\subsubsection{Condições de contorno}

Os resultados dos ensaios mecânicos de cisalhamento, principalmente das forças e deslocamentos dos três modelos físicos foram utilizados para comparar com os resultados das simulações, e com isso validar os modelos digitais propostos. Para definir as condições de contorno (figura 26), foram selecionadas as regiões de aplicação de cargas na direção do eixo Z de $10 \mathrm{~N}$ inicial, com acréscimo de $10 \mathrm{~N}$ por vez até totalizar $60 \mathrm{~N}$. E nas demais direções (eixos $\mathrm{X}$ e $\mathrm{Y}$ ) não foram aplicadas nenhum carregamento. Posteriormente, foram delimitados as regiões de restrição de movimentos (fixados), marcadas em todas as direções dos eixos $X Y Z$, de deslocamento e rotação. Estas restrições são para garantir que o sistema tenha um perfeito alinhamento sem haver deslocamento e/ou rotação. 
Figura 26. Condições de Contorno Vista frontal (A) (região de aplicação de cargas), Dorsal (B) (região de aplicação de cargas) e Inferior (C) indicados pela seta (região de restrição de movimentos, fixação).
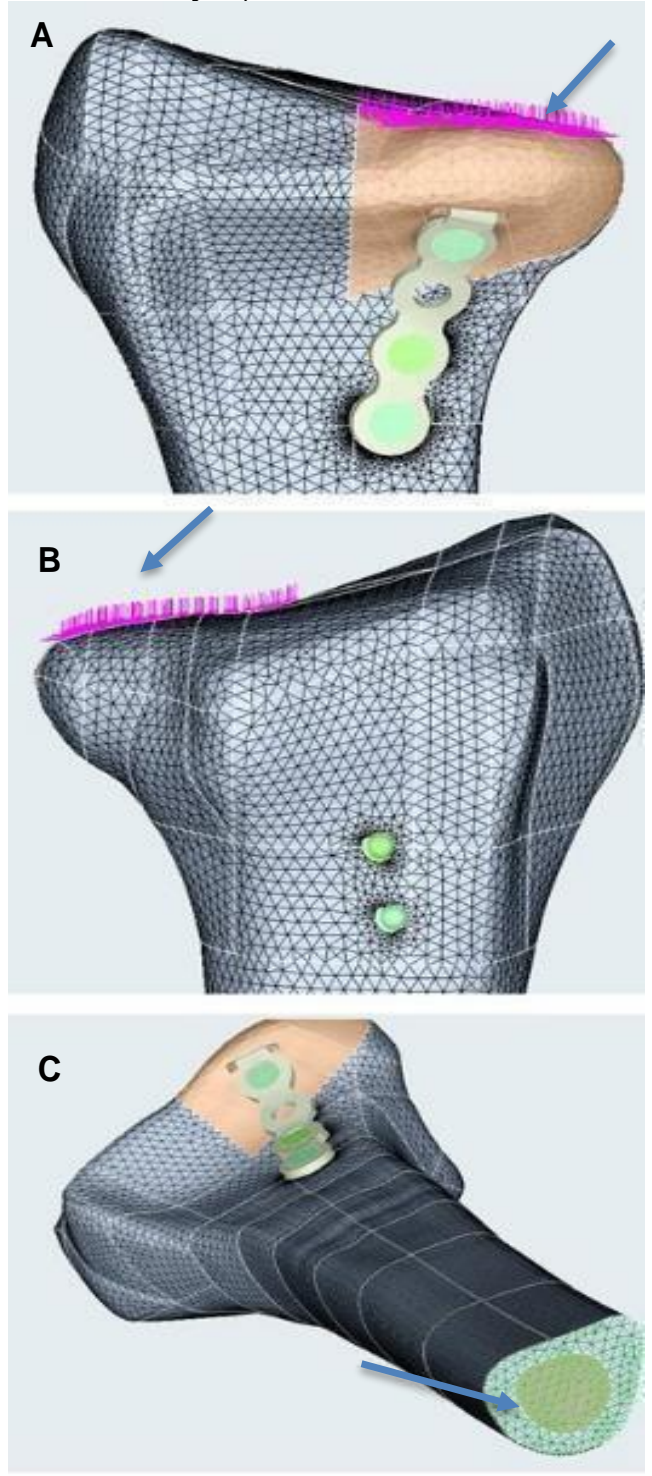

\subsection{Simulação}

Após a caracterização dos materiais e determinação das condições de contorno foi iniciado o processamento das simulações no programa SimLab utilizando o solver Optistruct.

Depois da realização da simulação foram avaliados, deslocamento, forças máximas, mínimas e Von Mises, os deslocamentos resultantes de cada força aplicada ao obtido no ensaio mecânico. 
5. Resultados 



\section{RESULTADOS}

Os deslocamentos correspondentes a cada força para $O$ ensaio de compressão na Máquina Universal de Ensaios (MUE) M1F, M2F e M2F, e no MEF dos grupos M1D M2D e M3D são representados na tabela a seguir (tabela 5).

Tabela 5. Deslocamentos Dos Ensaios Mecânicos e do Método dos Elementos Finitos

\begin{tabular}{|c|c|c|c|c|c|c|}
\hline \multicolumn{7}{|c|}{ Deslocamentos (mm) } \\
\hline & \multicolumn{2}{|c|}{ M1D } & \multicolumn{2}{|c|}{ M2D } & \multicolumn{2}{|c|}{ M3D } \\
\hline Força (N) & M UE & M E F & M UE & M E F & MUE & M E F \\
\hline 10 & 0,191 & 0,021 & 0,122 & 0,020 & 0,119 & 0,021 \\
\hline 20 & 0,208 & 0,045 & 0,146 & 0,046 & 0,141 & 0,043 \\
\hline 30 & 0,227 & 0,060 & 0,164 & 0,063 & 0,166 & 0,063 \\
\hline 40 & 0,244 & 0,084 & 0,183 & 0,090 & 0,192 & 0,087 \\
\hline 50 & 0,264 & 0,113 & 0,199 & 0,118 & 0,220 & 0,109 \\
\hline
\end{tabular}

Os gráficos Força $(\mathrm{N}) \times$ Deslocamento $(\mathrm{mm})$ foram traçados para cada grupo estudado (Figuras 27 à 29)

Figura 27. Força $(\mathrm{N}) \times$ Deslocamento $(\mathrm{mm})$ para o ensaio Mecânico (MUE) e pelo Método dos Elementos Finitos (MEF) para o grupo M1D

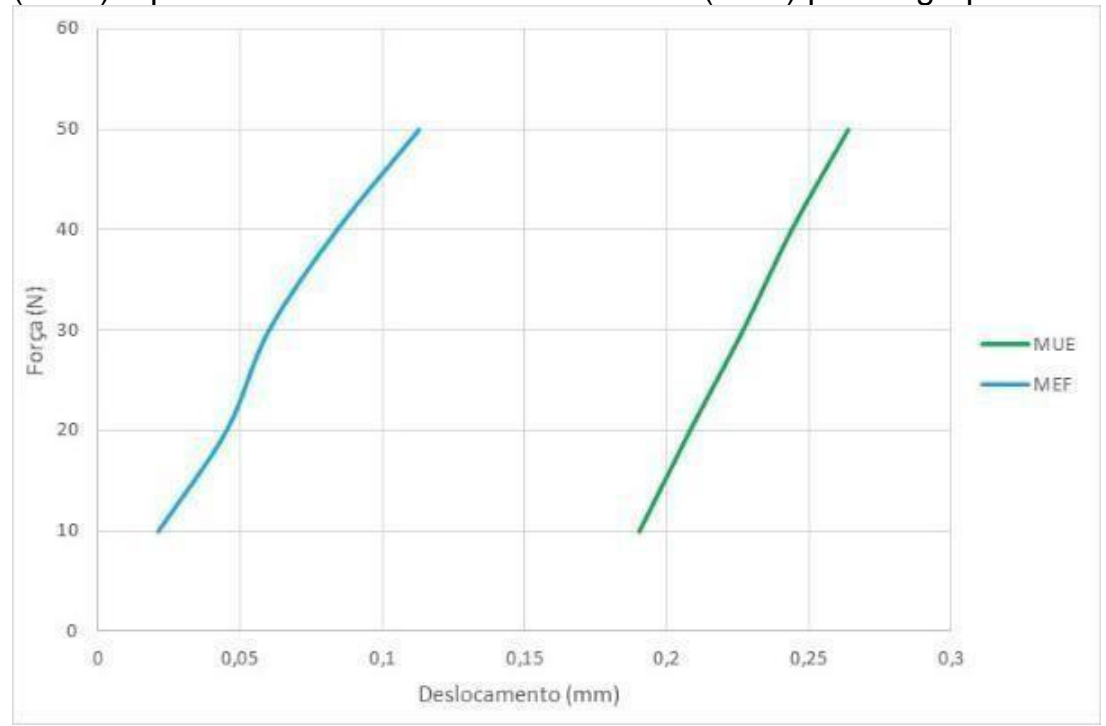


Figura 28. Força $(\mathrm{N}) \times$ Deslocamento $(\mathrm{mm})$ para $\circ$ ensaio Mecânico (MUE) e pelo Método dos Elementos Finitos (MEF) para o grupo M2D

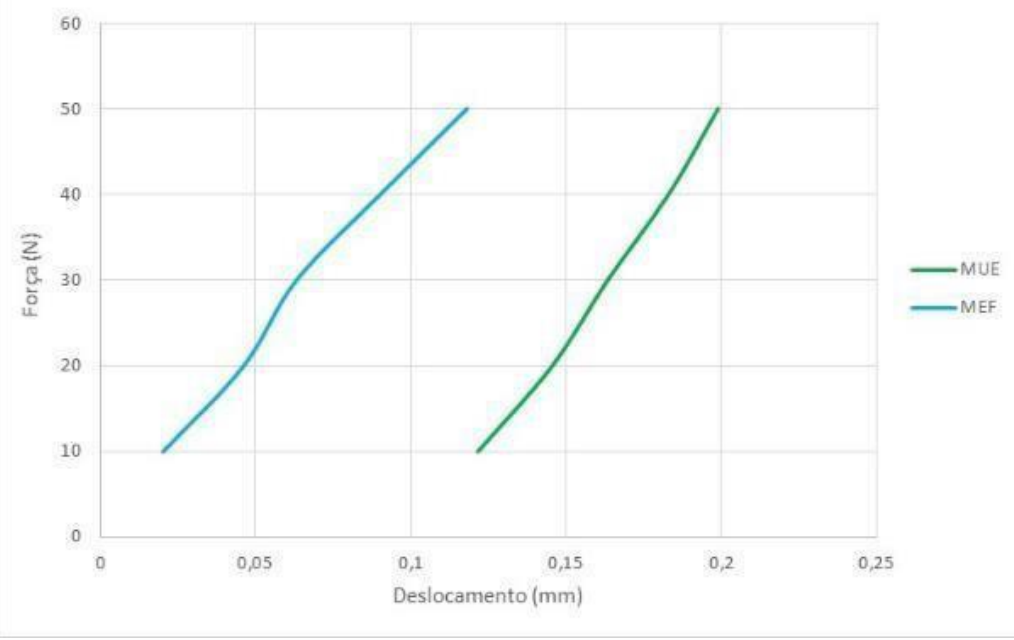

Figura 29. Força $(\mathrm{N}) \times$ Deslocamento $(\mathrm{mm})$ para o ensaio Mecânico (MUE) e pelo Método dos Elementos Finitos (MEF) para o grupo M3D

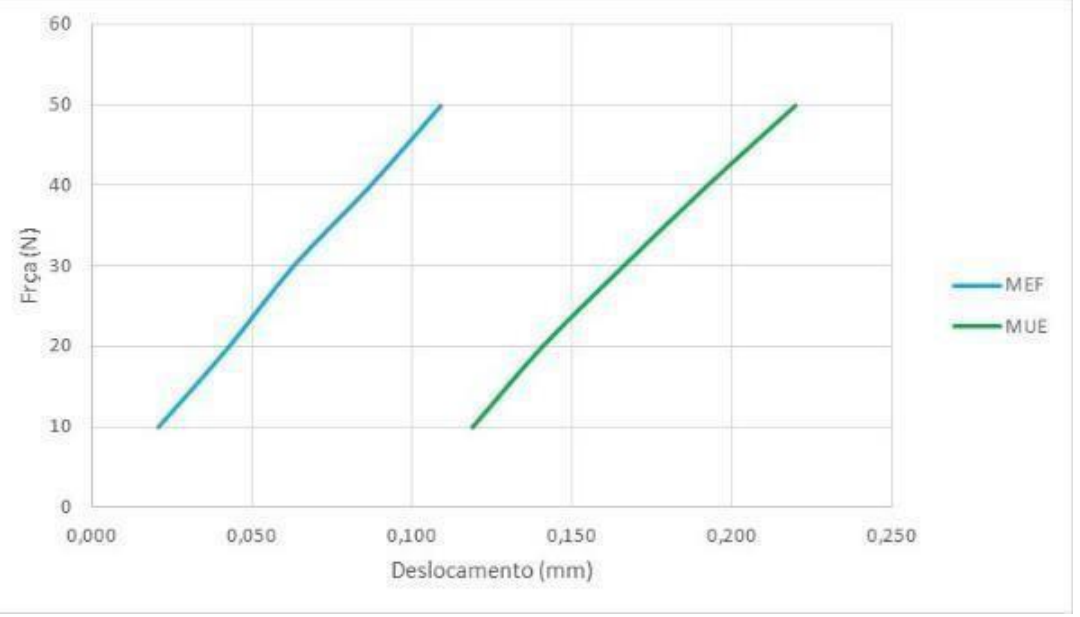

A partir dos gráficos foi feita a curva de tendência, utilizando a inclinação da reta se obteve a rigidez relativa de cada método de ensaio (tabela 6). Foram encontradas as divergências entre os métodos de 18,99\% para M1D e M1F; 19,66 para M2D e M2F; 14,98 para M3D e M3F.

Tabela 6. Rigidez Relativa do conjunto

\begin{tabular}{cccc}
\hline & Riqidez Relativa (N/mm) & & $\begin{array}{c}\text { Diferença entre os } \\
\text { Métodos (\%) }\end{array}$ \\
\hline M1D & M U E & M F & 18,99 \\
\hline M2D & 547,76 & 443,76 & 19,66 \\
\hline M3D & 518,02 & 416,2 & 14,98 \\
\hline
\end{tabular}


Validados os modelos, podemos observar os deslocamentos e a distribuição de tensão em cada grupo em questão.

A figura 30 (A e B) representa o deslocamento gerado por $\mathrm{F} 60 \mathrm{~N}$ e a deformação do modelo M1D.

Figura 30. Osso vista frontal (A), Osso vista sagital (B)

A
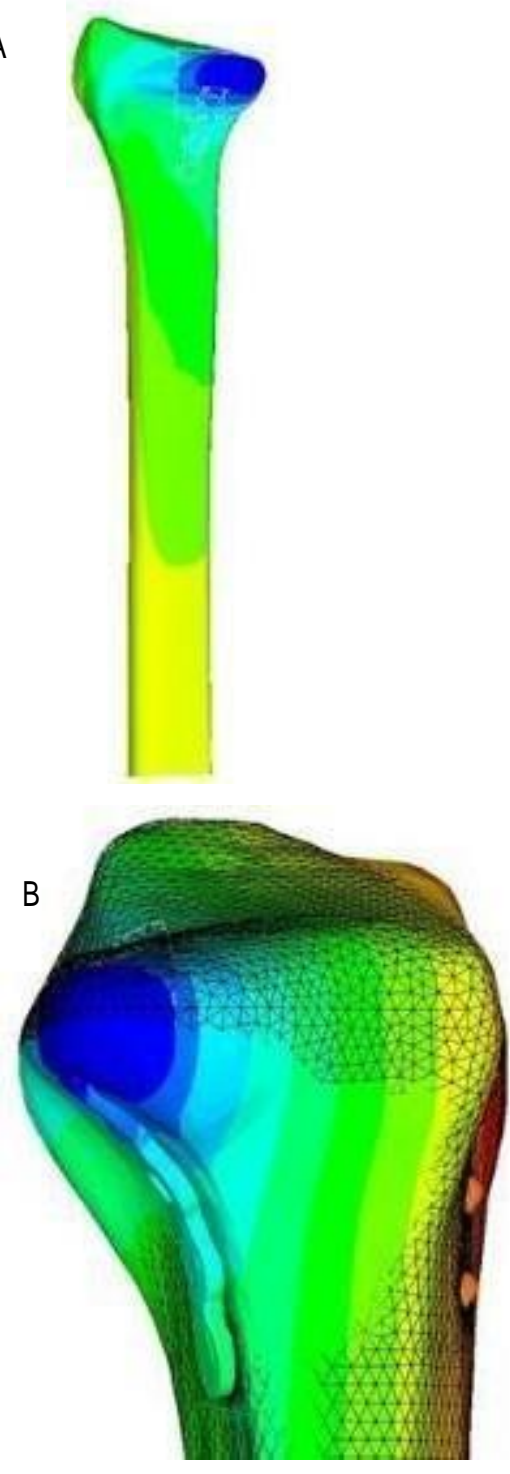

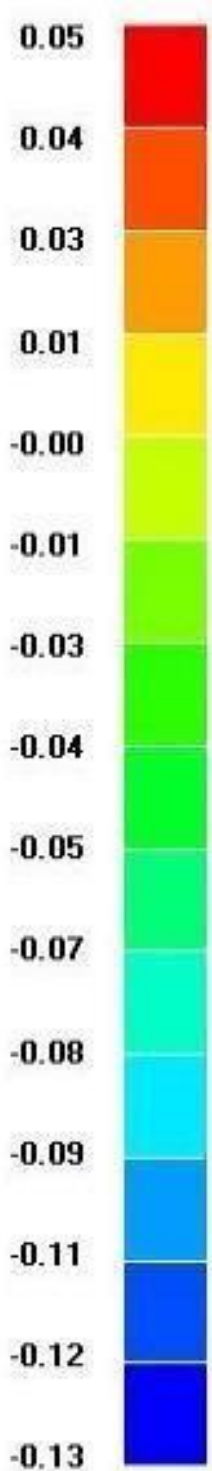

$-0.13$

Como podemos observar, o deslocamento foi de $0,132 \mathrm{~mm}$ com a presença do gancho de $3 \mathrm{~mm}$ com a angulação de $90^{\circ}$. 
A figura $31(\mathrm{~A})$ e $(\mathrm{B})$ representam o deslocamento $(\mathrm{mm})$ gerado por $\mathrm{F}=60 \mathrm{~N}$ e a deformação do modelo M3D.

Figura 31. Osso vista frontal (A), Osso vista sagital (B)

A
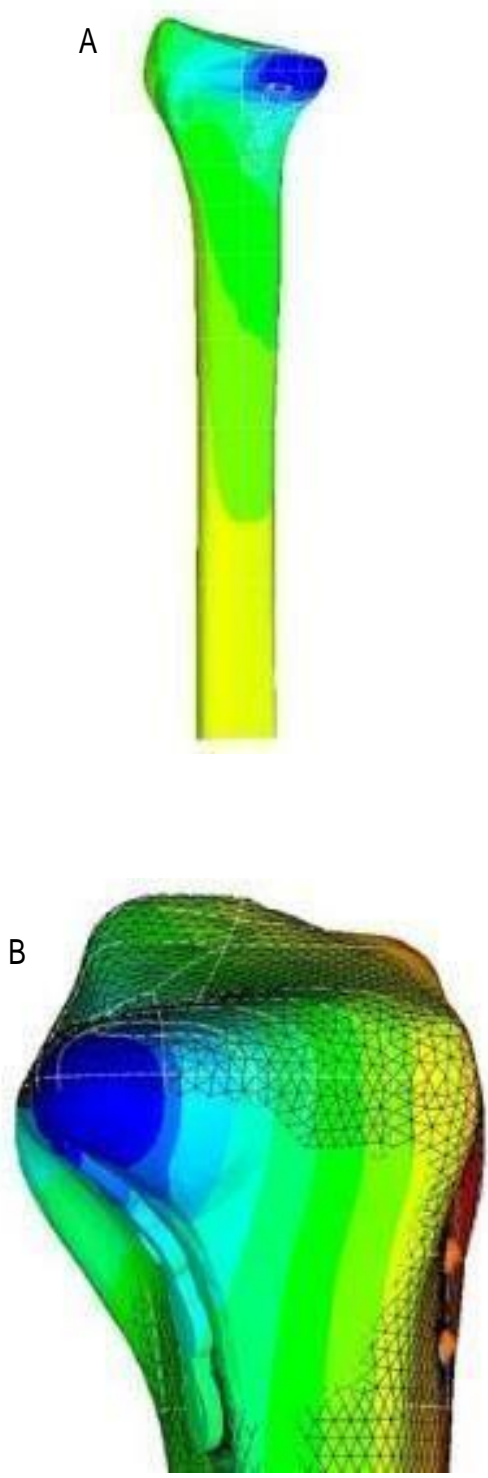

0.05

0.04

0.03

0.01

$-0.00$

$-0.02$

$-0.03$

$-0.04$

$-0.06$

$-0.07$

$-0.08$

$-0.10$

$-0.11$

$-0.13$

$-0.14$

Como podemos observar o deslocamento foi de $0,139 \mathrm{~mm}$ com a presença do gancho de $3 \mathrm{~mm}$ com a angulação de $120^{\circ}$. 
A figura $32(A)$ e $(B)$ representam o deslocamento gerado por $F=60 \mathrm{~N}$ e a deformação do modelo M2D

Figura 32. Osso vista frontal (A), Osso vista sagital (B)

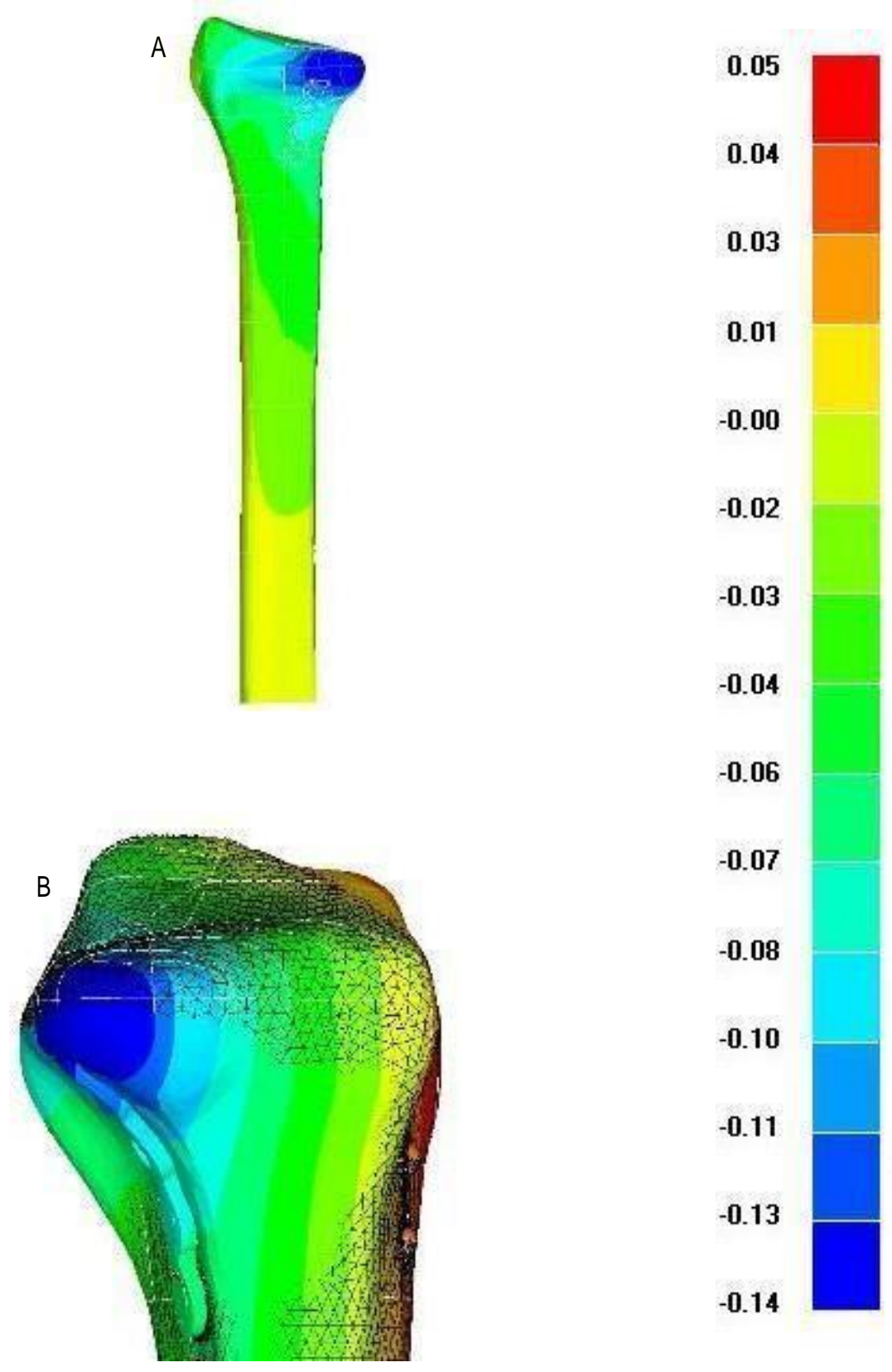

Como podemos observar, o deslocamento foi de $0,131 \mathrm{~mm}$ com a presença do gancho de $3 \mathrm{~mm}$ com a angulação de $60^{\circ}$. 
A figura $33(A)$ e $(B)$ representam o deslocamento gerado por $F=60 \mathrm{~N}$ e a deformação do modelo M4D.

Figura 33. Osso vista frontal (A), Osso vista sagital (B)

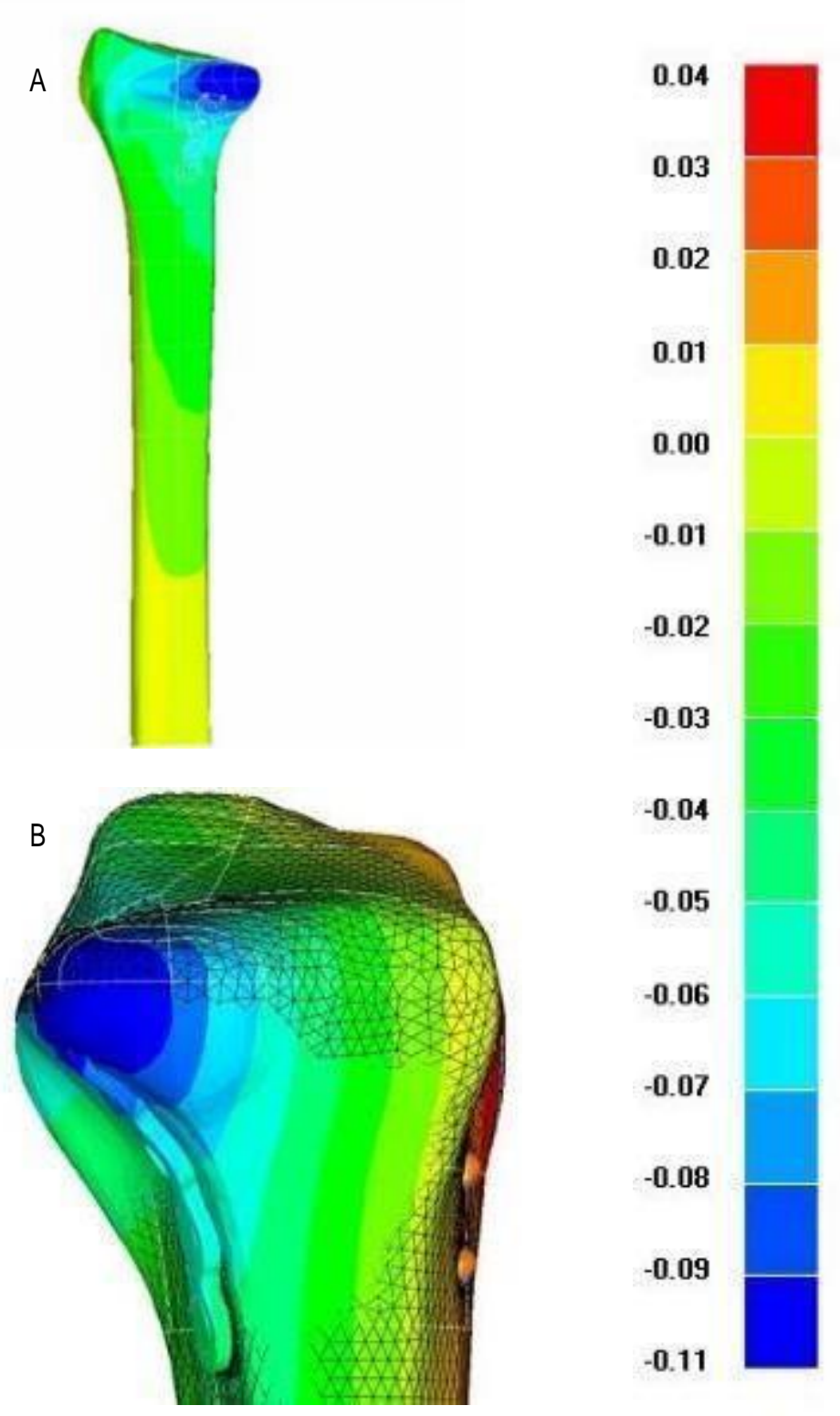

Como podemos observar, o deslocamento foi de $0,105 \mathrm{~mm}$ com a presença do gancho de $6 \mathrm{~mm}$ com a angulação de $90^{\circ}$. 
A figura $344(A)$ e $(B)$ representam o deslocamento gerado por $F=60 \mathrm{~N}$ e a deformação do modelo M6D.

Figura 34. Osso vista frontal (A), Osso vista sagital (B)

A

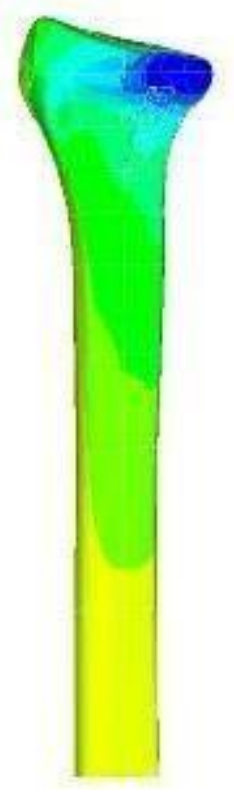

0.05

0.04

0.03

0.01

$-0.00$

$-0.01$

$-0.03$

$-0.04$

$-0.05$

$-0.07$

$-0.08$

$-0.09$

$-0.11$

$-0.12$

$-0.13$

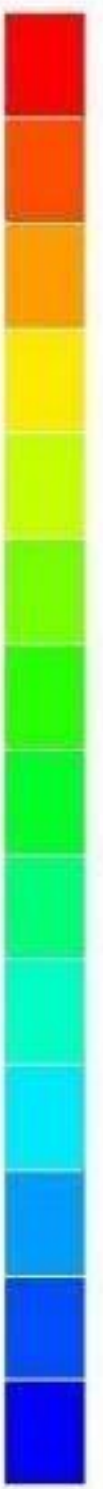

Como podemos observar, o deslocamento foi de $0,131 \mathrm{~mm}$ com a presença do gancho de $6 \mathrm{~mm}$ com a angulação de $120^{\circ}$. 
A figura $35(\mathrm{~A})$ e $(\mathrm{B})$ representam o deslocamento gerado por $\mathrm{F}=60 \mathrm{~N}$ e a deformação do modelo M5D.

Figura 35. Osso vista frontal (A), Osso vista sagital (B)

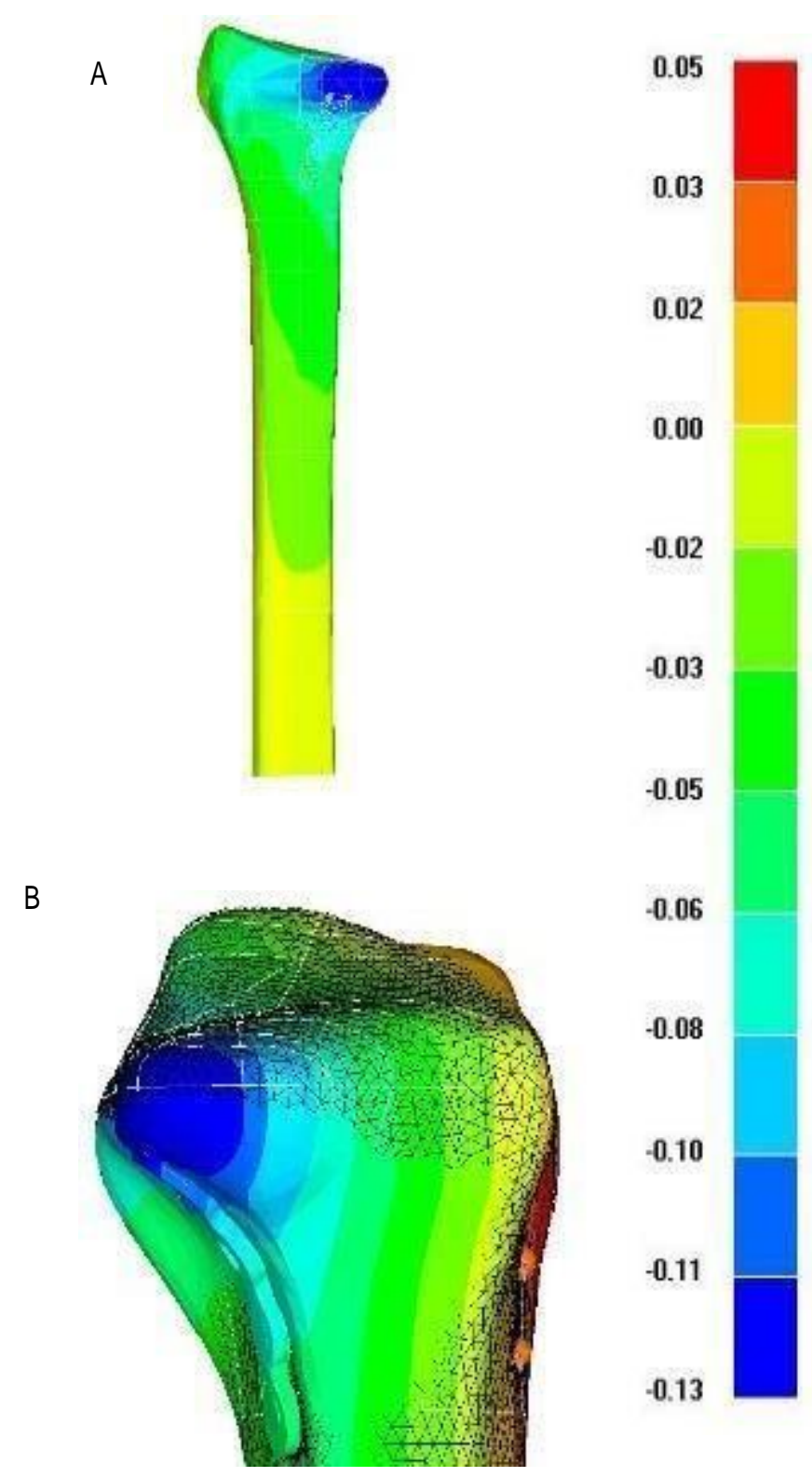

Como podemos observar, o deslocamento foi de $0,131 \mathrm{~mm}$ com a presença do gancho de $6 \mathrm{~mm}$ com a angulação de $60^{\circ}$. 
Como podemos observar, o deslocamento do grupo M4D foi o que demonstrou menor deslocamento em relação a todos os outros grupos, salientando ainda que no grupo de $3 \mathrm{~mm}$, o grupo M1D foi o de menor deslocamento quando comparado a M2D e M3D.

Podemos observar no quadro 2, os deslocamentos $(\mathrm{mm})$ gerados a partir da aplicação de força variando de $10 \mathrm{~N}$ a $60 \mathrm{~N}$ no MEF.

Quadro 2. Deslocamentos dos modelos pelo Método Dos Elementos Finitos

\begin{tabular}{|c|c|c|c|c|c|c|}
\hline Força N & M1D & M2D & M3D & M4D & M5D & M6D \\
\hline 10 & 0,021 & 0,020 & 0,021 & 0,017 & 0,021 & 0,011 \\
\hline 20 & 0,045 & 0,046 & 0,043 & 0,035 & 0,043 & 0,043 \\
\hline 30 & 0,060 & 0,063 & 0,063 & 0,052 & 0,065 & 0,065 \\
\hline 40 & 0,084 & 0,090 & 0,087 & 0,070 & 0,087 & 0,087 \\
\hline 50 & 0,113 & 0,118 & 0,109 & 0,087 & 0,109 & 0,109 \\
\hline 60 & 0,132 & 0,139 & 0,131 & 0,105 & 0,131 & 0,131 \\
\hline
\end{tabular}

Figura 36. Gráfico força x Deslocamento pelo Método dos Elementos Finitos

60

\section{Força XDeslocamento}

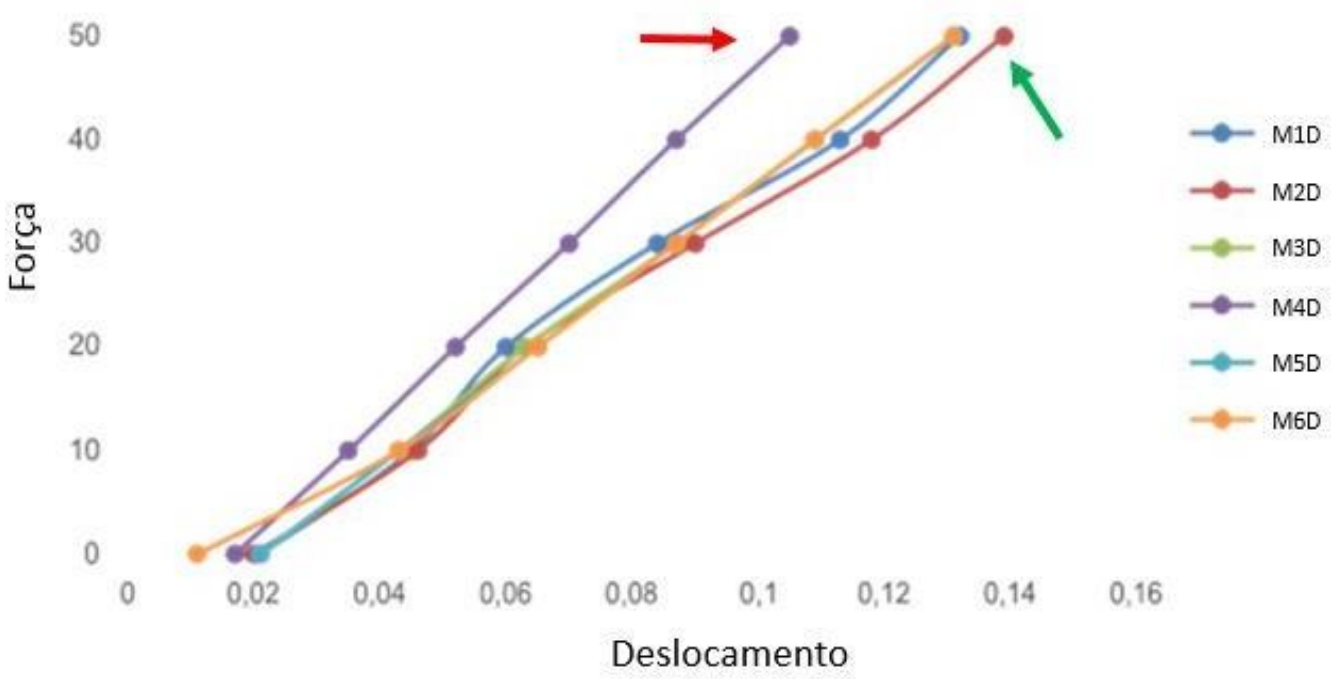


A figura 37 ilustra a vista frontal apresentando a Tensão Máxima Principal, observadas nos modelos para o ensaio de compressão para uma $\mathrm{F}=60 \mathrm{~N}$.

Figura 37. Comparações da Tensão Máxima Principal vista dorsal demonstrando pelas setas os pontos de tensão: seta vermelha $\uparrow$ ) na região do primeiro parafuso, seta preta $\uparrow$ ) região do
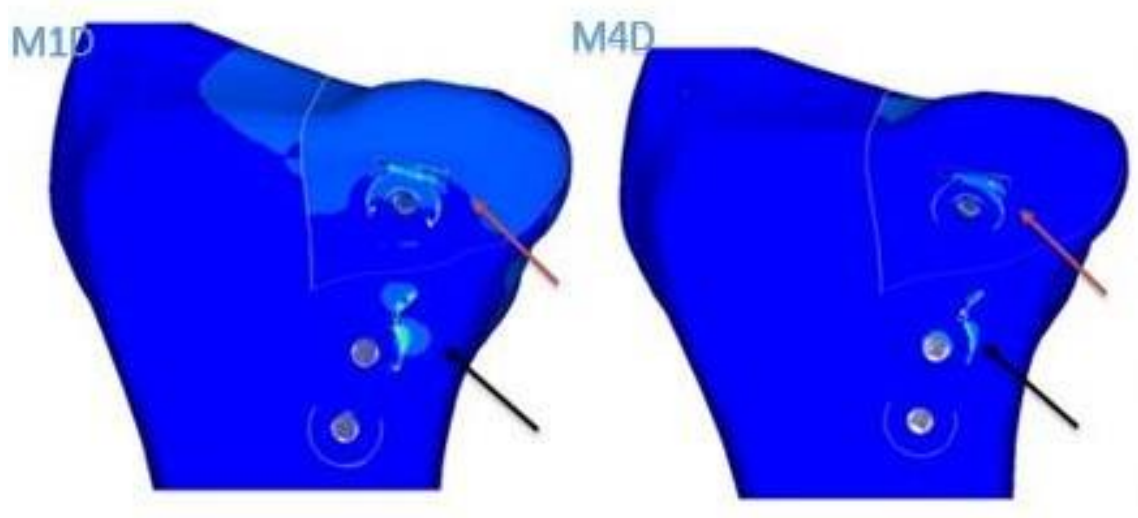

30.00

27.71

25.43

23.14

20.86

M2D

M5D
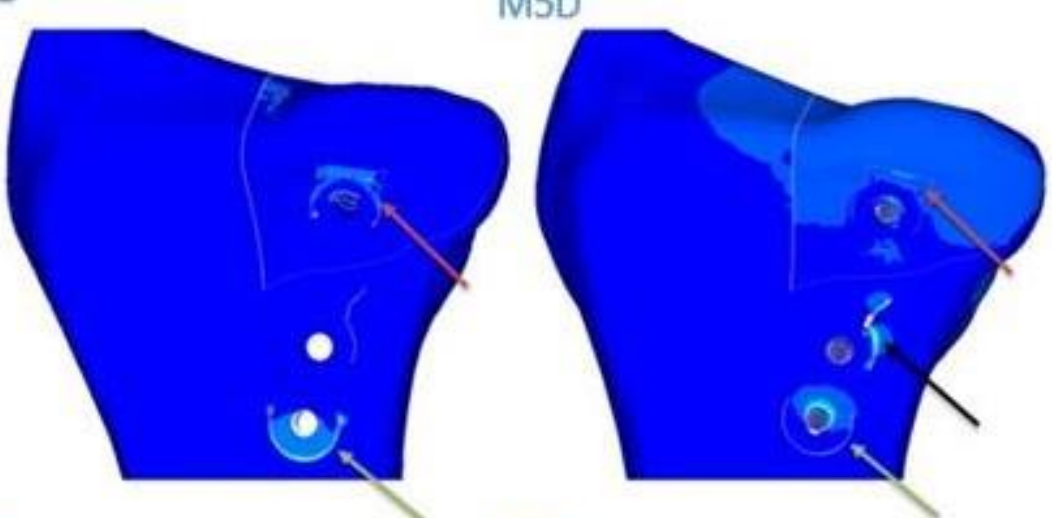

18.57

16.29

14.00

11.71

9.43

M3D

M6D
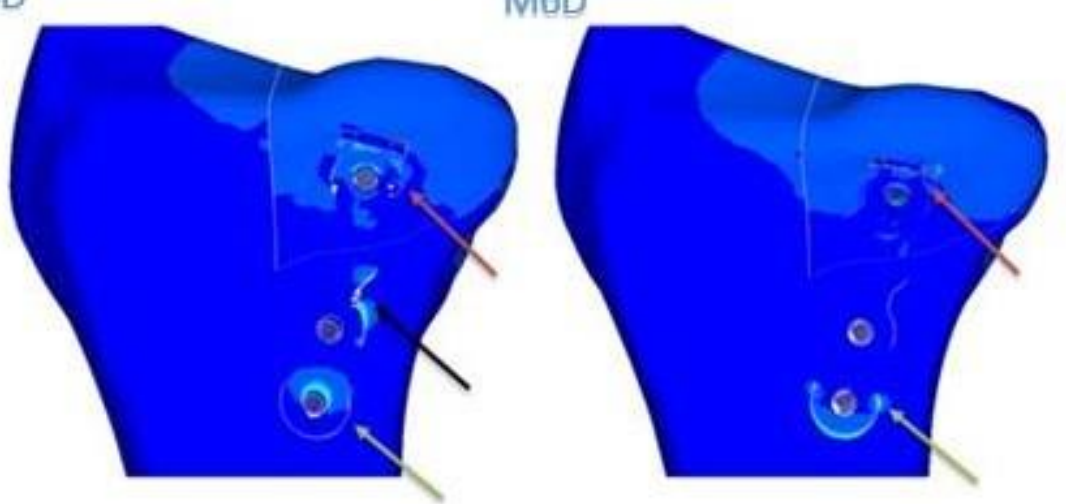

7.14

4.86

2.57

0.29

$-2.00$

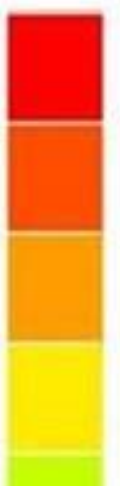


ancora no osso seta preta $27,71 \mathrm{kPa}$. No grupo M2D apresenta o valor de Tensão Máxima principal de $146 \mathrm{kPa}$, mostrando que as regiões mais solicitadas do osso na vista frontal foram as regiões de ancoragem osso placa primeiro parafuso seta vermelha $2,57 \mathrm{kPa}$ na região baixa da placa onde se encontra o terceiro parafuso seta verde 9,43 $\mathrm{kPa}$. No grupo M3D apresenta um valor de Tensão Máxima principal de $210 \mathrm{kPa}$, mostrando que as regiões mais solicitadas do osso na vista frontal foram as regiões de ancoragem da placa no primeiro parafuso seta vermelha $4,86 \mathrm{kPa}$, segundo parafuso seta preta $14 \mathrm{kPa}$ e ao redor do terceiro parafuso seta verde $16,29 \mathrm{kPa}$. No grupo M4D apresenta um valor de Tensão Máxima principal de $71 \mathrm{kPa}$, mostrando que as regiões mais solicitadas do osso na vista frontal foram as regiões de ancoragem da placa no primeiro parafuso seta vermelha $2,57 \mathrm{kPa} e$ região segundo parafuso seta preta 9,43 $\mathrm{kPa}$. No grupo M5D apresenta um valor de Tensão Máxima principal de $194 \mathrm{kPa}$, mostrando que as regiões mais solicitadas do osso na região frontal foram as regiões de ancoragem da placa no primeiro parafuso seta vermelha $2,57 \mathrm{kPa}$, ao redor do segundo parafuso seta preta $18,57 \mathrm{kPa}$ e no terceiro parafuso seta preta 4,86 kPa. No grupo M6D apresenta um valor de Tensão Máxima principal de $292 \mathrm{kPa}$, mostrando que as regiões mais solicitadas do osso na vista frontal foram as regiões de ancoragem da placa no primeiro parafuso seta vermelha $2,57 \mathrm{kPa}$, e nas regiões e na região de ancoragem da placa pelo terceiro parafuso seta preta $14 \mathrm{kPa}$. 
A figura 38 ilustra a vista dorsal apresentando a Tensão Máxima Principal, observadas nos modelos para o ensaio de compressão para uma $\mathrm{F}=60 \mathrm{~N}$.

Figura 38. Comparações da Tensão Máxima Principal vista dorsal: demonstrando pelas setas os pontos de tensão seta vermelha $\uparrow$ ) na região do primeiro parafuso, seta preta $(\uparrow)$ região onde a
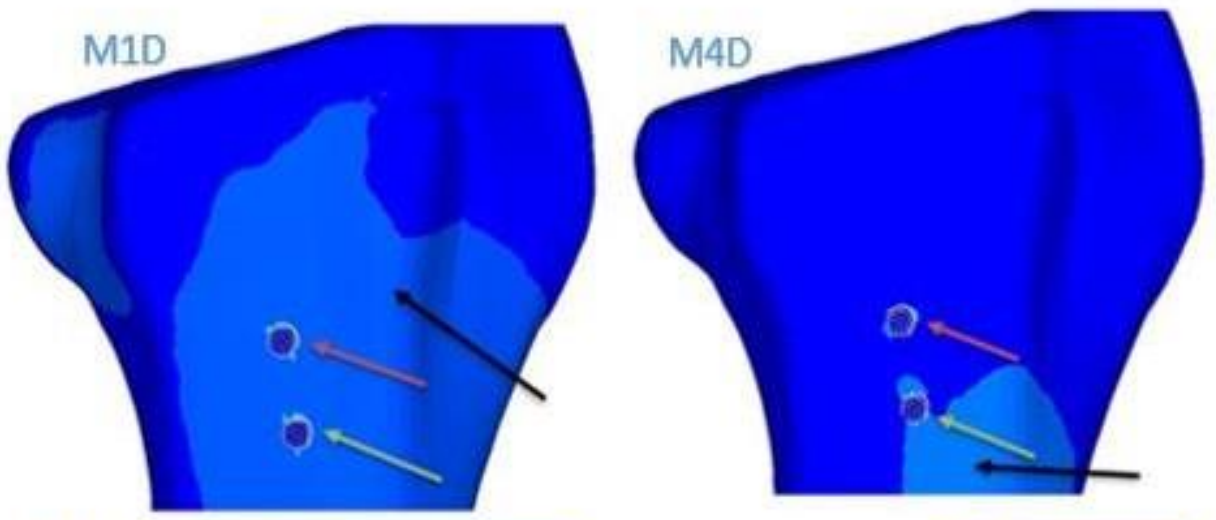

30. 00

27.71

25.43

23.14

20.86
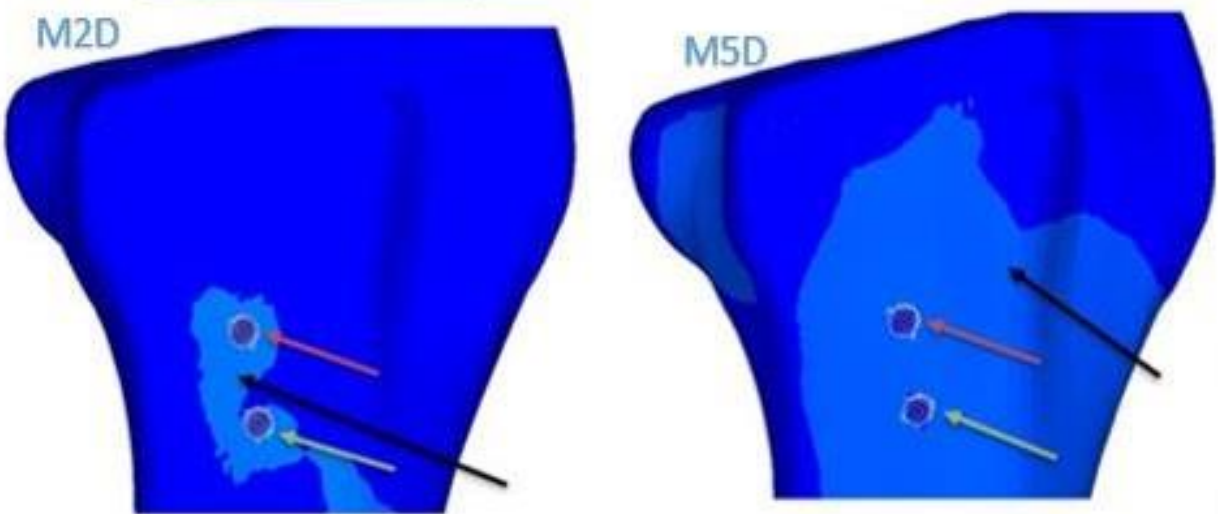

18.57

16. 29

14.00

11.71

9.43
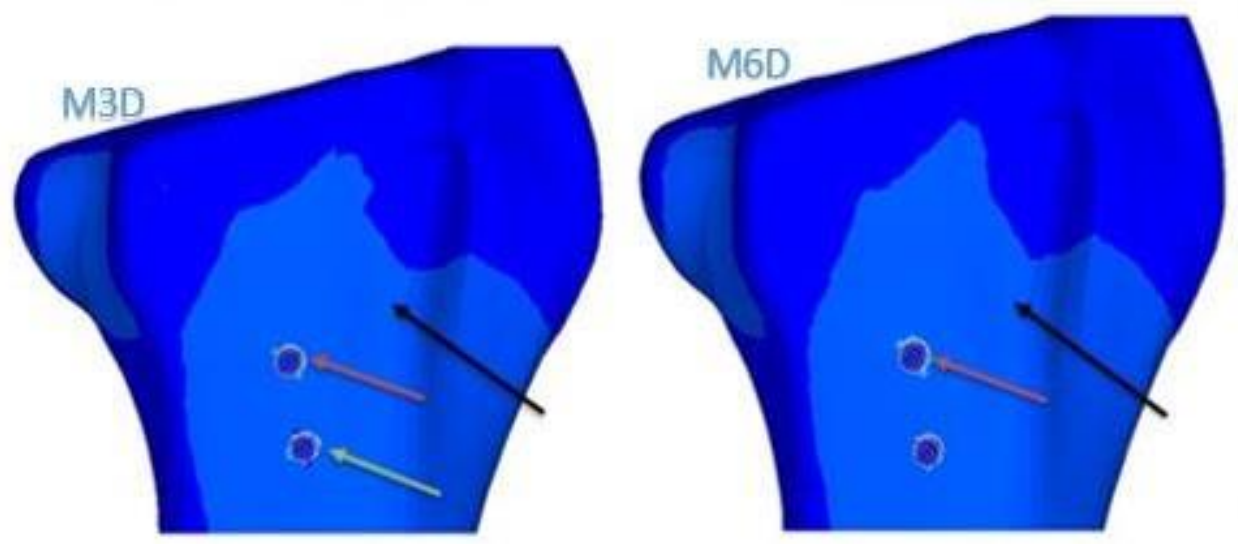

7.14

4.86

2.57

0. 29

$-2.00$

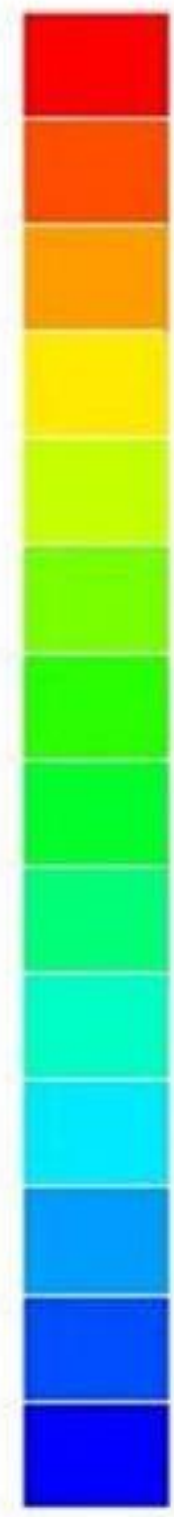

No grupo M1D apresenta o valor de Tensão Máxima principal de $180 \mathrm{kPa}$, mostrando que as regiões mais solicitadas do osso na vista dorsal foram as regiões ao redor do segundo parafuso seta vermelha 4,86 kPa e terceiro parafuso seta 
verde $9,43 \mathrm{kPa}$ e podemos observar um pouco de tensão na região dorsal espalhada seta preta $0,29 \mathrm{kPa}$. No grupo M2D apresenta o valor de Tensão Máxima principal de $146 \mathrm{kPa}$, mostrando que as regiões mais solicitadas do osso na vista dorsal foram as regiões ao redor do segundo parafuso seta vermelha $7,14 \mathrm{kPa}$ e terceiro parafuso seta verde $9,43 \mathrm{kPa}$ e observamos um pouco de tensão espalhada ao redor seta preta $0,29 \mathrm{kPa}$. No grupo M3D apresenta um valor de Tensão Máxima principal de $210 \mathrm{kPa}$, mostrando que as regiões mais solicitadas do osso na vista dorsal foram as regiões de ancoragem da placa no segundo parafuso seta vermelha $7,14 \mathrm{kPa}$ segundo parafuso seta verde 9,43 $\mathrm{kPa}$ e espalhada ao redor da região dorsal seta preta $0,29 \mathrm{kPa}$. No grupo M4D apresenta um valor de Tensão Máxima principal de $71 \mathrm{kPa}$, mostrando que as regiões mais solicitadas do osso na vista dorsal foram as regiões ao redor do segundo parafuso seta vermelha $7,14 \mathrm{kPa}$, ao redor do terceiro parafuso seta verde $2,57 \mathrm{kPa}$ e espalhada ao redor seta preta 0,29 $\mathrm{kPa}$. No grupo M5D apresenta um valor de Tensão Máxima principal de $194 \mathrm{kPa}$, mostrando que as regiões mais solicitadas do osso na vista dorsal foram as regiões ao redor do segundo parafuso seta vermelha, $7,14 \mathrm{kPa}$, ao redor do segundo parafuso seta verde $9,43 \mathrm{kPa}$ espalhada ao redor seta preta $0,29 \mathrm{kPa}$. No grupo M6D apresenta um valor de Tensão Máxima principal de $292 \mathrm{kPa}$, mostrando que as regiões mais solicitadas do osso na vista dorsal foram ao redor do segundo parafuso seta vermelha $7,14 \mathrm{kPa}$, e espalha ao redor da região dorsal seta preta $0,29 \mathrm{kPa}$. 
A figura 39 ilustra a vista longitudinal apresentando a Tensão Máxima Principal, observadas nos modelos para o ensaio de compressão para uma $F=60$ N.

Figura 39. Comparações da Tensão Máxima Principal vista longitudinal: demonstrando pelas setas os pontos de tensão seta vermelha 4 ) na região do segundo parafuso, setałpreta ( ) região do primeiro parafuso, seta verde 4 ) região do terceiro parafuso, seta azul 4 ) seła laranja ( ) região frontal.
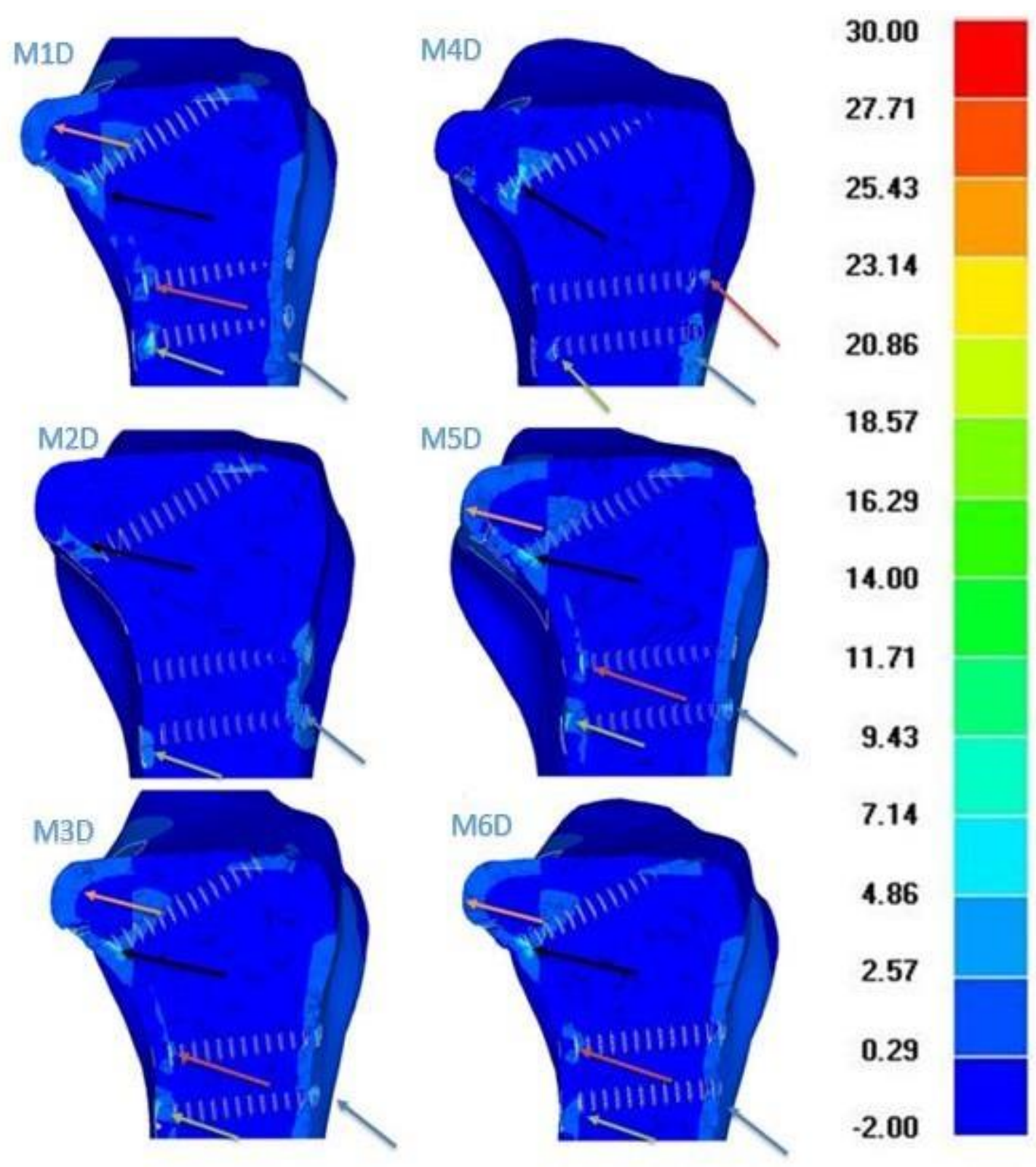
No grupo M1D apresenta o valor de Tensão Máxima principal de $180 \mathrm{kPa}$, mostrando que as regiões mais solicitadas do osso na região com corte lateral foram ao redor primeiro parafuso seta preta $11,71 \mathrm{kPa}$, segundo parafuso seta vermelha $14 \mathrm{kPa}$ terceiro parafusos seta verde $18,57 \mathrm{kPa}$, e podemos observar um pouco de tensão na região dorsal seta azul $0,29 \mathrm{kPa}$ e na região do fragmento apresenta pouca tensão seta laranja $0,29 \mathrm{kPa}$. No grupo M2D apresenta o valor de Tensão Máxima principal de $146 \mathrm{kPa}$, mostrando que as regiões mais solicitadas do osso na região com corte lateral foram as regiões ao redor do primeiro parafuso seta preta $4,86 \mathrm{kPa}$, terceiro parafuso seta verde $11,71 \mathrm{kPa}$ e observamos um pouco de tensão espalhada ao redor da região dorsal seta azul $0,29 \mathrm{kPa}$, já para a região de contato fragmento osso observamos pouca tensão seta laranja $0,29 \mathrm{kPa}$. No grupo M3D apresenta um valor de Tensão Máxima principal de $210 \mathrm{kPa}$, mostrando que as regiões mais solicitadas do osso na região com corte lateral foram as regiões primeiro e segundo parafuso seta preta $9,43 \mathrm{kPa}$, ao redor do segundo parafuso nos primeiros passos de rosca seta vermelha $9,43 \mathrm{kPa}$, ao redor do terceiro parafuso seta verde $7,14 \mathrm{kPa}$ observamos pouca tensão na região frontal seta laranja 0,29 $\mathrm{kPa}$ e na região dorsal seta azul 0,29 kPa. No grupo M4D apresenta um valor de Tensão Máxima principal de $71 \mathrm{kPa}$, mostrando que as regiões mais solicitadas do osso na região com corte lateral foram as regiões do primeiro, segundo e terceiro passos de rosca seta preta $9,43 \mathrm{kPa}$ e pouca na primeira rosca do terceiro parafuso seta verde $2,57 \mathrm{kPa}$, apresenta pouca tensão na região dorsal seta azul 0,29 kPa. No grupo M5D apresenta um valor de Tensão Máxima principal de $194 \mathrm{kPa}$, mostrando que as regiões mais solicitadas do osso na vista lateral foram as regiões no primeiro parafuso seta preta e ao do segundo parafuso seta vermelha $7,14 \mathrm{kPa}$ no terceiro parafuso seta verde $7,14 \mathrm{kPa}$ ambos nos primeiros passos de rosca, e apresenta pouca tensão na região frontal e na região dorsal. No grupo M6D apresenta um valor de Tensão Máxima principal de $292 \mathrm{kPa}$, mostrando que as regiões mais solicitadas do osso na região com corte lateral foram as regiões do primeiro parafuso seta preta $11,71 \mathrm{kPa}$, segundo parafuso seta vermelha 2,57 kPa e terceiro parafuso seta verde $2,57 \mathrm{kPa}$ apresentando sempre maior tensão nos primeiros passos de rosca, na região frontal seta laranja 0,29 e dorsal pouca tensão seta azul 0,29 kPa. 
A figura 40 ilustra a vista do osso sem fragmento apresentando a Tensão Máxima Principal, observadas nos modelos para o ensaio de compressão para uma $\mathrm{F}=60 \mathrm{~N}$.
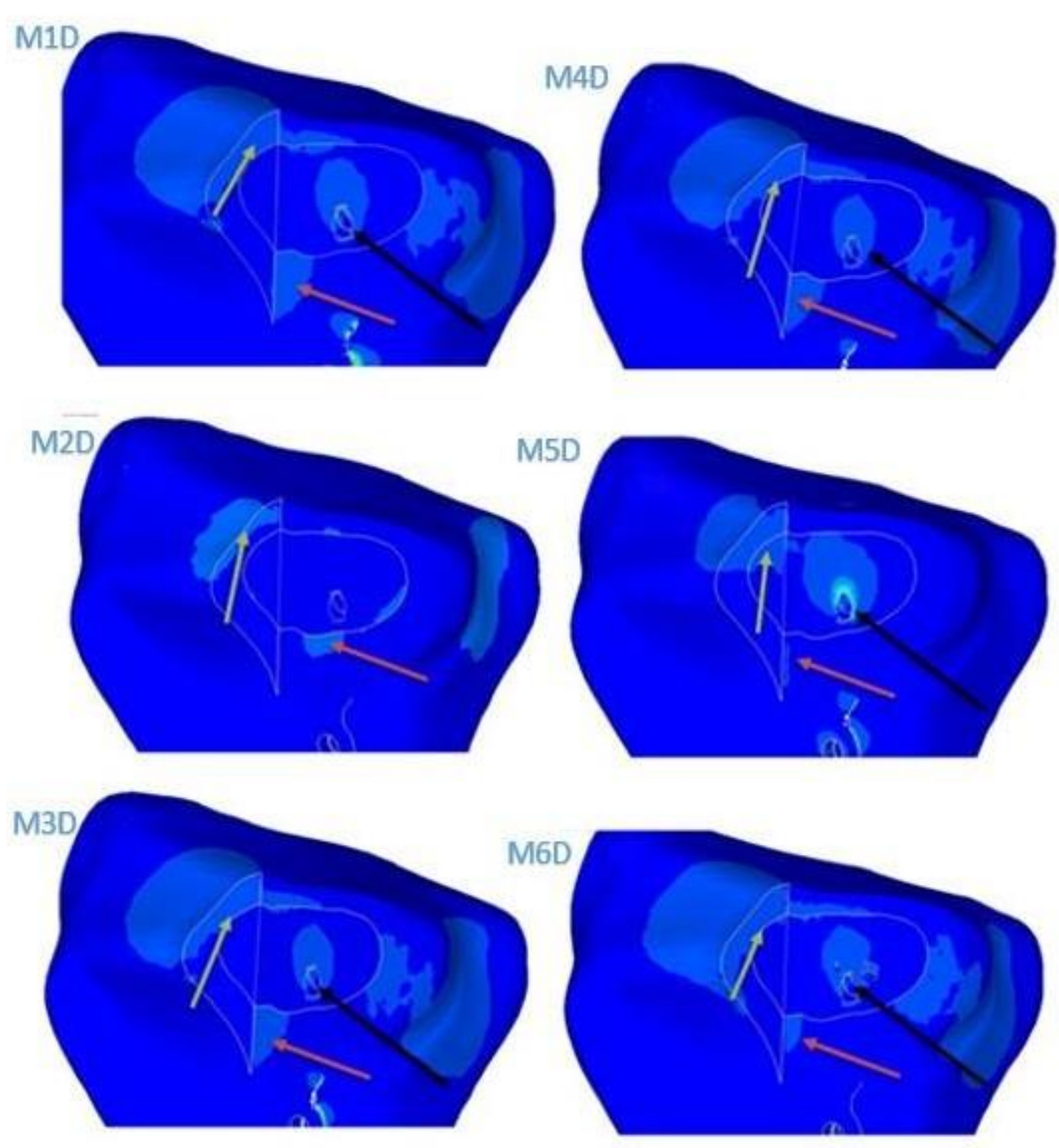

Figura 40. Comparações da Tensão Máxima Principal vista frontal osso sem o fragmento: demonstrado pelas setas as regiões contato fragmento e osso seta vermelha 4 ) na região de contato osso e fragmento (inferior), seta preta $\uparrow$ ) região do primeiro parafuso, seta $\uparrow$ )região de contato osso e fragmento (inferior).

No grupo M1D apresenta o valor de Tensão Máxima principal de $180 \mathrm{kPa}$, mostrando que as regiões mais solicitadas são ao redor do primeiro parafuso seta 
preta $2,57 \mathrm{kPa}$ e na região de apoio do fragmento setas verde e vermelha $0,29 \mathrm{kPa}$ espalhados pela região do osso. No grupo M2D apresenta o valor de Tensão Máxima principal de $146 \mathrm{kPa}$, mostrando que as regiões mais solicitadas são na região de apoio do fragmento setas verde e vermelha $0,29 \mathrm{kPa}$ espalhados pela região do osso. No grupo M3D apresenta um valor de Tensão Máxima principal de $210 \mathrm{kPa}$, mostrando que as regiões mais solicitadas são ao redor do primeiro parafuso seta preta $2,57 \mathrm{kPa}$ e espalhadas no local onde se encostam o fragmento $\mathrm{e}$ o osso setas vermelha e verde $0,29 \mathrm{kPa}$. No grupo M4D apresenta um valor de Tensão Máxima principal de $71 \mathrm{kPa}$, mostrando que as regiões mais solicitadas são ao redor do primeiro parafuso indicado pela seta preta $2,57 \mathrm{kPa}$ e espalha no local onde se encostam fragmento e o osso setas verde e vermelha $0,29 \mathrm{kPa}$. No grupo M5D apresenta um valor de Tensão Máxima principal de $194 \mathrm{kPa}$, mostrando que as regiões mais solicitadas são mais acentuadas ao redor do primeiro parafuso seta preta $11,71 \mathrm{kPa}$ na lateral onde se insere o fragmento e o osso setas vermelha $\mathrm{e}$ verde $0,29 \mathrm{kPa}$. No grupo M6D apresenta um valor de Tensão Máxima principal de $292 \mathrm{kPa}$, mostrando que as regiões mais solicitadas são ao redor do primeiro parafuso seta preta $2,57 \mathrm{kPa}$ e espalhado na região de contato fragmento e o osso setas vermelha e verde $0,29 \mathrm{kPa}$. 
A figura 41 ilustra a vista axial Tensão Máxima Principal, observadas nos modelos para o ensaio de compressão para uma $\mathrm{F}=60 \mathrm{~N}$.

Figura 42. Comparações da Tensão Máxima Principal vista axial corte no local do fragmento em que o gancho entra: demonstrando pelas setas os pontos de tensão seta laranja( $\uparrow$ ) na região ao redor
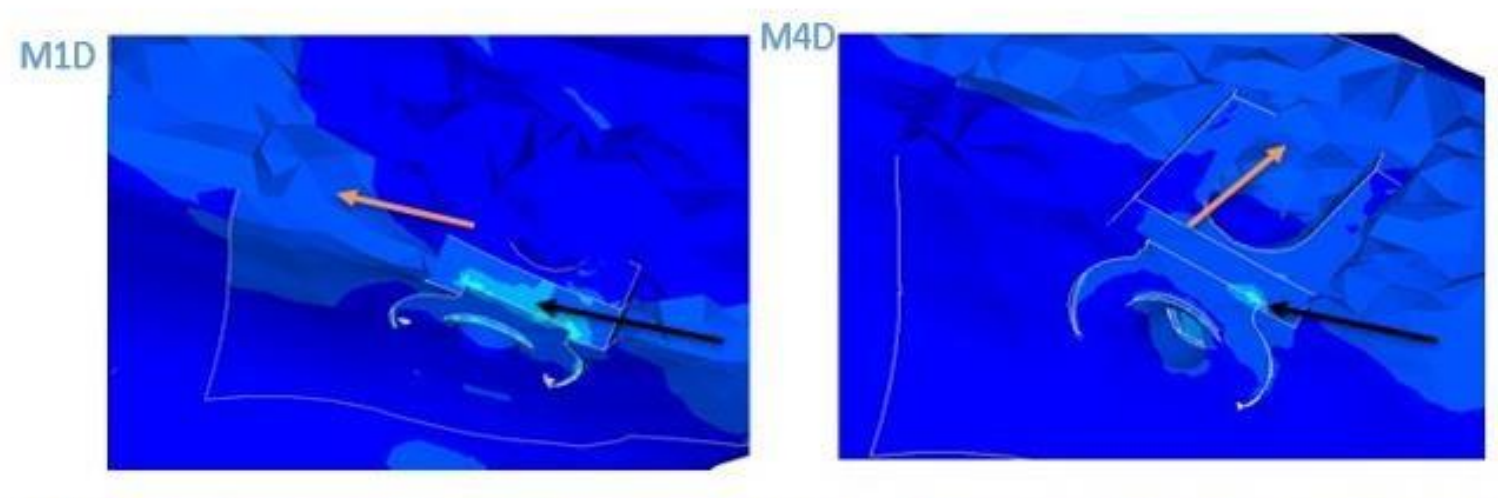

30.00

27.71

25.43

23.14

20. 86
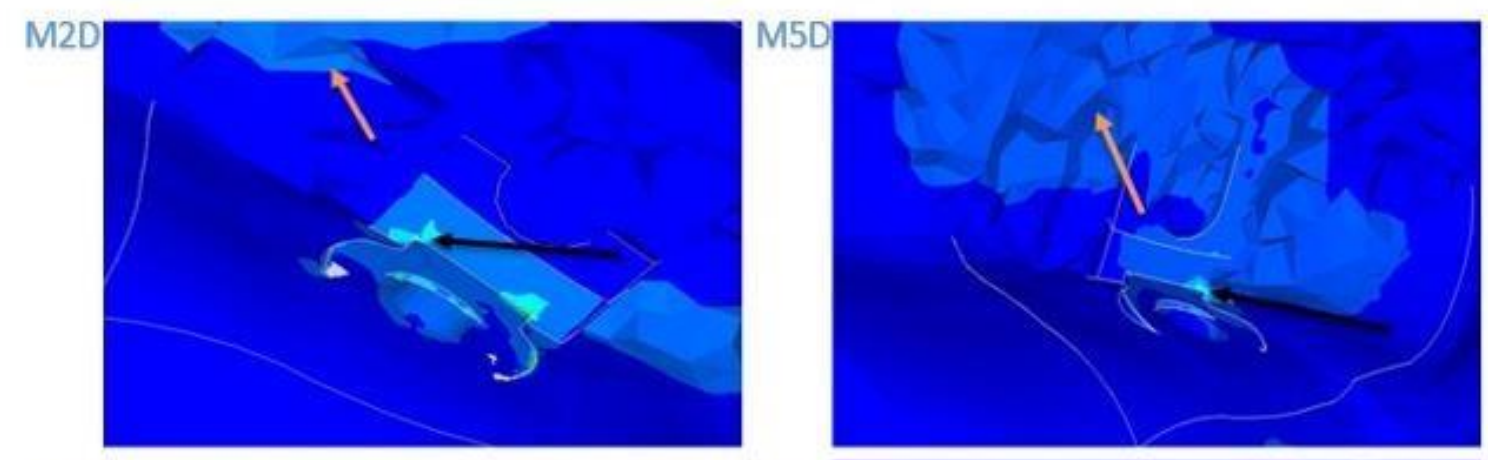

18.57

16.29

14.00

11.71

9.43
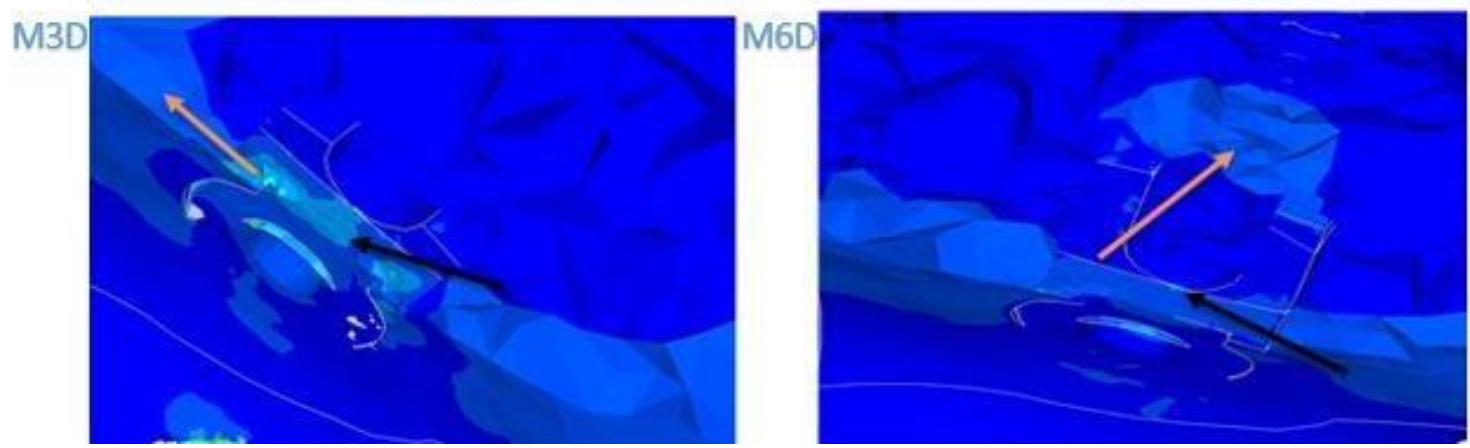

7.14

4.86

2.57

0. 29

$-2.00$

No grupo M1D apresenta o valor de Tensão Máxima principal de $180 \mathrm{kPa}$, mostrando que as regiões mais solicitadas do osso são os pontos de fixação do gancho na placa indicado pela seta preta $11,71 \mathrm{kPa}$ e ao redor do gancho seta laranja 0,29 kPa. No grupo M2D apresenta o valor de Tensão Máxima principal de $146 \mathrm{kPa}$, mostrando que as regiões mais solicitadas do osso são na fixação osso placa no início do gancho seta preta $14 \mathrm{kPa}$ e ao redor do gancho seta laranja 0,29 kPa. No grupo M3D apresenta um valor de Tensão Máxima principal de $210 \mathrm{kPa}$, mostrando que as regiões mais solicitadas do osso são as regiões do início do gancho seta preta 9,43 
$\mathrm{kPa}$ e ao redor do gancho seta laranja 9,43 $\mathrm{kPa}$. No grupo M4D apresenta um valor de Tensão Máxima principal de $71 \mathrm{kPa}$, mostrando que as regiões mais solicitadas do osso no início do gancho seta preta $7,14 \mathrm{kPa}$ e ao redor do gancho seta laranja 0,29 kPa. No grupo M5D apresenta um valor de Tensão Máxima principal de 194 $\mathrm{kPa}$, mostrando que as regiões mais solicitadas do osso são no início do gancho seta preta $7,14 \mathrm{kPa}$ e ao redor do gancho seta laranja 0,29 $\mathrm{kPa}$. No grupo M6D apresenta um valor de Tensão Máxima principal de $292 \mathrm{kPa}$, mostrando que as regiões mais solicitadas do osso no início do gancho seta preta $2,57 \mathrm{kPa}$ e ao redor do gancho seta laranja $0,29 \mathrm{kPa}$. 
A figura 42 ilustra a vista frontal apresentando a Tensão Mínima Principal, observadas nos modelos para o ensaio de compressão para uma $F=60 \mathrm{~N}$

Figura 42. Comparações da Tensão Mínima Principal vista frontal osso sem o fragmento demonstrando pelas setas as regiões de tensão: seta vermelha $\uparrow$ ) na região de ancoragem da placa e primeiro parafuso; seta preta $\uparrow$ ) região ao redor do gancho (inferior ao gancho), seta laranja ( 4 ) região de ancoragem da placa, seta azul ( 4 ) região espalhada ao redor dos segundos e terceiros parafusos, seta verde $\uparrow$ ) região de ancoragem da região do terceiro parafuso da placa.
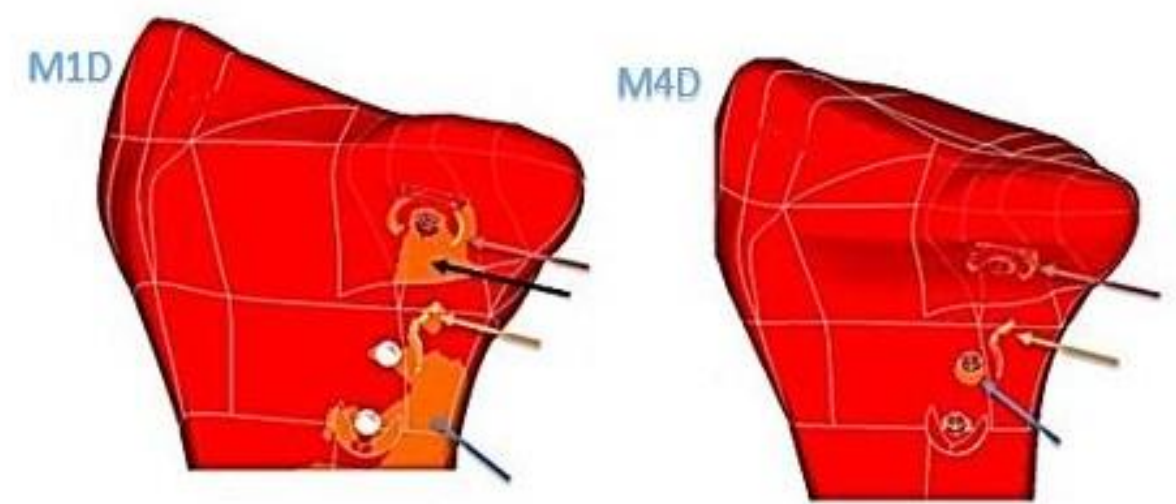

\subsection{0}

$-2.50$

$-10.00$

$-17.50$

$-25.00$
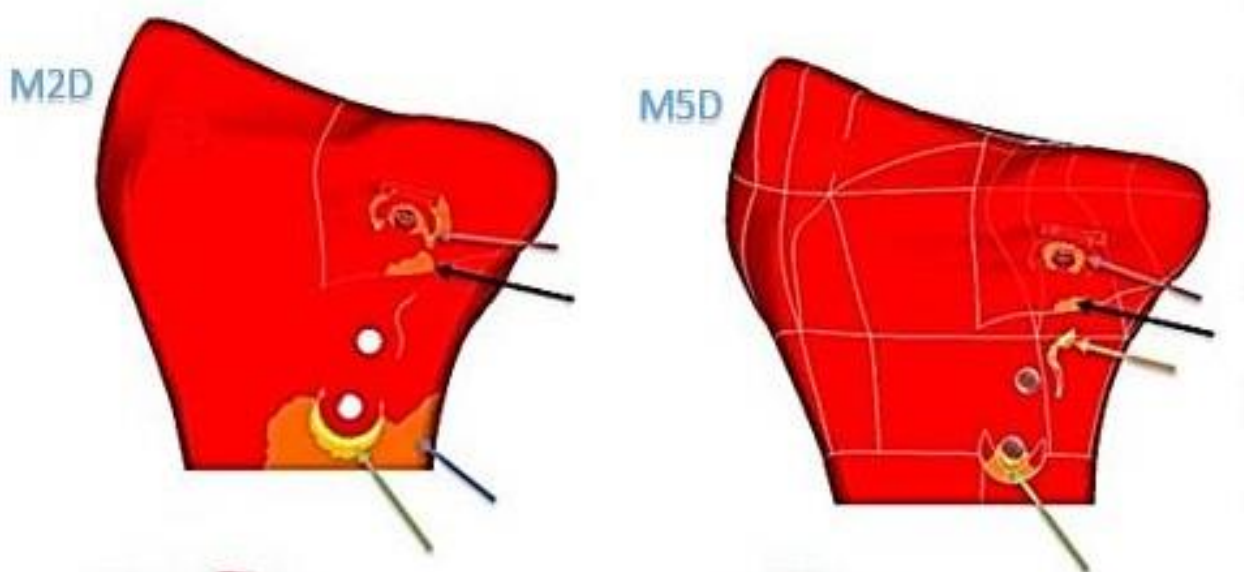

$-32.50$

.40 .00

$-47.50$

.55 .00

$-62.50$
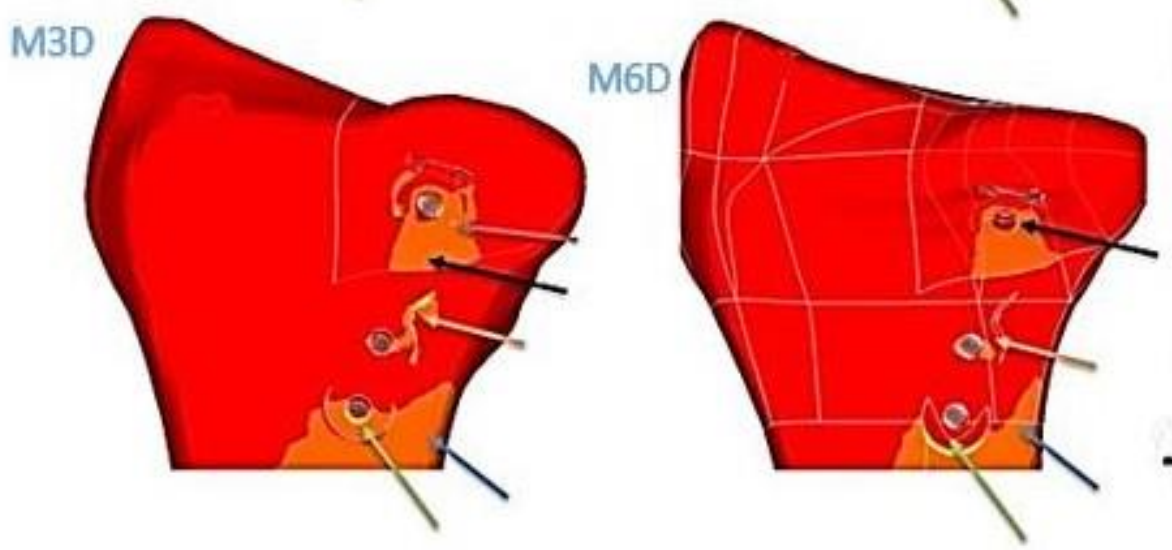

.70 .00

.77 .50

.85 .00

$-92.50$

.100 .00

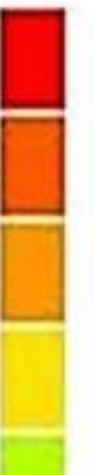


No grupo M1D apresenta um valor de Tensão Mínima Principal de -297,22 $\mathrm{kPa}$, mostrando que as regiões mais solicitadas foram ao redor do primeiro parafuso seta vermelha $-25 \mathrm{kPa}$, ao redor do ponto de fixação osso placa seta preta -10, próximo ao segundo parafuso seta laranja $-32,50 \mathrm{kPa}$, ao redor do terceiro furo seta verde espalhadas pelo osso seta azul -10 kPa. No grupo M2D apresenta um valor de Tensão Mínima Principal de -626,30 kPa mostrando que as regiões mais solicitadas foram ao redor do primeiro parafuso seta vermelha $-32,50 \mathrm{kPa}$, ao redor do ponto de fixação osso placa seta preta -10 , ao redor do terceiro furo seta verde $-47,50 \mathrm{kPa}$ espalhadas pelo osso seta azul $-10 \mathrm{kPa}$. No grupo M3D apresenta um valor de Tensão Mínima Principal de $-467,00 \mathrm{kPa}$, mostrando que as regiões mais solicitadas foram ao redor do primeiro parafuso seta vermelha $-17,50 \mathrm{kPa}$, ao redor do ponto de fixação osso placa seta preta -10, próximo ao segundo parafuso seta laranja $-32,50$ $\mathrm{kPa}$, ao redor do terceiro furo seta verde $-10 \mathrm{kPa}$ espalhadas pelo osso seta azul -10 kPa. No grupo M4D apresenta um valor de Tensão Mínima Principal de -227,83 kPa, mostrando que as regiões mais solicitadas foram ao redor do primeiro parafuso seta vermelha -10 $\mathrm{kPa}$, próximo ao segundo parafuso seta laranja $-17,50 \mathrm{kPa}$, espalhadas pelo osso seta azul $-10 \mathrm{kPa}$. No grupo M5D apresenta um valor de Tensão Mínima Principal de -256,86 kPa, mostrando que as regiões mais solicitadas foram ao redor do primeiro parafuso seta vermelha $-10 \mathrm{kPa}$, ao redor do ponto de fixação osso placa seta preta -10, próximo ao segundo parafuso seta laranja $-32,50$ $\mathrm{kPa}$, ao redor do terceiro furo seta verde $-25 \mathrm{kPa}$. No grupo M6D apresenta um valor de Tensão Mínima Principal de $-599,01 \mathrm{kPa}$, mostrando que as regiões mais solicitadas foram ao redor do ponto de fixação osso placa seta preta -10, próximo ao segundo parafuso seta laranja $-10 \mathrm{kPa}$, ao redor do terceiro furo seta verde $-25 \mathrm{kPa}$ espalhadas pelo osso seta azul $-10 \mathrm{kPa}$. 
A figura 43 ilustra a vista dorsal apresentando a Tensão Mínima Principal, observadas nos modelos para o ensaio de compressão para uma $\mathrm{F}=60 \mathrm{~N}$.

Figura 43. Comparações da Tensão Mínima Principal vista dorsal demonstrando pelas setas os pontos de tensão: seta vermelha ( $\uparrow$ ) na região dorsal ao redor do segundo e terceiro parafuso, seta verde $(\uparrow)$ região espalhada na lateral do9rsal do osso.

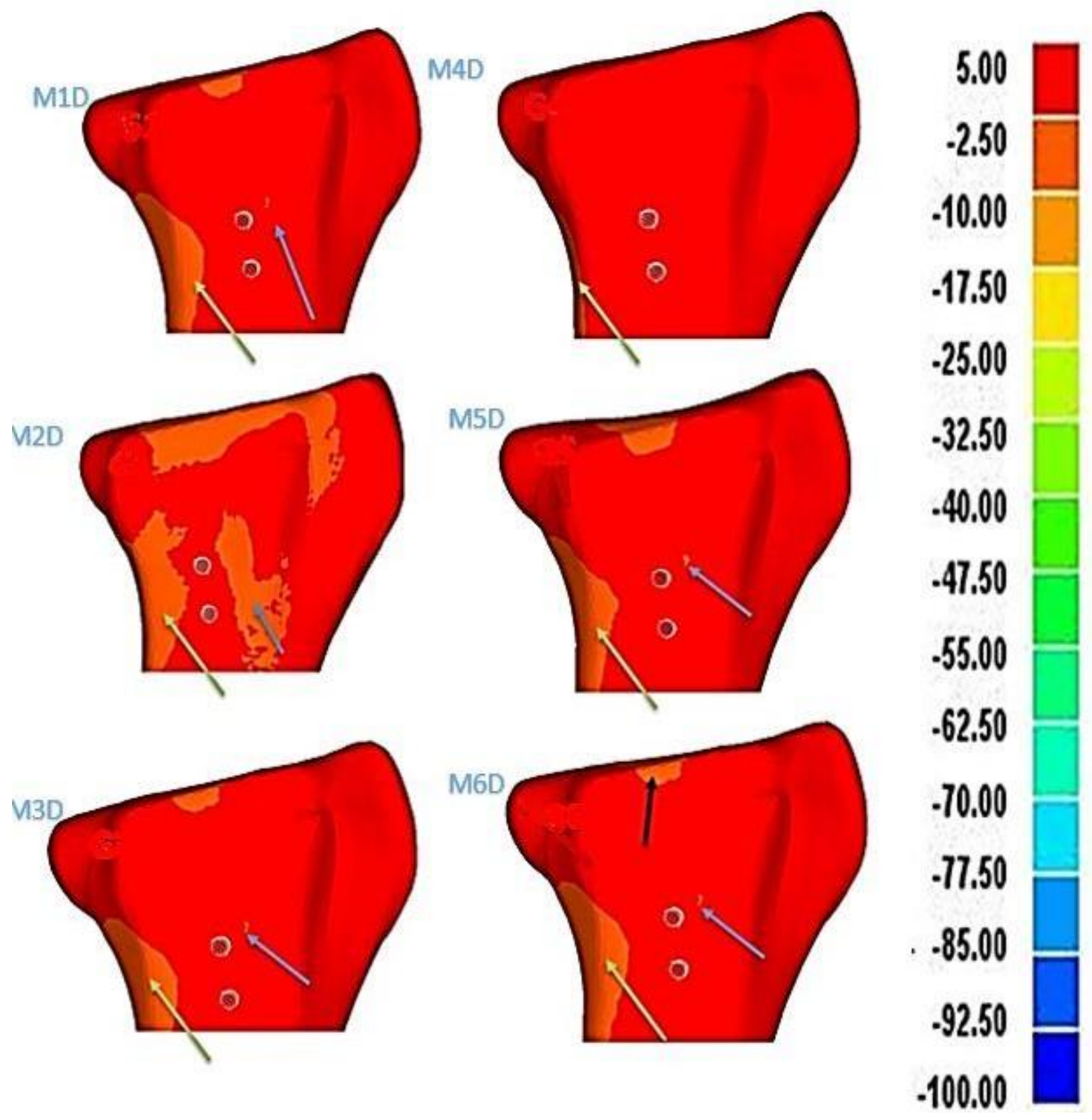

No grupo M1D apresenta um valor de Tensão Mínima Principal de -297,22 $\mathrm{kPa}$, mostrando que as regiões mais solicitadas são parte superior, na lateral e uma pequena porção próximo ao primeiro parafuso setas verde azul e preta -10 kpa. 
No grupo M2D apresenta um valor de Tensão Mínima Principal de -626,30 kPa mostrando que as regiões mais solicitadas são uma grande porção superior seta preta $-10 \mathrm{kPa}$, lateral e espalhada na região dorsal verde e azul $-10 \mathrm{kPa}$. No grupo M3D apresenta um valor de Tensão Mínima Principal de $-467,00 \mathrm{kPa}$, mostrando que as regiões mais solicitadas são pequena porção superior seta verde $-2,50 \mathrm{kPa}$, lateral e uma pequena região próxima ao primeiro parafuso setas azul e verde -10 kPa. No grupo M4D apresenta um valor de Tensão Mínima Principal de $-227,83 \mathrm{kPa}$, mostrando que as regiões mais solicitadas são uma pequena porção lateral seta verde $-2,50 \mathrm{kPa}$. No grupo M5D apresenta um valor de Tensão Mínima Principal de $256,86 \mathrm{kPa}$, mostrando que as regiões mais solicitadas são pequena porção superior seta verde $-2,50 \mathrm{kPa}$, lateral e uma pequena região próxima ao primeiro parafuso setas azul e verde $-10 \mathrm{kPa}$. No grupo M6D apresenta um valor de Tensão Mínima Principal de $-599,01 \mathrm{kPa}$, mostrando que as regiões mais são pequena porção superior seta verde $-2,50 \mathrm{kPa}$, lateral e uma pequena região próxima ao primeiro parafuso setas azul e verde $-10 \mathrm{kPa}$. 
A figura 44 ilustra a vista sagital apresentando a Tensão Mínima Principal, observadas nos modelos para o ensaio de compressão para uma $\mathrm{F}=60 \mathrm{~N}$.

Figura 44. Comparações da Tensão Máxima Principal vista sagital demonstrando pelas setas os pontos de tensão: seta laranja ( $\uparrow$ ) região frontal (fragmento), seta preta $(\uparrow)$ região do primeiro

parafuso, seta vermelha ( 4 ) região frontal, seta verde $\uparrow$ ) região do ter, seta 4 ) região dorsal, seta laranja ( ) região frontal.
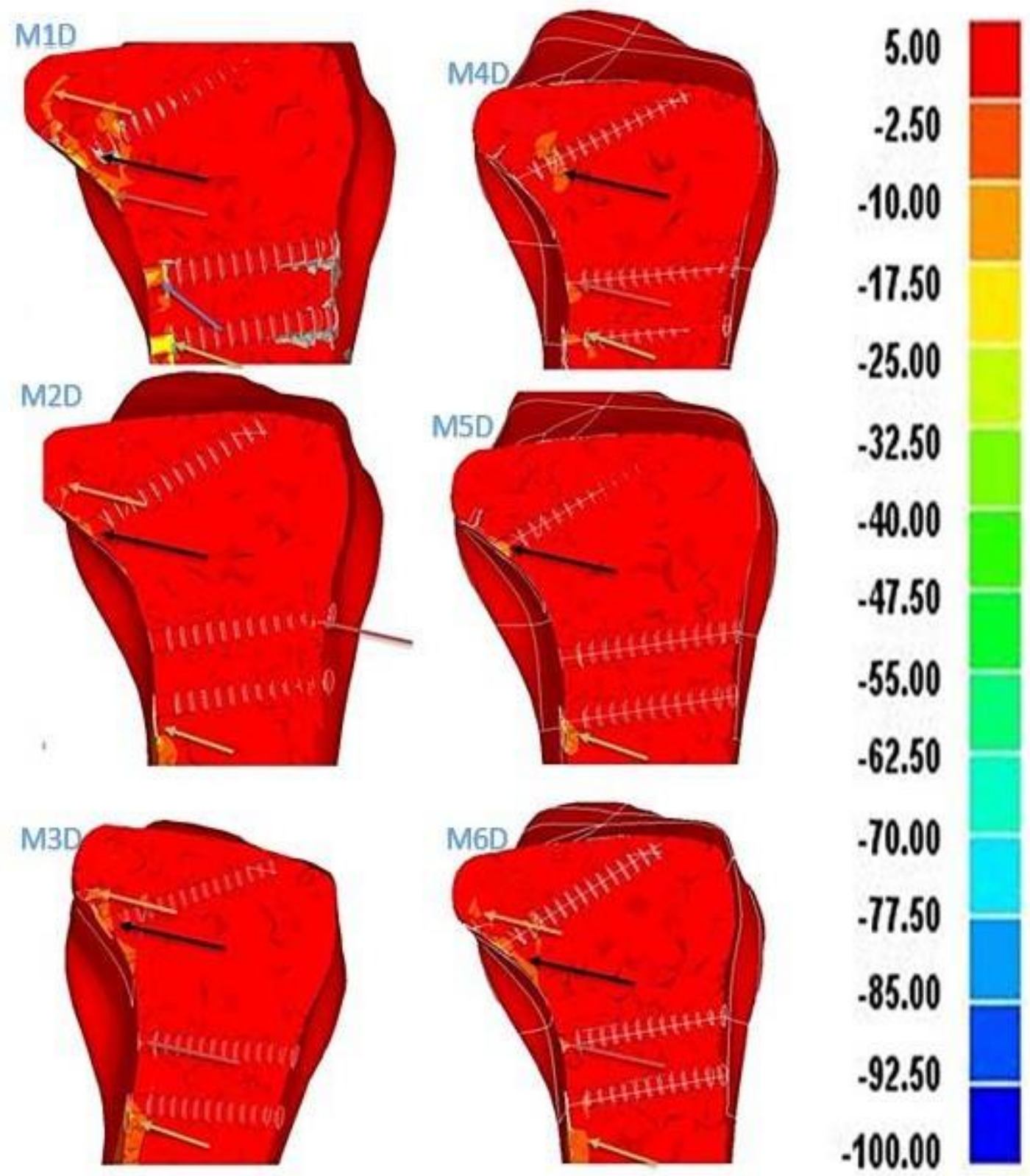
No grupo M1D apresenta um valor de Tensão Mínima Principal de -297,22 kPa mostrando que as regiões mais solicitadas são dos primeiros passos de rosca e ao redor do primeiro parafuso seta preta $-25 \mathrm{kPa}$, no segundo parafuso apresenta tensão na região dos primeiros passos de rosca pela seta azul $-10 \mathrm{kPa}$ assim como no terceiro parafuso seta verde $-47,50$, região espalhada no osso seta vermelha $-17,50 \mathrm{kPa}$, região de contato fragmento e osso seta laranja $-10 \mathrm{kPa}$. No grupo M2D apresenta um valor de Tensão Mínima Principal de -626,30 kPa mostrando que as regiões mais solicitadas foram ao redor da haste primeiro parafuso seta preta $-10 \mathrm{kPa}$, no último passo de rosca do segundo parafuso seta vermelha $-17,50 \mathrm{kPa}$ e no início da haste do terceiro parafuso seta verde $-40 \mathrm{kPa}$. No grupo M3D apresenta um valor de Tensão Mínima Principal de $-467,00 \mathrm{kPa}$, mostrando que as regiões mais solicitadas foram ao redor dos segundos passos de rosca do primeiro parafuso seta preta $-10 \mathrm{kPa}$, ao redor da haste do segundo parafuso seta vermelha $-2,5 \mathrm{kPa}$ e ao redor da haste e primeiro passo de rosca do terceiro parafuso seta verde $-17,5 \mathrm{kPa}$ e região de contato fragmento e osso seta laranja -10 kPa. No grupo M4D apresenta um valor de Tensão Mínima Principal de $-227,83 \mathrm{kPa}$, mostrando que as regiões mais são dos primeiros passos de rosca e ao redor do primeiro parafuso seta preta $-2,50 \mathrm{kPa}$, no segundo parafuso apresenta tensão na região dos primeiros passos de rosca seta vermelha $-10 \mathrm{kPa}$ assim como no terceiro parafuso seta verde $-10 \mathrm{kPa}$. No grupo M5D apresenta um valor de Tensão Mínima Principal de $-256,86 \mathrm{kPa}$, mostrando que as regiões mais solicitadas na haste do primeiro parafuso seta preta $-10 \mathrm{kPa}$ e na haste do terceiro parafuso seta verde $-25 \mathrm{kPa}$. No grupo M6D apresenta um valor de Tensão Mínima Principal de -599,01 kPa, mostrando que as regiões mais solicitadas foram no fragmento na haste do primeiro parafuso $-2,50 \mathrm{kPa}$, na haste do segundo parafuso seta vermelha $-10 \mathrm{kPa}$ e na região ao redor do terceiro parafuso seta verde $-17,5 \mathrm{kPa}$. 
A figura 45 ilustra a vista do osso sem fragmento apresentando a Tensão Máxima Principal, observadas nos modelos para o ensaio de compressão para uma $\mathrm{F}=60 \mathrm{~N}$.

Figura 45. Comparações da Tensão Máxima Principal vista frontal do fragmento demonstrando pelas setas os pontos de tensão: seta verde 4 ) região ao redor do primeiro parafuso, seta 4 ) região espalhada de contato fragmento osso.

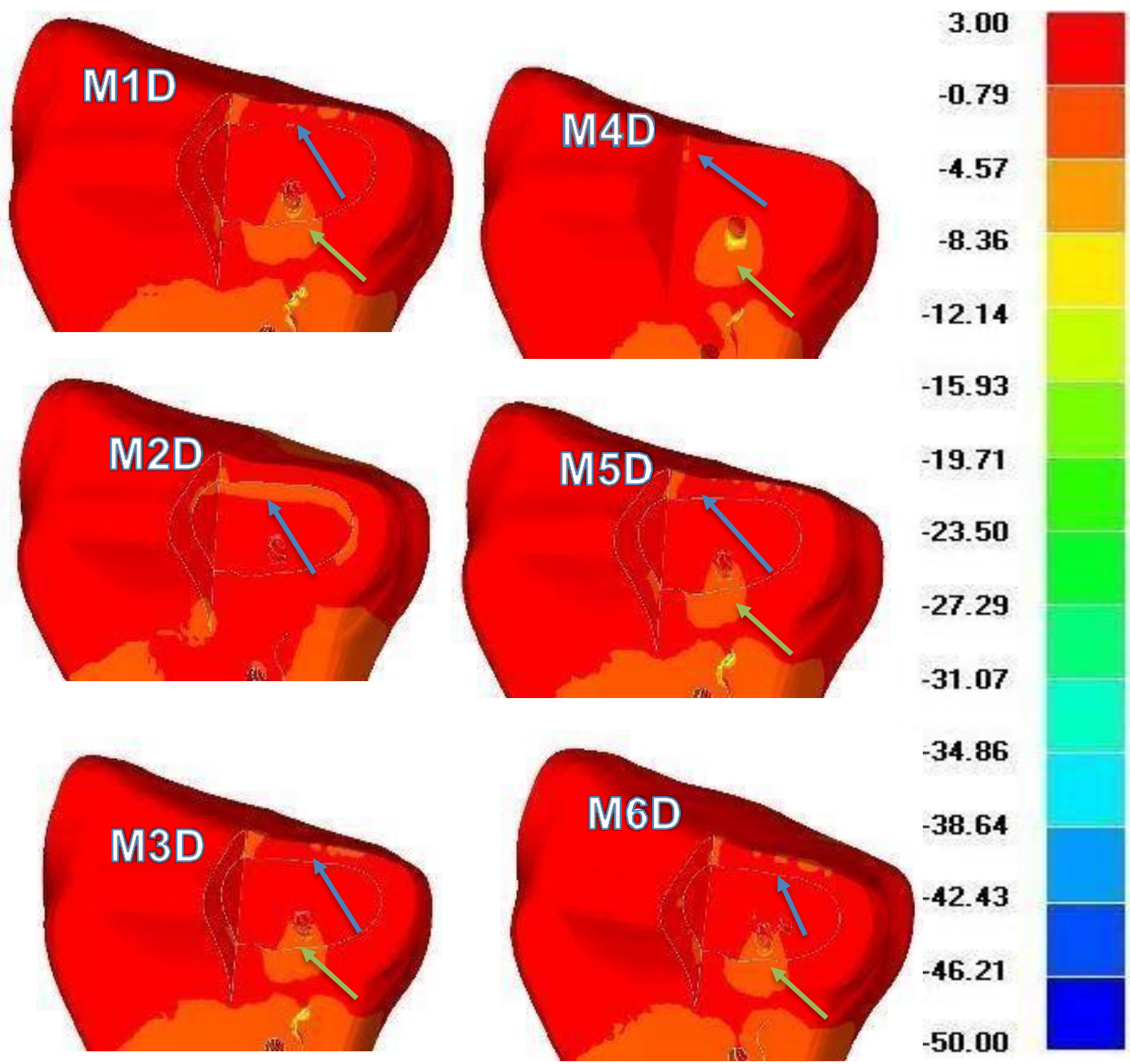


No grupo M1D apresenta um valor de Tensão Mínima Principal de -297,22 $\mathrm{kPa}$ mostrando que as regiões mais solicitadas são ao redor do primeiro parafuso e espalhada ao redor da região do fragmento. No grupo M2D apresenta um valor de Tensão Mínima Principal de $-626,30$ kPa mostrando que as regiões mais solicitadas são espalhadas ao redor da região do fragmento no osso trabecular. No grupo M3D apresenta um valor de Tensão Mínima Principal de $-467,00 \mathrm{kPa}$, mostrando que as regiões mais solicitadas são ao redor do primeiro parafuso e na região superior do fragmento. No grupo M4D apresenta um valor de Tensão Mínima Principal de $227,83 \mathrm{kPa}$, mostrando que as regiões mais solicitadas são ao redor do primeiro parafuso e pouco na região do fragmento. No grupo M5D apresenta um valor de Tensão Mínima Principal de $-256,86 \mathrm{kPa}$, mostrando que as regiões mais solicitadas são ao redor do primeiro parafuso e na região do osso cortical do fragmento. No grupo M6D apresenta um valor de Tensão Mínima Principal de $-599,01 \mathrm{kPa}$, mostrando que as regiões mais solicitadas foram ao redor do primeiro parafuso e na região do fragmento na parte cortical. 
A figura 46 ilustra a vista axial Tensão Máxima Principal, observadas nos modelos para o ensaio de compressão para uma $\mathrm{F}=60 \mathrm{~N}$

Figura 46. Comparações da Tensão Mínima Principal vista axial corte no local do fragmento em que o gancho entra, demonstrando pelas setas os pontos de tensão: seta verde ( 4 ) na região ao redor do fragmento, seta azul 4 ) região ao redor do primeiro parafuso e locais de contato osso placa.
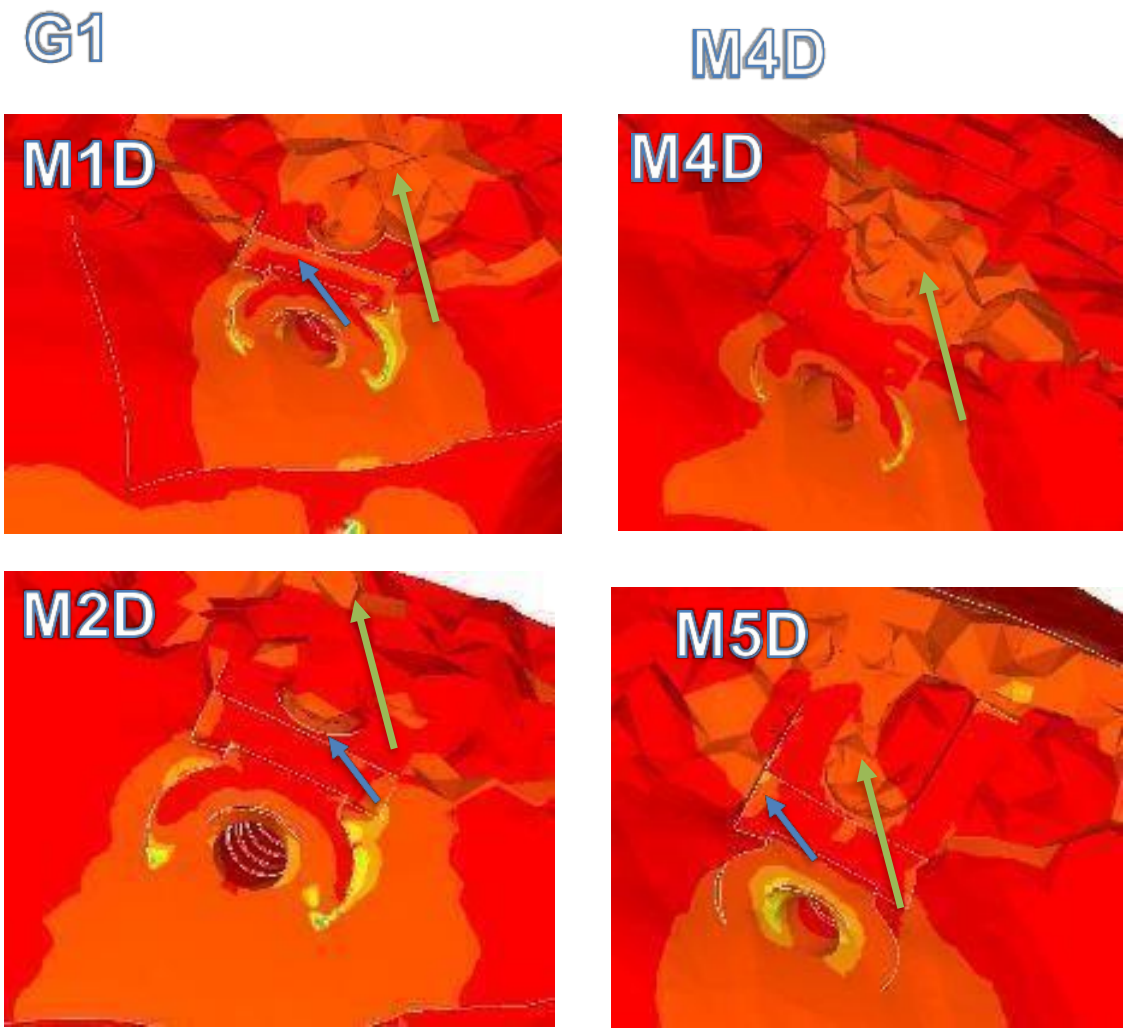

$-15.93$

$-19.71$

$-23.50$

$-27.29$

$-31.07$
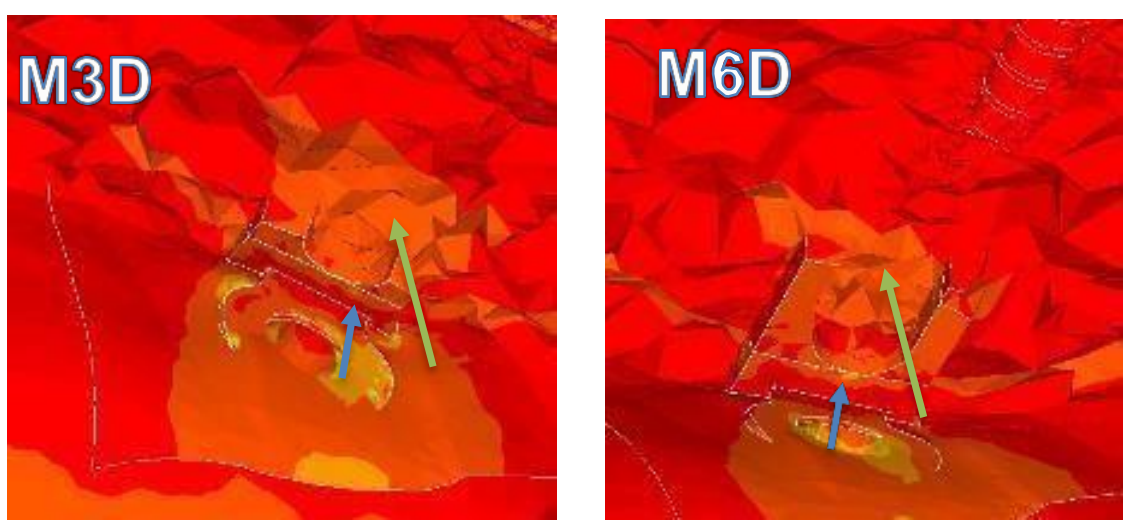

$-34.86$

$-38.64$

$-42.43$

$-46.21$

$-50.00$

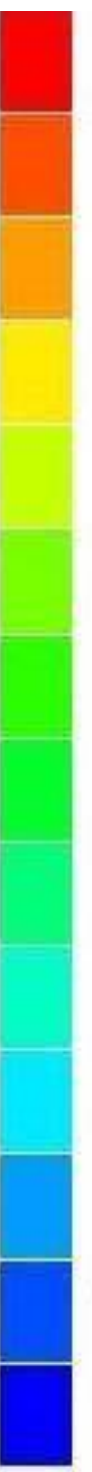


No grupo M1D apresenta um valor de Tensão Mínima Principal de -297,22 $\mathrm{kPa}$ mostrando que as regiões mais solicitadas do osso são os pontos de fixação do gancho a placa seta verde $8,36 \mathrm{kPa}$ e ao redor do primeiro parafuso seta azul 0,79 kPa. No grupo M2D apresenta um valor de Tensão Mínima Principal de -626,30 kPa mostrando que as regiões mais solicitadas estão ao redor do gancho nos pontos de ancoragem osso placa seta verde $-4,57 \mathrm{kPa}$ e ao redor do primeiro parafuso seta azul 0,79 kPa. No grupo M3D apresenta um valor de Tensão Mínima Principal de $467,00 \mathrm{kPa}$, mostrando que as regiões mais solicitadas são ao redor do gancho na parte final do mesmo nas regiões de apoio osso placa seta verde $-4,57 \mathrm{kPa}$ e ao redor do primeiro parafuso $8,36 \mathrm{kPa}$. No grupo M4D apresenta um valor de Tensão Mínima Principal de $-227,83 \mathrm{kPa}$, mostrando que as regiões mais solicitadas são ao redor do gancho, mais acentuadas em seu final seta verde $-0,79 \mathrm{kPa}$. No grupo M5D apresenta um valor de Tensão Mínima Principal de -256,86 kPa, mostrando que as regiões mais solicitadas são ao redor do gancho, mais acentuada entre os ganchos seta verde $-4,57 \mathrm{kPa}$ e ao redor do primeiro parafuso seta azul $-4,57 \mathrm{kPa}$. No grupo M6D apresenta um valor de Tensão Mínima Principal de $-599,01 \mathrm{kPa}$, mostrando que as regiões mais solicitadas ao redor do gancho, mais para seu final seta verde $-0,79 \mathrm{kPa}$ e ao redor do primeiro parafuso seta azul $-8,36 \mathrm{kPa}$. 
A figura 47 ilustra a vista dorsal apresentando a Tensão Equivalente de Von Mises, observadas nos modelos para o ensaio de compressão para uma $F=60 \mathrm{~N}$.

Figura 47. Comparações da Tensão Mínima Principal vista axial corte no local do fragmento em que o gancho entra, demonstrando pelas setas os pontos de tensão: seta laranja ( 4 ) região da curvatura do gancho, seta vermelha 4 ) região do primeiro parafuso, seta preta

( $\uparrow$ ) região do segundo

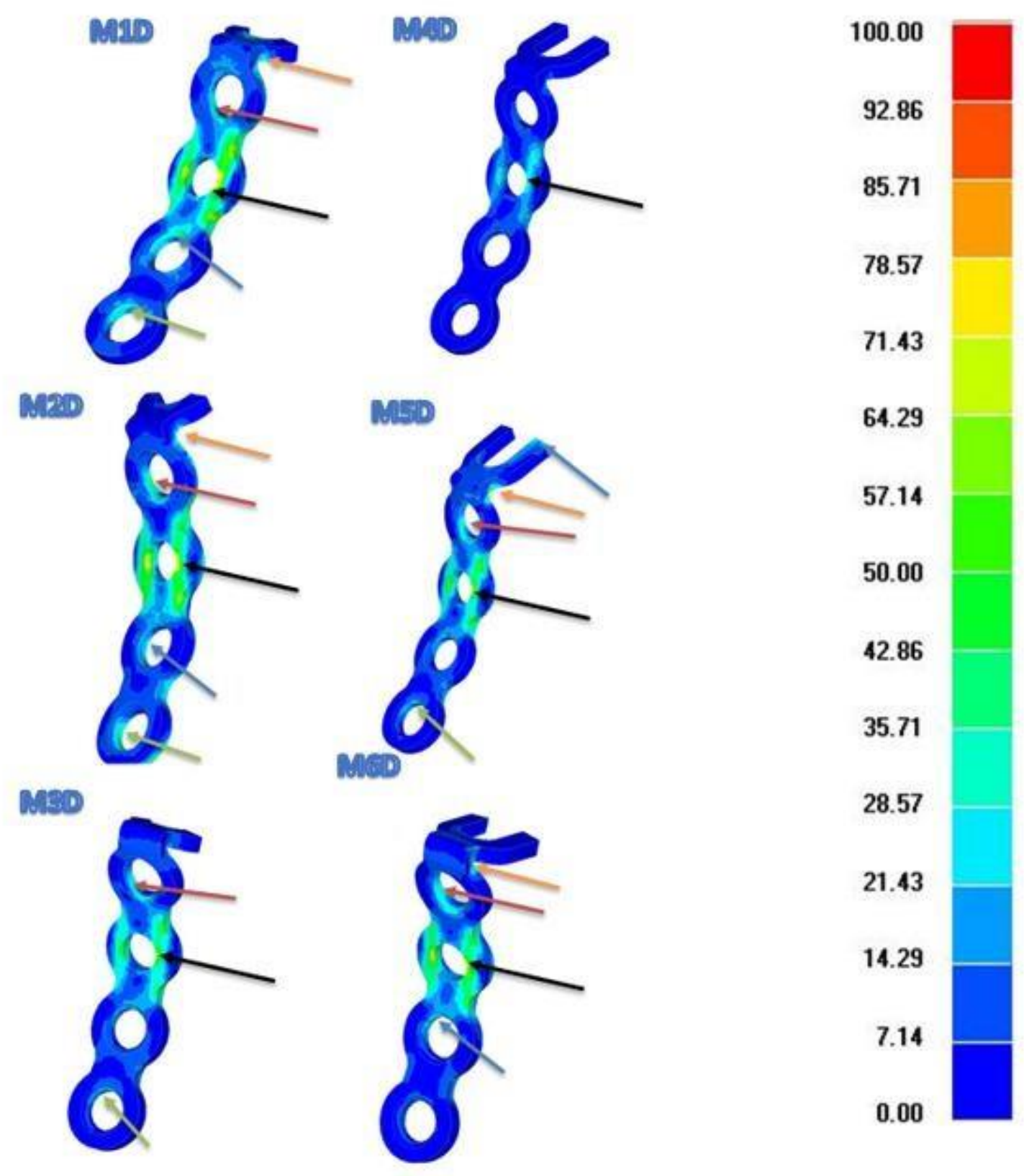

afuso, seta azul ( ) região onde não tem parafuso (terceiro orifício da placa), seta verde ( ) região do terceiro parafuso. 
No grupo M1D apresenta um valor de Tensão Equivalente de Von Mlses 290,58 kPa mostrando que as regiões mais solicitadas são na região do gancho seta laranja $35,71 \mathrm{kpa}$, no primeiro parafuso seta vermelha $28,57 \mathrm{kPa}$, segundo furo da placa seta preta $85,71 \mathrm{kPa}$, segundo parafuso seta azul $35,71 \mathrm{kPa}$, terceiro parafuso seta verde 28,57 kPa.. No grupo M2D apresenta um valor de Tensão Equivalente de Von Mises de 633,30 kPa mostrando que as regiões mais solicitadas são na região do gancho seta laranja $35,71 \mathrm{kpa}$, no primeiro parafuso seta vermelha $78,57 \mathrm{kPa}$, segundo furo da placa seta preta $85,71 \mathrm{kPa}$, segundo parafuso seta azul $28,57 \mathrm{kPa}$, terceiro parafuso seta verde $21,43 \mathrm{kPa}$. No grupo M3D apresenta um valor de Tensão Equivalente de Von Mises de 504,37 kPa, mostrando que as regiões mais solicitadas são na região do gancho seta laranja $28,57 \mathrm{kpa}$, no primeiro parafuso seta vermelha $21,43 \mathrm{kPa}$, segundo furo da placa seta preta $28,57 \mathrm{kPa}$, terceiro parafuso seta verde $21,43 \mathrm{kPa}$. No grupo M4D apresenta um valor de Tensão Equivalente de Von Mises de 247,63 kPa, mostrando que as regiões mais solicitadas são na região do segundo furo seta preta 21,43 $\mathrm{kPa}$. No grupo M5D apresenta um valor de Tensão Equivalente de Von Mises de 259,47 kPa, mostrando que as regiões mais solicitadas são na região do gancho seta laranja $35,71 \mathrm{kpa}$, no primeiro parafuso seta vermelha $28,57 \mathrm{kPa}$, segundo furo da placa seta preta 85,71 $\mathrm{kPa}$, ponta do gancho seta azul $35,71 \mathrm{kPa}$, terceiro parafuso seta verde $28,57 \mathrm{kPa}$. M6D apresenta um valor de Tensão Equivalente de Von Mises de 602,22 kPa, mostrando que as regiões mais solicitadas são na região do gancho seta laranja $28,57 \mathrm{kpa}$, no primeiro parafuso seta vermelha $28,57 \mathrm{kPa}$, segundo furo da placa seta preta $85,71 \mathrm{kPa}$, segundo parafuso seta azul $35,71 \mathrm{kPa}$.

As figuras ilustram a vista frontal apresentando a Tensão Equivalente de Von Mises, observadas nos modelos para o ensaio de compressão para uma $F=60$ $\mathrm{N}$. 
A figura 48 ilustra a vista dorsal apresentando a Tensão Equivalente de Von Mises, observadas nos modelos para o ensaio de compressão para uma $F=60 \mathrm{~N}$.

Figura 48. Comparações da Tensão Mínima Principal vista axial corte no local do fragmento em que o gancho entra, demonstrando pelas setas os pontos de tensão: seta laranja ( $\hat{\imath}$ ) região da curvatura do gancho, seta vermelha ( $\uparrow)$ região do primeiro parafuso, seta preta $\uparrow$ ) região do segundo parafuso, seta azul 4 ) região onde não tem parafuso (terceiro orifício da placa), seta verde 4 ) região do terceiro parafuso.

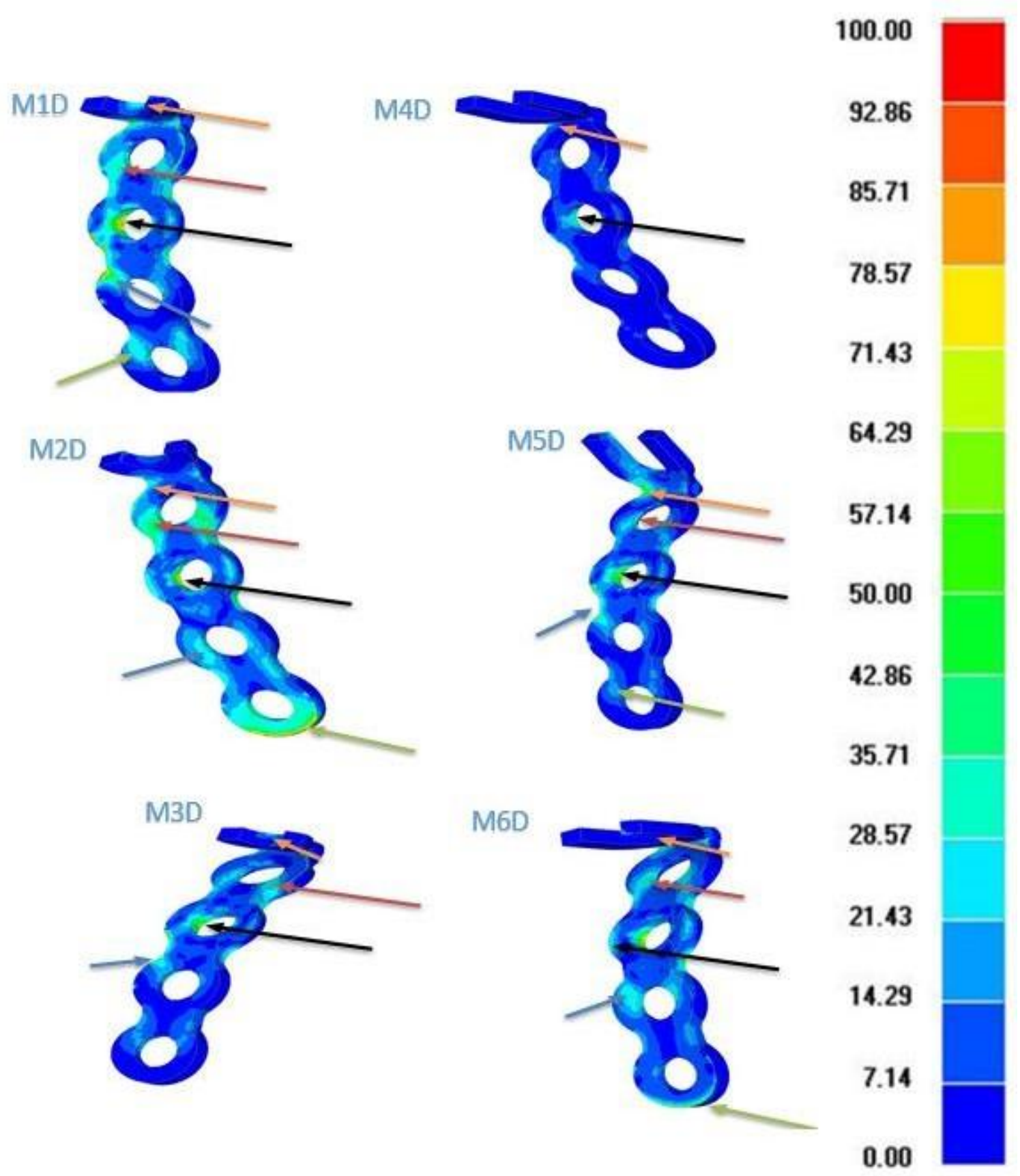


No grupo M1D apresenta um valor de Tensão Equivalente de Von Mises 290,58 kPa mostrando que as regiões mais solicitadas são nas regiões entre os ganchos seta laranja $28,57 \mathrm{kPa}$, região do primeiro parafuso seta vermelha $50 \mathrm{kPa}$, região do segundo furo da placa seta preta 92,86, região do segundo parafuso seta azul $28,57 \mathrm{kPa}$ e região do terceiro parafuso seta verde $21,43 \mathrm{kPa}$. No grupo M2D apresenta um valor de Tensão Equivalente de Von Mises de 633,30 kPa mostrando 
que as regiões mais solicitadas são nas regiões nos ganchos seta laranja 21,43 kPa, região do primeiro parafuso seta vermelha $35,71 \mathrm{kPa}$, região do segundo furo da placa seta preta $71,43 \mathrm{kPa}$, região do segundo parafuso seta azul $21,43 \mathrm{kPa}$ e região do terceiro parafuso seta verde $92,86 \mathrm{kPa}$. No grupo M3D apresenta um valor de Tensão Equivalente de Von Mises de $504,37 \mathrm{kPa}$, mostrando que as regiões mais solicitadas são nas regiões entre os ganchos seta laranja $28,57 \mathrm{kPa}$, região do primeiro parafuso seta vermelha $28,57 \mathrm{kPa}$, região do segundo furo da placa seta preta $21,43 \mathrm{kPa}$, região do segundo parafuso seta azul $28,57 \mathrm{kPa}$. No grupo M4D apresenta um valor de Tensão Equivalente de Von Mises de 247,63 kPa, mostrando que as regiões mais solicitadas são nas regiões entre os ganchos seta laranja 14,29 $\mathrm{kPa}$, região do segundo furo da placa seta preta $21,43 \mathrm{kPa}$. No grupo M5D apresenta um valor de Tensão Equivalente de Von Mises de 259,47 kPa, mostrando que as regiões mais solicitadas são na ancoragem osso placa e na curvatura do gancho. No grupo M6D apresenta um valor de Tensão Equivalente de Von Mises de $602,22 \mathrm{kPa}$, mostrando que as regiões mais solicitadas são nas regiões dos ganchos seta laranja $28,57 \mathrm{kPa}$, região do primeiro parafuso seta vermelha 21,43 $\mathrm{kPa}$, região do segundo furo da placa seta preta $28,57 \mathrm{kPa}$, região do segundo parafuso seta azul $28,57 \mathrm{kPa}$ e região do terceiro parafuso seta verde $21,43 \mathrm{kPa}$. 
A figura 49 ilustra a vista dos parafusos apresentando a Tensão Equivalente de Von Mises, observadas nos modelos para o ensaio de compressão para uma $\mathrm{F}=$ $60 \mathrm{~N}$.

Figura 49. Comparações da Tensão Equivalente de Von Mises demonstrando pelas setas os pontos de tensão: seta laranja ( 4 ) região de passos de rosca primeiro parafuso, seta vermelha $(\uparrow)$ região da haste e cabeça primeiro parafuso, seta preta ( $\uparrow$ )região dos passos de rosca segundo parafuso, seta azul 4 ) região haste e cabeça terceiro parafuso 4 ) região dos passos de rosca terceiro parafuso.
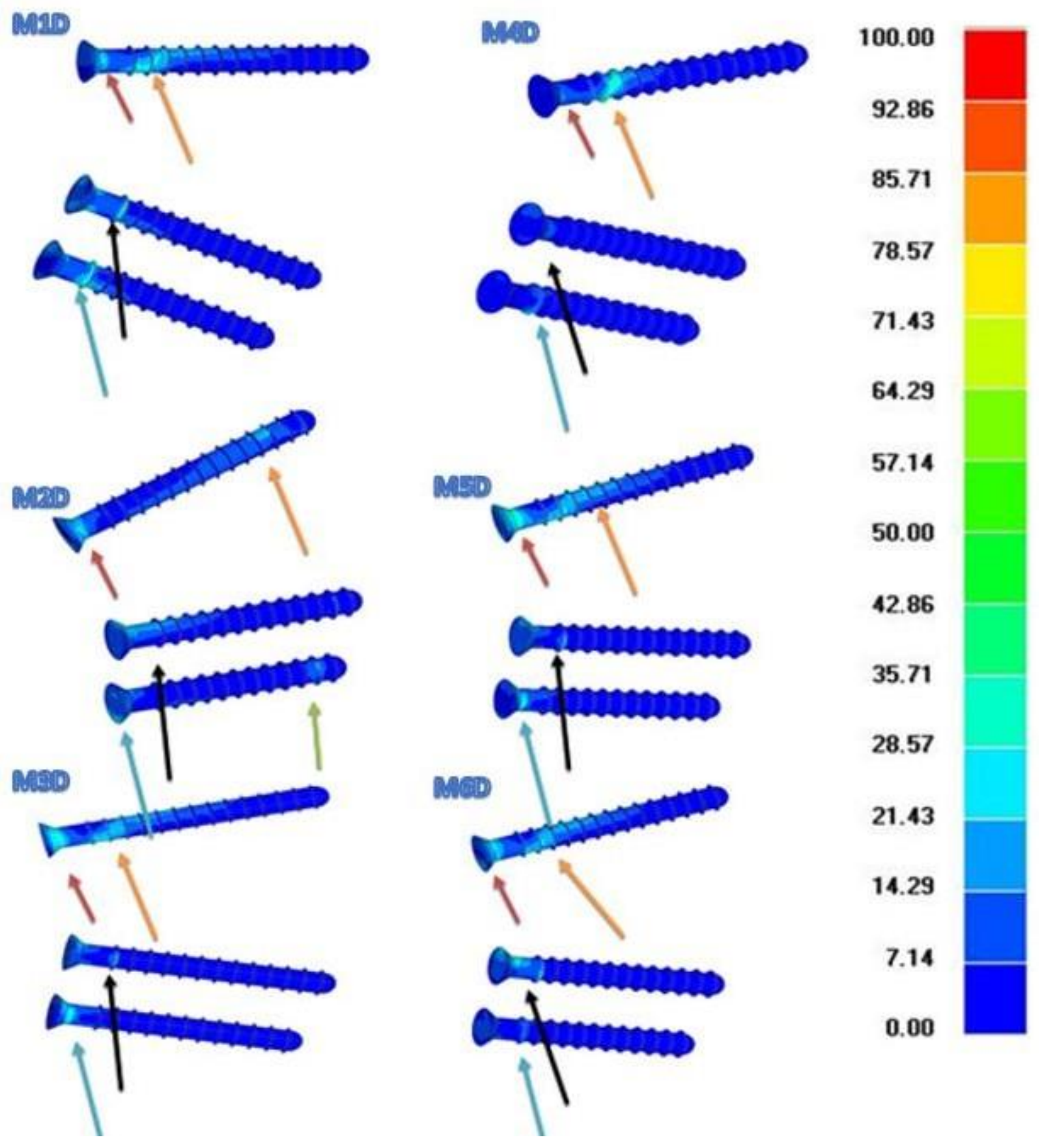
No grupo M1D apresenta um valor de Tensão Equivalente de Von Mises $290,58 \mathrm{kPa}$ mostrando que as regiões mais solicitadas são no primeiro parafuso próximo a cabeça na haste seta vermelha $28,57 \mathrm{kPa}$ e no meio seta laranja 21,43 $\mathrm{kPa}$, para o segundo parafuso seta preta $21,43 \mathrm{kPa}$ e terceiro parafuso observamos próxima a cabeça e na haste seta azul $35,71 \mathrm{kPa}$. No grupo M2D apresenta um valor de Tensão Equivalente de Von Mises de 633,30 kPa mostrando que as regiões mais solicitadas são no primeiro parafuso próximo a cabeça na haste seta vermelha $28,57 \mathrm{kPa}$ e no meio seta laranja $14,29 \mathrm{kPa}$, para o segundo parafuso seta preta $14,29 \mathrm{kPa}$ e terceiro parafuso observamos próxima a cabeça e na haste seta azul $14,29 \mathrm{kPa}$, no fim do terceiro parafuso seta verde $14,29 \mathrm{kPa}$. No grupo M3D apresenta um valor de Tensão Equivalente de Von Mises de 504,37 kPa, mostrando que as regiões mais solicitadas são no primeiro parafuso próximo a cabeça na haste seta vermelha $28,57 \mathrm{kPa}$ e no meio seta laranja $21,43 \mathrm{kPa}$, para o segundo parafuso seta preta $14,29 \mathrm{kPa}$ e terceiro parafuso observamos próxima a cabeça e na haste seta azul 35,71 kPa. No grupo M4D apresenta um valor de Tensão Equivalente de Von Mises de $247,63 \mathrm{kPa}$, mostrando que as regiões mais solicitadas são no primeiro parafuso próximo a cabeça na haste seta vermelha $21,43 \mathrm{kPa}$ e no meio seta laranja $21,43 \mathrm{kPa}$, para o segundo parafuso seta preta $7,14 \mathrm{kPa}$ e terceiro parafuso observamos próxima a cabeça e na haste seta azul 14,29 $\mathrm{kPa}$. M5D apresenta um valor de Tensão Equivalente de Von Mises de 259,47 kPa, mostrando que as regiões mais solicitadas são no primeiro parafuso próximo a cabeça na haste seta vermelha $28,57 \mathrm{kPa}$ e no meio seta laranja $21,43 \mathrm{kPa}$, para o segundo parafuso seta preta $14,29 \mathrm{kPa}$ e terceiro parafuso observamos próxima a cabeça e na haste seta azul 28,57 kPa. No grupo M6D apresenta um valor de Tensão Equivalente de Von Mises de $602,22 \mathrm{kPa}$, mostrando que as regiões mais solicitadas são no primeiro parafuso próximo a cabeça na haste seta vermelha $28,57 \mathrm{kPa}$ e no meio seta laranja $28,57 \mathrm{kPa}$, para o segundo parafuso seta preta $21,43 \mathrm{kPa}$ e terceiro parafuso observamos próxima a cabeça e na haste seta azul 7,14 kPa. 
A figura 50 ilustra a vista frontal apresentando a Tensão Equivalente de Von Mises, observadas nos modelos para o ensaio de compressão para uma $\mathrm{F}=60 \mathrm{~N}$.

Figura 50. Comparações da Tensão Equivalente de Von Mises demonstrando pelas setas os pontos de tensão: seta vermelha ( $\uparrow$ ) região de contato parafuso placa, seta preta ( $\uparrow$ )região da cabeça do parafuso.
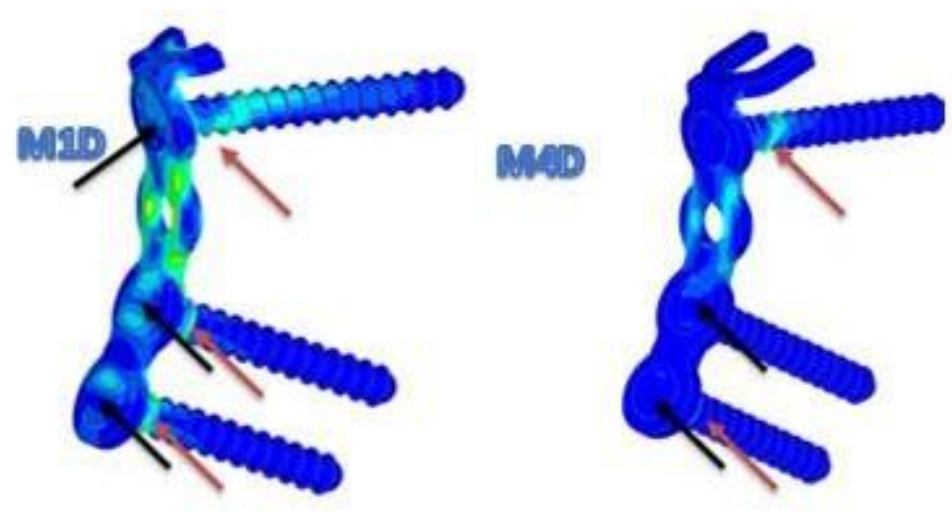

100.00

92.86

85.71

78.57

71.43
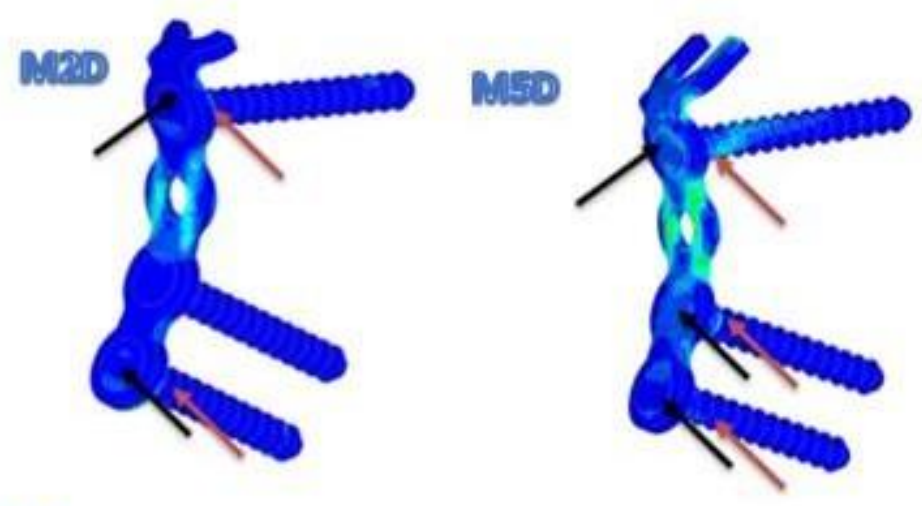

64.29

57.14

50.00

42.86

35.71

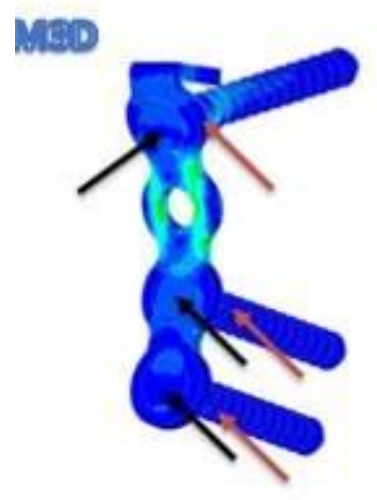

MED

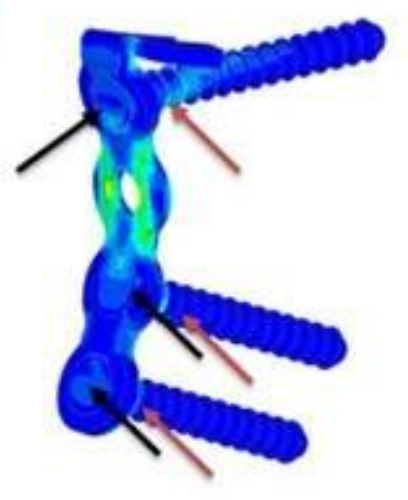

28.57

21.43

14.29

7.14

0.00 
No grupo M1D apresenta um valor de Tensão Equivalente de Von Mises 290,58 kPa mostrando que as regiões mais solicitadas são nos locais onde se tocam parafuso e placa seta vermelha $28,57 \mathrm{kPa}$, na cabeça de todos os parafusos seta preta 14,29 kPa. No grupo M2D apresenta um valor de Tensão Equivalente de Von Mises de 633,30 kPa mostrando que as regiões mais solicitadas são nos locais onde se tocam parafuso e placa seta vermelha $14,29 \mathrm{kPa}$, na cabeça de todos os parafusos seta preta 7,14 $\mathrm{kPa}$. No grupo M3D apresenta um valor de Tensão Equivalente de Von Mises de 504,37 kPa, mostrando que as regiões mais solicitadas são nos locais onde se tocam parafuso e placa seta vermelha $14,29 \mathrm{kPa}$, na cabeça de todos os parafusos seta preta 7,14 kPa. M4D apresenta um valor de Tensão Equivalente de Von Mises de 247,63 kPa, mostrando que as regiões mais solicitadas são na região de contato parafuso placa $28,57 \mathrm{kPa}$ e na cabeça do segundo parafuso $7,14 \mathrm{kPa}$. No grupo M5D apresenta um valor de Tensão Equivalente de Von Mises de 259,47 kPa, mostrando que as regiões mais solicitadas são na região de contato parafuso placa $28,57 \mathrm{kPa}$ e na cabeça de todos os parafusos $7,14 \mathrm{kPa}$. No grupo M6D apresenta um valor de Tensão Equivalente de Von Mises de 602,22 $\mathrm{kPa}$, mostrando que as regiões mais solicitadas são na região de contato parafuso placa $21,43 \mathrm{kPa}$ e na cabeça de todos os parafusos $7,14 \mathrm{kPa}$.

\subsection{Comparação de Angulação}

Das radiografias feitas foram analisadas a angulação do gancho de cada placa dos modelos M1F, M2F e M3F para comparação da angulação (Figura $50 \mathrm{~A}$, $B, C, D, E, F)$. 
Figura 51. Comparações das angulações através de radiografias do rádio antes e depois do Ensaio Mecânico de Compressão Axial: A, C e E antes do Ensaio Mecânico; B, D e F depois do Ensaio Mecânico.
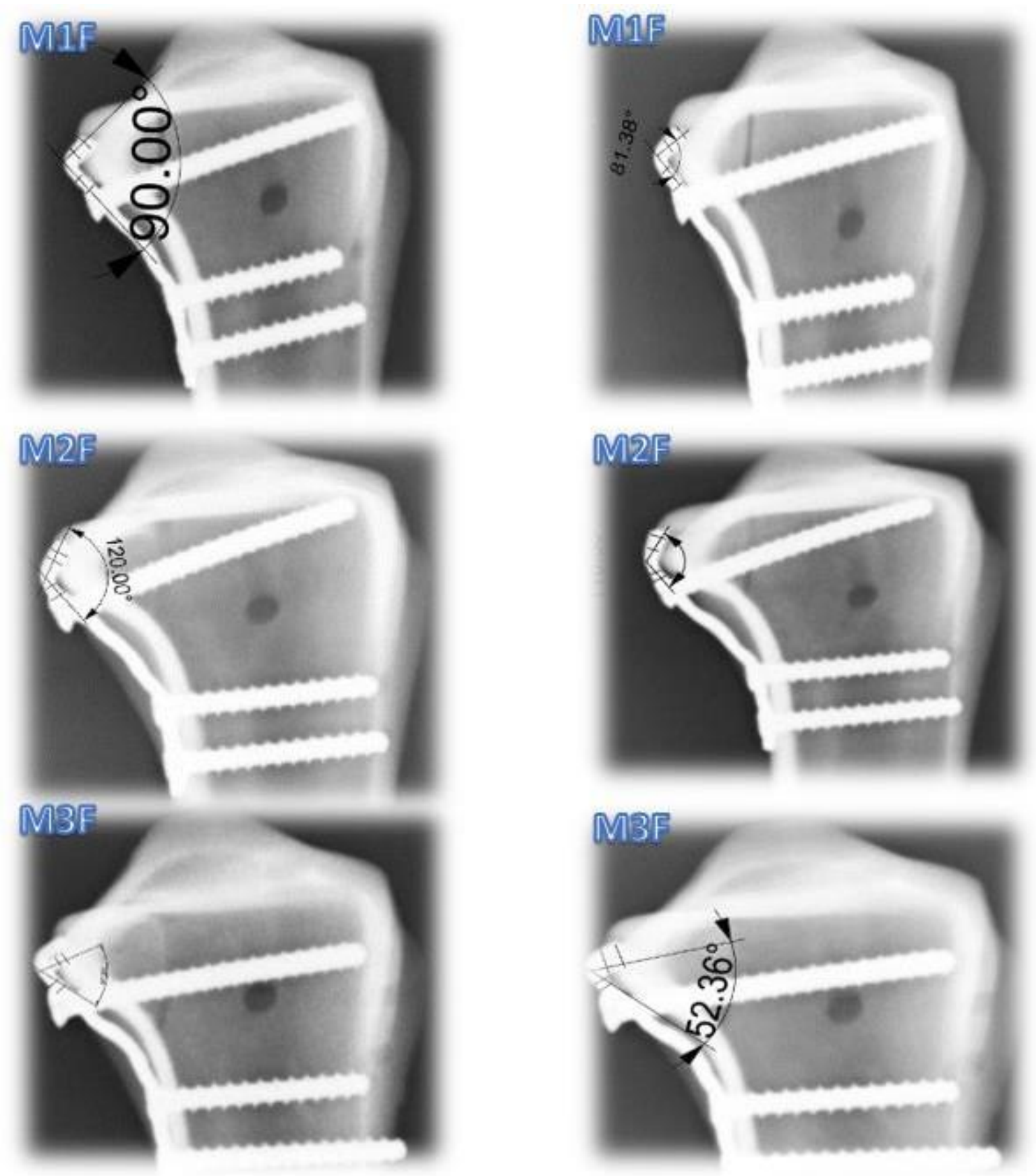
Podemos observar os valores das angulações antes e depois do ensaio mecânico no quadro a seguir

Quadro 3. Comparação das angulações antes e depois

\begin{tabular}{|c|c|c|c|}
\hline & \multicolumn{2}{|c|}{ Angulação $^{\circ}$} & \\
\hline Grupos & antes & depois & Diferença $\%$ \\
\hline M1D e M1F & $90,00^{\circ}$ & $81,38^{\circ}$ & $10,59 \%$ \\
\hline M2D e MF & $120,00^{\circ}$ & $116,33^{\circ}$ & $3,15 \%$ \\
\hline M3D e M3F & $60,00^{\circ}$ & $52,36^{\circ}$ & $14,59 \%$ \\
\hline
\end{tabular}

Podemos observar que após a compressão axial dos grupos todos acabaram tendo a diminuição da angulação, com isso ocorrendo o deslocamento do gancho juntamente ao conjunto osso placa e parafusos. 
6.Discussão 



\section{DISCUSSÃO}

Os fatores que mais contribuem para o sucesso e evolução do uso do Método dos Elementos Finitos estão relacionados aos conceitos obrigatórios da utilização do MEF. Entretanto, uma vasta gama de profissionais das áreas das ciências exatas e biológicas encontram dificuldades inicialmente em seus trabalhos, pelo fato de tratar-se de um método matemático complexo em que se faz o uso de modelagem de problemas com um número finito de variáveis (VILARINHO, 2000).

Frequentemente, o estudo é de tal ordem de grandeza em técnicas matemáticas que, no decorrer do tempo surge a dúvida de onde aplicar tal conceito na prática, são recomendados os fundamentos conceituais necessários visando a utilização do MEF. É obrigatório o envolvimento de profissionais das áreas da saúde e das ciências exatas para se ter o desenvolvimento da técnica e conseguir modelos tridimensionais o mais confiável possível.

Vemos que as dificuldades maiores encontradas no trabalho foram na confecção dos modelos tridimensionais, uma vez que estes apresentavam irregularidades constantes pelo fato do osso ser uma superfície não homogênea. Com relação às placas, as dificuldades foram na variação do tamanho de ganchos e angulações, pois todos os grupos se diferenciavam pelo comprimento do gancho ou pela sua variação angular. $\mathrm{Na}$ simulação as dificuldades encontradas relacionadas foram feitas ao menos dez vezes para cada grupo para se ter a exatidão dos valores. Foram assumidos os valores da força de compressão através da média dos valores obtidos nos ensaios mecânicos de cisalhamento.

A fratura da extremidade distal do rádio com a presença de um fragmento específico denominado canto volar ulnar do semilunar é uma lesão incomum, que pela falta de estabilização deste fragmento acarreta a luxação rádiocárpica e/ou luxação da rádio-ulnar distal, por estarem inseridos neste osso os ligamentos rádio semilunar curto e o ligamento volar rádio-ulnar distal. $O$ tratamento deve ser instituído a redução anatômica, a fixação estável e a mobilização precoce do punho e antebraço para evitar possíveis incapacidades provocadas por consolidação viciosa ou por imobilização LIU et al., 2014). 
A indicação da placa gancho se dá pelo fato da placa volar não garantir a devida fixação e redução do fragmento de tamanho específico e com características peculiares (HARNES, 2004). Para evitar a complicação da subluxação do carpo volar são necessários os cuidados pré-operatórios e intraoperatório de vigilância clínica e radiográfica para visualizar o fragmento da faceta lunar volar e sua fixação adequada. Por causa da anatomia irregular desse fragmento, é difícil conseguir uma fixação adequada usando a fixação com uma placa volar (ANDERMAHR, 2006). A extensão volar da faceta lunar do rádio distal parece particularmente vulnerável às forças de cisalhamento e a dificuldade em assegurar que este fragmento está instável. Placas volares padrão podem não garantir o controle adequado deste fragmento, mesmo quando colocados suficientemente distais. (HARNES et al., 2004).

O tratamento dessas fraturas é auxiliado pela identificação precisa da morfologia única do fragmento usando radiografias simples ou imagens adicionais com tomografias computadorizadas bidimensionais e tridimensionais, seguidas por uma abordagem para permitir a visualização adequada da fratura (ANDERMAHR, 2006). Diante disso, a escolha da placa de redução e fixação com gancho variável poderia ser uma grande opção de escolha pré-cirúrgica, pois o gancho varia em comprimento e angulo de acordo com o tamanho do fragmento em questão traria maiores opções de travamento do mesmo. Assim, disso todas essas superfícies tiveram que ser revisadas e muitas vezes redesenhadas para que o programa de Elementos Finitos conseguisse reconhecê-las, o que gerou uma fase de muito trabalho e estudo, pois em cada tipo de fixação havia duas variáveis que mudavam ângulo e comprimento.

No Método dos Elementos Finitos devemos assumir alguns conceitos de condições de contorno do osso, no caso dos sólidos osso, placa, parafusos foram feitas as condições de contato respeitando as condições de contorno impostas sendo coladas ou deslizantes, os carregamentos aplicados nos modelos foram valores de $10 \mathrm{~N}$ a $60 \mathrm{~N}$ com variação de $10 \mathrm{~N}$ de uma simulação para outra. Com isso foi possível fazer a comparação do MEF com o Ensaio Mecânico. Também foram feitas as comparações de todos os grupos na simulação pelo MEF em deslocamento, Tensão Máxima Principal, Tensão Mínima Principal e Tensão Equivalente de Von Mises. 
A construção de modelos virtuais $3 \mathrm{D}$ do sistema de fixação do rádio juntamente com o uso do MEF proporciona visualização e avaliação das tensões. Para validação dos modelos, ensaios mecânicos de cisalhamento foram realizados para validação do modelo. Segundo estudo de Hsu et al. (2005) divergências de até $20 \%$ são aceitas entre o ensaio mecânico e os resultados do MEF.

Modelos estes foram reconhecidos pelo programa de simulação, exigido a estes a geração das malhas, com isso foram verificados os elementos e nós gerados, as partes de contato parafuso placa e placa parafuso foram feitos 0 refinamento do contato das superfícies para se ter o mais próximo ao real possível eliminando as deformidades.

Dividimos em seis grupos em que variavam o tamanho de gancho de $3 \mathrm{~mm}$ e $6 \mathrm{~mm}$, de comprimento variavam angulação de $60^{\circ}, 90^{\circ}$ e $120^{\circ}$, na comparação dos grupos em relação ao deslocamento percebemos que o grupo M4D, que possui $6 \mathrm{~mm}$ de tamanho de gancho e angulação de $90^{\circ}$ em relação à placa, mostrou 0 menor deslocamento dentre todos os outros grupos, na comparação do subgrupo de $3 \mathrm{~mm}$ observamos que o grupo de menor deslocamento foi o grupo M3D que possuía $3 \mathrm{~mm}$ de gancho e angulação de menor que $90^{\circ} \mathrm{em}$ relação à placa.

A análise pelo MEF é uma ferramenta complementar para avaliar a viabilidade, eficácia e biomecânica global características de diferentes técnicas. Apesar dos ensaios clínicos poderiam resumir os resultados gerais diferentes métodos de fixação, muitas questões fundamentais ainda permanecem controversas e pouco compreendidas. Frequentemente, investigações científicas são simuladas pela introdução de novos dispositivos de tratamento. Contudo, investigações sistemáticas são necessárias para testar os princípios de tratamento. A análise pelo MEF é elementar, técnica de simulação que pode monitorar o estresse e respostas biomecânicas de diferentes tratamentos sem influência clínica (SORIANO, 2003).

A influência da variação de angulação e comprimento de gancho tem se mostrado de grande valia, pois percebemos que há variação de tensões e deslocamentos nos modelos. Sendo que no estudo foi utilizado para validar os modelos o ensaio mecânico de compressão, em que foi estudada a região da fase elástica do gráfico Força $(\mathrm{N}) \times$ Deslocamento $(\mathrm{mm})$, podendo ser observado que sua fase elástica é preservada, sendo na parte plástica observamos a deformação do material. 
Ao se aplicar a força, é possível observar o deslocamento do conjunto osso placa e parafusos. Os valores de mínima tensão equivalente ocorrem nesta região. A concentração de tensão nesta área pode acarretar na falha do sistema, ao se atingir a força máxima.

Ao se avaliar o deslocamento em cada modelo, observamos que com o aumento do comprimento do gancho e angulação de $90^{\circ}$ obtivemos o menor deslocamento apresentado pelo grupo M4D com $6 \mathrm{~mm}$ de comprimento e angulação de $90^{\circ}$. Este fato pode acontecer pelo maior apoio do gancho e angulação de $90^{\circ}$ garantir maior estabilidade do sistema, observamos o maior deslocamento para o M2D com a presença de gancho de $3 \mathrm{~mm}$ de comprimento e angulação superior a $90^{\circ}$.

Ao se observar a Tensão Máxima Principal em cada modelo, podemos ver que o grupo M4D foi o que apresentou a menor tensão, entretanto os grupos que apresentam maiores tensões são os grupos M3D e M6D o primeiro com gancho de 3 $\mathrm{mm}$ e $6 \mathrm{~mm}$ respectivamente ambos com a angulação menor que $90^{\circ}$, isso se dá pelo fato de que a maior tração acontece nos pontos de ancoragem osso e placa e com a presença dessa angulação que torna o gancho mais fechado, levando ao aumento da tensão máxima principal mostrando assim que o comprimento do gancho não interfere no aumento Tensão Máxima Principal e sim a angulação do gancho.

Ao se avaliar as a Tensão Mínima Principal em cada modelo, podemos observar que o grupo M4D foi o que apresentou o menor demonstrando que a angulação de $90^{\circ}$ e o gancho de $6 \mathrm{~mm}$ garantiram um menor estresse de compressão no osso e fragmento, entretanto os grupos que mais apresentaram Tensão Mínima Principal foram os grupos M2D e M6D pelo fato de apresentar maior solicitação na região de ancoragem do terceiro parafuso servindo assim o osso como um batente à placa, com isso podemos observar que a angulação de $90^{\circ}$ garantiu a menor Tensão Mínima Principal e o gancho com angulações menor ou maior que $90^{\circ}$ e que o gancho maior se mostrou superior àquele com tamanho menor. 
Ao se avaliar a Tensão Equivalente de Von Mises em cada modelo, podemos observar que o grupo M4D foi o que apresentou a menor tensão seguido do grupo M5D e M1D, entretanto os grupos que apresentaram maior tensão são os grupos M2D e M6D o primeiro com gancho de $3 \mathrm{~mm}$ e $6 \mathrm{~mm}$ respectivamente. Observamos que o gancho com menor tamanho leva na grande maioria ao aumento de regiões de tensão com e na variação da angulação tem se mostrado que o ângulo de $90^{\circ}$ tem garantido maior estabilidade em relação aos outros ângulos maiores ou menores.

A partir do momento que se realiza a fixação e redução da fratura o sistema fica sujeito a inúmeros tipos de técnicas cirúrgicas e escolha do tipo a ser usada. $O$ uso de novas metodologias e tecnologias são sempre bem vindos, havendo a necessidade de também associá-las a estudos clínicos de acompanhamento. 
7.Conclusão 



\section{CONCLUSÃO}

O conjunto M4D nos mostrou ser o melhor dentre os estudados, gerou maior estabilidade do sistema. O de pior resultado de estabilidade foi o grupo M2D.

Podemos observar em todos os modelos que o ponto de maior Tensão Equivalente de Von Mises foi na região onde não se tem parafuso, gerando assim um estresse e possível falha do material.

Os ganchos de angulação de $90^{\circ}$ pela estabilidade do ângulo e comprimento de $6 \mathrm{~mm}$ garantiram maior estabilidade, menor tensão, e menores deslocamentos do sistema.

Possibilidade de variação do comprimento do gancho para valores superiores aos apresentados no presente estudo, para futuros trabalhos. 


ALLURI, R. K.; HILL, J. R.; GHIASSI, A. Distal Radius Fractures: Approaches, Indications, and Techniques. Journal of Hand Surgery, v. 41, n. 8, p. 845-854, 2016 Aug.

Andermahr J, Lozano-Calderon S, Trafton T, Crisco JJ, Ring D. The volar extension of the lunate facet of the distal radius: a quantitative anatomic study. J Hand Surg Am 2006;31(6):892-895.

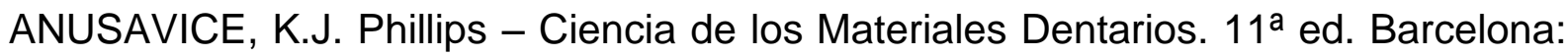
Elsevier Saunders, 2005. p. 79-85.

Beck JD, Harness NG, Spencer HT. Volar plate fixation failure for volar hearing distal radius fractures with small lunate facet fragments. J Hand Surg Am 2014;39(4):670678.

BORIE, E.A.E. Análise biomecânica por meio de elementos finitos da distribuição de tensões em implantes e osso perimplantar com diferentes diâmetros e comprimentos posicionados na região anterior da maxila. Dissertação (Mestrado) - USP, Ribeirão Preto, 2013.

CATTANEO, P.M.; DALSTRA, M.; MELSEN, B. The finite element method: a tool to study orthodontic tooth movement. J. Dent. Res., v.84, n.5, p.428-433, maio, 2005.

CHIN, K. R.; JUPITER, J. B. Wire-loop fixation of volar displaced steochondral fractures of the distal radius. Journal of Hand Surgery, v. 24, n. 3, p. 525-533, 1999.

CHU, C.M.; HUANG, H.L.; HSU, J.T.; FUH, L.J. Influences of internal tapered abutment designs on bone stresses around a dental implant: three-dimensional finite element method with statistical evaluation. J. Periodontol., v.83, n.1, p. 111-118, jan, 2012.

current concepts. J Hand Surg Am, v. 37, p. 1718-1725, 2012

DARVELL, B.W. Ciência dos materiais para Odontologia restauradora. 9a ed.São Paulo: Santo, 2012. p.4-11.

DEJAK, B.; MLOTKOWSKI, A. Three-dimensional finite element analysis of strength and adhesion of composite resin versus ceramic inlays in molars. Journal of Prosthetic Dentistry, v. 99, n. 2, p. 131-140, 2008.

DETOLLA, D. H ET AL. Role of the finite element model in dental implants. Journal of Oral Implantol, v. 26, n. 2 p. 77-81, 2000.

DONATO, G. H. B.; BIANCHI, M. Numerical modeling of uneven thermoplastic polymers behaviour using experimental stress-strain data and pressure dependent von Mises yield criteria to improve design practices. Procedia Engineering, v. 10, p. 1871-1876, 2011. 
EDWARDS, W.B.; TROY, K.L. Finite element prediction of surface strain and fracture strength at the distal radius. Medical Engineering \& Physics, v. 34, p. 290-298, 2012.

Gerostathopoulos N, Kalliakmanis A, Fandridis E, et al. Trimed fixation system for displaced fractures of the distal radius. JTrauma. 2007;62:913-8.

GOEL, V. K.; PANJABI, M. M.; PATWARDHAN, A. G.; DOORIS, A. P.; SERHAN,H. Tests Protocols for Evaluation of Spinal Implants. Journal of Bone and Joint Surgery (American), Boston, v. 88, p. 103-9, 2006. Supplement 2.

Grindel SI, Wang M, Gerlach M, McGrady LM, Brown S. Biomechanical comparison of fixed-angle volar plate versus fixed-angle volar plate plus fragment-specific fixation in a cadaveric distal radius fracture model. J Hand Surg Am. 2007; 32(2):194-9.

Harness NG, Jupiter JB, Orbay JL, Raskin KB, Fernandez DL. Loss of fixation of the volar lunate facet fragment in fractures of the distal part of the radius. $\mathbf{J}$ Bone Joint Surg 2004;86A:1900-1908.

HSU, C. C.;CHAO, C. K.; WANG, J. L.; HOU,S.M.; TSAI, Y. T.; LIN, T. Increase of pullout strenght of spinal pedicle screws of spinal pedicles screws with conical core: biomechanical tests and finite element analyses. Journal of Ortopaedic Reserch, New York, v.23, n. 4, p. 788-94, 2005.

HUANG, H.L.; HSU, J.T.; FUH, L.J.; TU, M.G.; KO, C.C.; SHEN, Y.W. Bone stress and interfacial sliding analysis of implant designs on an immediately loaded maxillary implant: a non-linear finite element study. J. Dent., v.36, n.6, p.409-417, jun, 2008.

Huiskes, R., Chao, E.Y.S., 1983. A survey of finite element analysis in orthopaedic biomechanics: the first decade. J. Biomech. 16, 385-409.

J. D. Beck, N. G. Harness, and H. T. Spencer, "Volar plate fixation failure for volar shearing distal radius fractures with small lunate facet fragments," Journal of Hand Surgery, vol. 39, no. 4, pp. 670-678, 2014.

K. R. Chin and J. B. Jupiter, "Wire-loop fixation of volar displaced osteochondral fractures of the distal radius," Journal of Hand Surgery, vol. 24, no. 3, pp. 525533, 1999.

KACHOOEI, A. R.; TARABOCHIA, M.; JUPITER, J. B. Distal Radius Volar Rim Fracture Fixation Using DePuy-Synthes Volar Rim Plate. Journal of wrist surgery, v. 5 , n. 1, p. 2-8, 2016.

KANBARA, R.; NAKAMURA, Y.; OCHIAI, K.T.; KAWAI, T.; TANAKA

, Y. Three-dimensional finite element stress analysis: the technique and methodology of non-linear property simulation and soft tissue loading behavior for different partial denture designs. Dent. Mater. J., v.31, n.2, p.297-308, mar, 2012.

KIHARA, $\mathrm{H}$. et al. The stabilizing mechanism of the distal radioulnar joint during pronation and supination. Journal of Hand Surgery, v. 20, n. 6, p. 930-936, 1995. 
Konrath GA, Bahler S. Open reduction and internal fixation of unstable distal radius fractures: results using the trimed fixation system. J Orthop Trauma. 2002;16:57885.

KORIOTH, T.W.; VERSLUIS, A. Modeling the mechanical behavior of the jaws and their related structures by finite element (FE) analysis. Crit. Rev. Oral Biol. Med. v.8, n.1, p.90-104, 1997.

LIMBERT, G.; VAN LIERDE, C.; MURARU, OL.; WALBOOMERS, XF.; FRANK, M.; HANSSON, S.; MIDDLETON, J.; JAECQUES, S. Trabecular bone strains around a dental implant and associated micromotions--a micro-CT-based three-dimensional finite element study. J. Biomech., v.43, n.7, p.1251-1261, maio, 2010.

LIU, X. et al. Biomechanical comparison of osteoporotic distal radius fractures fixed by distal locking screws with different length. PLoS One, v. 9, n. 7, p. e103371, 2014.

MACEDO, A.P. Uso do método de elementos finitos na análise biomecânica de parafusos do sistema de fixação vertebral. Dissertação (Mestrado) Faculdade de Medicina, Universidade de são Paulo, Ribeirão Preto - SP, 2009.

MATSUNAGA, S.; OKUDERA, H.; ABE, S.; TAMATSU, Y.; HASHIMOTO, M.; IDE, $Y$. The influence of bite force on the internal structure of the mandible through implant: three-dimensional and mechanical analysis using micro-CT and finite element method. J. Oral Biosci., v.50, n.3, p.194-199, 2008.

MAXILA, A. D. A. F o r p. 2013.

MC ALISTER, G.B.; MOYLE, D.D. Some Mechanical properties of goose femoral cortical bone. Journal Biomech, New York, n. 16, p. 577-589, 1983.

MELONE, C.P. Jr. Articular fractures of the distal radius. Orthop Clin North Am, v. 15, p. 217-36, 1984.

MINO, D. E.; PALMER, A. K.; LEVINSOHN, E. M. The role of radiography and computerized tomography in the diagnosis of subluxation and dislocation of the distal radioulnar joint. Journal of Hand Surgery, v. 8, n. 1, p. 23-31, 1983.

MOORE A.M ; DENNISON D.G Distal radius fractures and the volar lunate facet fragment: Kirschner wire fixation in addition to volar-locked plating. American Association for Hand Surgery, 2013

Müller AO Classifi cation of Fractures_Long Bones. 2007.

MÜLLER, M.E. et al. The comprehensive classification of fractures of long bones. Berlin: Springer, 1990. 
ORBAY J.L.; FERNANDEZ, D.L. Volar fixation for dorsally displaced fractures of the distal radius: A preliminary report. J Hand Surg [Am], v. 27, p. 205-215, 2002.

ORBAY, J.L.; FERNANDEZ, D.L. Volar fixed-angle plate fixation for unstable distal radius fractures in the elderly patient. J Hand Surg, v. 29A, p. 96-102, 2004.

PESSAN, V. J. O.; VOLPON, J. B.; SHIMANO, A. C. Ensaio mecanico de flexao nas faces concava e convexa da diafise do femur de ratas. Revista Brasileira de Ortopedia, v. 31, n. 7, p. 600-604, 1996.

PETRIE, C. S.; WILLIAMS, J. L. Comparative evaluation of implant designs: Influence of diameter, length, and taper on strains in the alveolar crest - A threedimensional finite-element analysis. Clinical Oral Implants Research, v. 16, n. 4, p. 486-494, 2005.

ROZENTAL, T.D.; BLAZAR, P.E. Functional outcome and complications after volar plating for dorsally displaced, unstable fractures of the distal radius. J Hand Surg Am, v. 31, p. 359-365, 2006.

RUCH, D.S.; PAPADONIKOLAKIS, A. Volar versus dorsal plating in the management of the intra-articular distal radius fractures. J Hand Surg Am, v. 31, p. 9-16, 2006.

Saw N, Roberts C, Cutbush K, et al. Early experience with the TriMed fragmentspecific fracture fixation system in intraarticular distal radius fractures. J Hand Surg [Am]. 2008;33B:53-8.

SCHNEPPENDAHL, J.; WINDOLF, J.; KAUFMANN, R.A. Distal radius fractures: current concepts. J Hand Surg Am, v. 37, p. 1718-1725, 2012

SHIMANO, A.C. Analise das propriedades geométricas e mecânicas de tíbia humana: proposta de metodologia. São Carlos. Tese (Doutorado) - escola de Engenharia de São Carlos, Universidade de São Carlos, 1994.

SILVA, A.V Modelo de Suspensão pela cauda e seu efeito em algumas propriedades mecânicas do osso do rato/ Adriana Valadares da. São Carlos, 2002.

Smith RS, Crick JC, Alonso J, et al. Open reduction and internal fixation of volar lip fractures of the distal radius. J Orthop Trauma. 1988;2:181-7.

Smith RS, Crick JC, Alonso J, et al. Open reduction and internal fixation of volar lip fractures of the distal radius. J Orthop Trauma. 1988;2:181-7.

SORIANO, H. L. Método de Elementos Finitos em Análise de Estruturas;colaboração de Silvio de Souza Lima. São Paulo - Editora da Universidade de São Paulo, 2003. 
SYNEK, A. et al. Using self-drilling screws in volar plate osteosynthesis for distal radius fractures: a feasibility study. BMC Musculosk Dis, v. 17, n. 119, March 10, 2016.

TURNER, C.H.; RHO, J.; TAKANO, Y.; TSUI, T.Y.; PHARR, G.M. The elastic properties of trabecular and cortical bone tissues are similar: results from two microscopic measurement techniques. J. Biomech., v.32, n.4, p.437-441, abr, 1999.

VAN LENTHE, G. H.; STAUBER, M.; MÜLLER, R. Specimen-specific beam models for fast and accurate prediction of human trabecular bone mechanical properties. Bone, v. 39, n. 6, p. 1182-1189, 2006.

VILARINHO RCC. Uso do método dos elementos finitos na avaliação das propriedades mecânicas de um fixador externo. Ribeirão Preto - SP 2000. 


\section{Anexo 1}

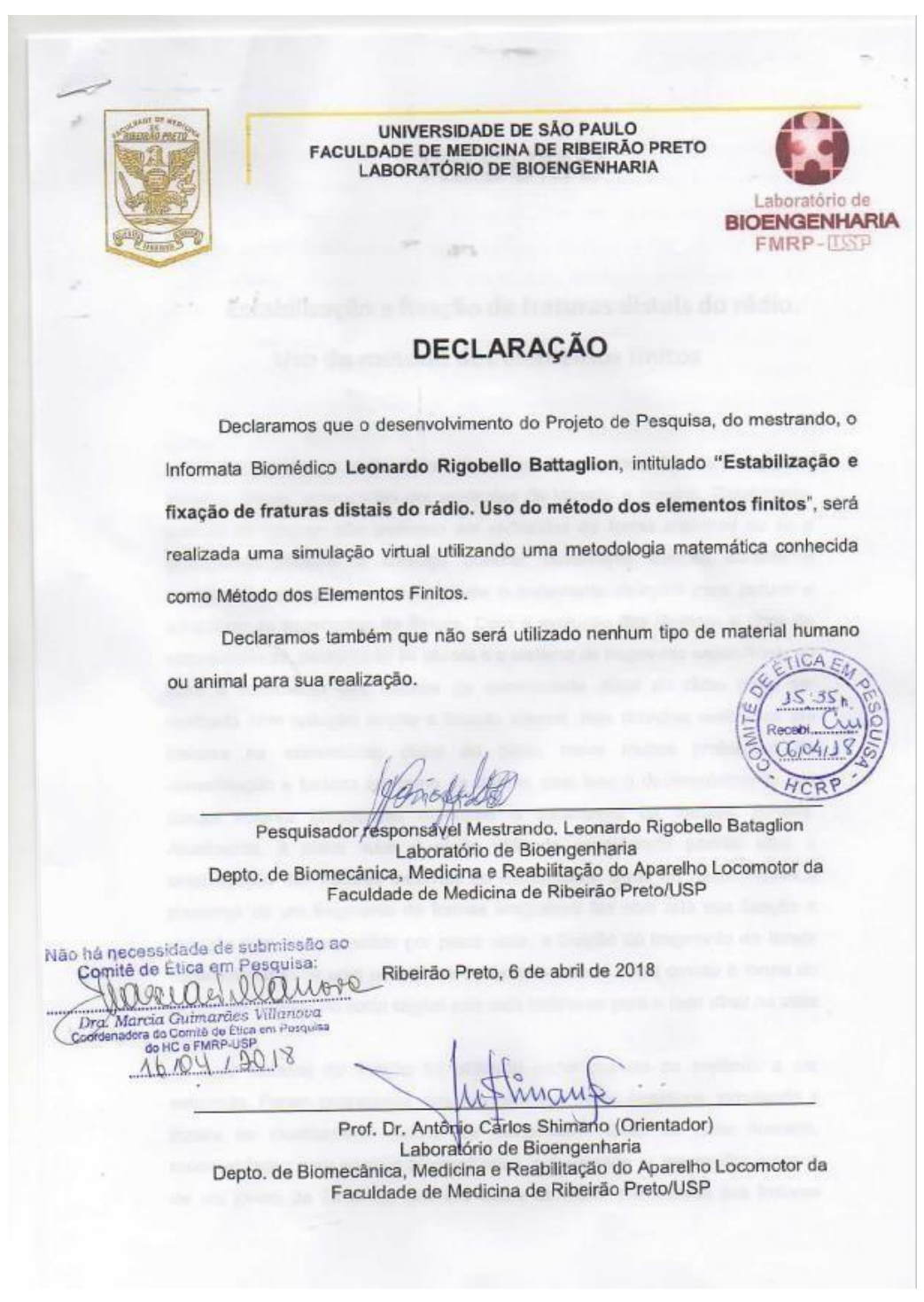

